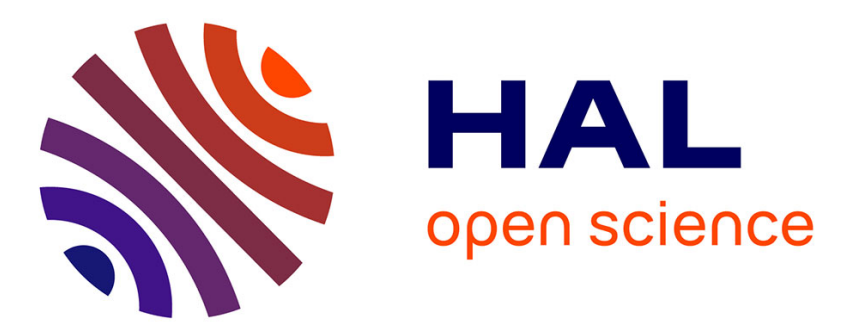

\title{
Thermal conductivities of solid and molten silicates: Implications for dynamos in mercury-like proto-planets
}

D. Freitas, J. Monteux, Denis Andrault, Geeth Manthilake, A. Mathieu, Federica Schiavi, N. Cluzel

\section{- To cite this version:}

D. Freitas, J. Monteux, Denis Andrault, Geeth Manthilake, A. Mathieu, et al.. Thermal conductivities of solid and molten silicates: Implications for dynamos in mercury-like proto-planets. Physics of the Earth and Planetary Interiors, 2021, 312, pp.106655. 10.1016/j.pepi.2021.106655 . hal-03164528

\author{
HAL Id: hal-03164528 \\ https://hal.uca.fr/hal-03164528
}

Submitted on 10 Mar 2021

HAL is a multi-disciplinary open access archive for the deposit and dissemination of scientific research documents, whether they are published or not. The documents may come from teaching and research institutions in France or abroad, or from public or private research centers.
L'archive ouverte pluridisciplinaire HAL, est destinée au dépôt et à la diffusion de documents scientifiques de niveau recherche, publiés ou non, émanant des établissements d'enseignement et de recherche français ou étrangers, des laboratoires publics ou privés. 


\title{
Thermal conductivities of solid and molten silicates: implications for dynamos in Mercury-like proto-planets
}

\author{
D. Freitas ${ }^{1, \$ *}$, J. Monteux $^{1}$, D. Andrault ${ }^{1}$, G. Manthilake ${ }^{1}$, A. Mathieu ${ }^{1}$, F. Schiavi $^{1}$, N. Cluzel $^{1}$ \\ ${ }^{1}$ Université Clermont Auvergne, CNRS, IRD, OPGC, Laboratoire Magmas et Volcans, F-6300 \\ Clermont-Ferrand, France \\ ${ }^{\$}$ Now at School of Geosciences, Grant Institute, The King’s Buildings, The University of \\ Edinburgh, West Mains Road, Edinburgh EH9 3JW, United Kingdom
}

*Corresponding Author: Damien Freitas (damien.freitas@ed.ac.uk)

\begin{abstract}
Remanent magnetization and active magnetic fields have been detected for several telluric planetary bodies in the solar system (Earth, Mercury, Moon, Mars) suggesting the presence of core dynamos active at the early stages of the planet formation and variable lifetimes. Among the factors controlling the possibility of core dynamos generation, the dynamics of the surrounding silicate mantle and its associated thermal properties are crucial. The mantle governs the heat evacuation from the core and as a consequence the likeliness of an early thermally driven dynamo. In the case of planets with a thick mantle (associated with supercritical Rayleigh numbers), the core heat is efficiently removed by mantle convection and early thermally-driven dynamos are likely. At the opposite, planets with a thin mantle (associated with subcritical Rayleigh numbers) might evacuate their inner heat by diffusion only, making early thermally-driven dynamos difficult. Within the Solar System, Mercury is a potential example of such a regime. Its small mantle thickness over the planet radius ratio might be inherent to its small orbital semi-axis and hence, might be ubiquitous among the terrestrial objects formed close to their star.

To constrain the likeliness of a thermally driven dynamo on "Mercury-like" planets (i.e. with large Rc/R), we present new thermal diffusivity measurements of various solid, glassy and molten samples. We applied the Angstrom method on cylindrical samples during multi-anvil apparatus experiments at pressures of $2 \mathrm{GPa}$ and temperatures up to $1700 \mathrm{~K}$. Thermal diffusivities and conductivities were estimated for solid and partially molten peridotites, with various melt fractions, and for basaltic and rhyolitic glasses and melts. Our study demonstrates that melts have similar thermal properties despite a broad range of composition investigated. The melts reveal much lower thermal conductivities than the solids with almost an order of magnitude of decrease: $1.70( \pm 0.19)$ to $2.29( \pm 0.26) \mathrm{W} / \mathrm{m} / \mathrm{K}$ against $0.18( \pm 0.01)$ to $0.41( \pm 0.03) \mathrm{W} / \mathrm{m} / \mathrm{K}$ for peridotites at high temperatures and various melts respectively. Partially molten samples lie in between and several predictive laws are proposed as a function of the melt fraction and solid/melt texture.

Using our results into forward calculations of heat fluxes for dynamo generation for Mercurylike planets, we quantify the effect of mantle melting on the occurrence of thermally driven dynamos. The presence of a mushy mantle and partial melting could significantly reduce the ability of the mantle to evacuate the heat from the core and can prevent, shut or affect the presence of a planetary magnetic field. The buoyancy and fate of molten material in such bodies can thus influence the magnetic history of the planet. Future observations of Mercury-like planets accreted near their star and the detections of their magnetic signatures could provide constraints on their inner state and partial melting histories.
\end{abstract}

Keywords: Thermal diffusivity; thermal conductivity; melts; geodynamo; Mercury; 
Author contributions:

GM, AM, DA and DF set up the MAA apparatus and heating system for Angström measurements. DF and GM conceived the experiments. DF performed, processed and analyzed the experiments. FS significantly contributed to Raman micro-analyses. NC helped for sample selections, analyses and preparations prior experimental runs. JM, DA, GM and DF realized the modelling and discussion section. DF, JM and DA wrote the manuscript. All of the authors have agreed and contributed to the manuscript.

\section{Introduction}

The presence of internally generated magnetic fields is a variable feature among telluric bodies in the inner solar system. While few are currently active, such as for Mercury and Earth, several are now extinct, as observed for the Moon, Venus and Mars. On terrestrial planets currently exhibiting a dynamo, the generated magnetic fields characteristics are very different. Earth's magnetic field is very intense $25-65 \mu \mathrm{T}$, originating from the core and present for at least $3.5 \mathrm{Ga}$ (Tarduno et al. 2010). Mercury's field strength is much weaker, representing around a 1\% of Earth's one (Kabin et al. 2008; Anderson et al., 2011) and its shape is also unique among the different detection in the solar system (Tian et al., 2015). According to the remnant magnetization measured in the crust, it was proposed that such weak magnetic activity occurred during the last $3.9 \mathrm{Ga}$ (Johnson et al. 2015). The source of such a weak-and-prolonged dynamo is still largely debated (Manthilake et al. 2019). In the meantime, there are several evidences for an intrinsic dynamo during the early stages of both Mars and Moon (Acuña et al., 1999; Hood et al., 2010). Their dynamo seems to cease around 4.1-3.9 Ga ago for Mars (Johnson and Phillips, 2005; Lillis et al., 2008, Lillis et al., 2013) and exhibits a somewhat complicated history for the Moon with a strong dynamo between 4.25 and $3.5 \mathrm{Ga}$, followed by a weak persistence up to 2.5-2 Ga ago (Tikoo et al. 2014, Lawrence et al. 2008, Garrick-Bethell et al., 2009, Mighani et al. 2020). For Venus, the early presence of a dynamo remains yet unconstrained but may be detectable in future explorations (Nimmo et al. 2002; O'Rourke et al. 2019). More broadly, evidences of paleomagnetic anomalies indicate that the angrite parent bodies, originating from inner regions of the solar system, were subject to an early internally generated dynamo (Weiss et al. 2008). All these elements suggest that transient dynamos might be a somewhat common feature in telluric bodies (Monteux et al. 2011).

The presence of early dynamos is highly conditioned by the internal structure of the planet and its capacity to release the heat accumulated during the accretion processes (accretion, metal/silicate differentiation, core and mantle crystallization) as well as short-lived radiogenic heating. As heat conduction is an inefficient heat transport process in silicates at high temperatures (Hofmeister and Branlund, 2015), the onset of a mantle global convection is a crucial step in planet's thermal history. Convection starts when the Rayleigh number $(\mathrm{Ra})$ of the terrestrial mantle is larger than the critical Rayleigh number $\left(\mathrm{Ra}_{\mathrm{c}}\right)$. The higher is $\mathrm{Ra}$, the stronger the convection, and the more efficient the heat transport. In contrast, heat is only transported by conduction for a terrestrial mantle with a $\mathrm{Ra}<\mathrm{Ra}$. As Ra scales with mantle thickness ( $\mathrm{h}_{\text {mantle }}$ ) as $h_{\text {mantle }}{ }^{3}$, convection should take place easily in planets with a thick silicate mantle, even after the solidification of the early magma ocean stage. Consequences are efficient evacuation of the inner heat and the possible occurrence of a dynamo. At the opposite, bodies with a thinner mantle lead to smaller Ra values, making convection unlikely and dynamos more difficult to generate.

Mercury is the most interesting planet for our study. Indeed, its mantle is thin $420 \pm 30 \mathrm{~km}$ (Hauck et al. 2013) and its core occupies almost 55\% of planet's volume and $65 \%$ of the planet mass (Strom and Spague, 2003; Charlier and Namur, 2019). Hence, the mantle of Mercury is controversially at the limit between conductive and convective regimes (Breuer et al. 2007). Different scenarios could 


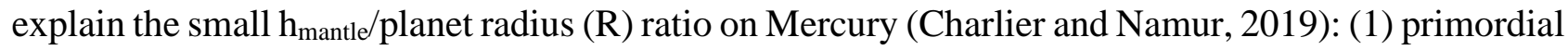
nebular processes, yielding to the enrichment of metal over silicate materials in the inner solar system (Ebel and Grossman, 2000; Wurm et al. 2013; Weidenschilling 1978), (2) highly energetic accretional collisions inducing a major loss of the silicate fraction (Benz et al. 1988, Asphaug and Reufer, 2014), and (3) post-accretion scenarios, with major vaporization of the volatile and silicate elements from the planet during magma ocean stage (Fegley and Cameron 1987; Boujibar et al., 2015). If scenarios (1) and (3) are dominant, then "Mercury-like" planets with small $h_{\text {mantle }} / \mathrm{R}$ ratio would be ubiquitous within all planetary systems. Moreover, such a small ratio would be prevailing during the whole accretionary processes. Mercury-like bodies could adopt a wide range of possible compositions depending on their history. For example, bodies accreted from reduced enstatite and/or carbonaceous bencubbinite chondrites (Malavergne et al. 2010) could present a mantle composition similar to terrestrial lherzolite, but with a sulfur content potentially as high as $11 \mathrm{wt}$ \% (Namur et al. 2016). Accordingly, the diversity of the silicate samples found on Earth in the forms of rocks, melts and glasses is a good proxy to decipher the properties of a range of mantle-relevant silicate compositions on Mercury-like bodies. Depending on the planet size and the $h_{\text {mantle }} / \mathrm{R}$ ratio, the internal pressure ranges from a few MPa to several GPa. We note that extensive mantle melting likely occurred at different stages of the history of such Mercury-like bodies. Major energy incomes are expected from the vicinity to the young Sun (2500 to $3500 \mathrm{~K}$ according Charlier and Namur, 2019), internal energy release (chemical and gravitational differentiation, core crystallization), and presence of short-period radioactive elements $\left(\mathrm{Al}^{26}, \mathrm{~K}^{40}\right.$ etc.). The very high temperatures likely induce extensive melting of the thin mantle up to the core-mantle boundary (CMB).

As mentioned above, dynamo generation could be difficult for Mercury-like planets, due to the subcritical value of Ra possibly disabling mantle convection. In such case, heat transfer by conduction would dominate the planet history and the thermal conductivity of the silicate mantle is a key parameter governing the early core heat flow. Silicates thermal conduction properties are now well characterized at ambient conditions (Hofmeister and Branlund, 2015). Among them, the most common geological minerals were characterized in the forms of single crystal and polycrystalline aggregates: olivine (Osako et al. 2004; Xu et al. 2004; Perterman and Hofmeister 2006; Gibert et al. 2005), periclase (Hofmeister and Branlund, 2015), feldspar (Pertermann et al. 2008; Hofmeister et al. 2009; Branlund and Hofmeister, 2012) and pyroxenes (Hofmeister 2012, Hofmeister and Pertermann 2008) as well as peridotite rocks (Gibert et al. 2005; Beck 1978), which have been extensively studied due to their important geological implications. The thermal diffusivities of minerals are linked to the characteristics of their lattice structure and modes of phonon generation and propagation as a function of temperature. For silicates, lattice thermal diffusivities usually decrease with increasing temperature following a $1 / \mathrm{T}$ dependence. At the opposite, the diffusivities increase while increasing pressure, however, the temperature dependence is much greater than that of pressure over the considered ranges for small planets. The resulting implication is that mantle rocks and minerals are poor thermal conductors in planetary interiors. Recent measurements of thermal diffusivities of glasses and melts at ambient pressure suggested that the non-crystalline silicates are even more insulating than the minerals (Hofmeister et al. 2009, 2014, Romine et al. 2012).

Measurements of thermal diffusivities at relevant conditions of planetary mantles encompass important difficulties, which were overcome by the use of different techniques (see Hofmeister and Brandlund 2015 for a critical review). Measurements were reported over a wide $\mathrm{P}$ and $\mathrm{T}$ range for large volume samples of olivine, periclase, bridgmanite using Angström or Pulse method in solid pressure apparatus (Osako et al. 2004; Xu et al. 2004; Manthilake et al. 2011a and 2011b, Zhang et al. 2019). Up to now, accurate measurements of geologically relevant silicate glass, partially molten systems and melts at planetary interior conditions remain scarce if not absent. The available results report a nearly flat evolution of thermal diffusivities with the temperature above $1000 \mathrm{~K}$ for silicates, glass and melts (Hofmeister et al. 2014; Hofmeister and Banlund, 2015), suggesting that the 
measurements above the melting temperature could be safely extrapolated to planetary P-T conditions.

In this study, we aim at better constraining the thermal properties of Mercury-like protoplanets where convection is unlikely and heat is mostly removed by diffusion. We perform HP-HT in situ thermal diffusivities measurements of solid, partially molten and fully molten silicate for various compositions in Multi-anvil apparatus and using Angström method. Then, we constrain the likeliness of a thermally driven dynamo during the early stages of the evolution of a Mercury-like planet. We consider a wide range of planet sizes $\left(1 \mathrm{~km}<\mathrm{R}<\mathrm{R}_{\text {Mercury }}\right)$ and thermal states (with solid and partially molten mantles) on the dynamo likeliness.

\section{Experimental and analytical methods}

\section{High-pressure assemblies:}

High-pressure and high-temperature experiments were performed using a 1500-ton Kawai type Multi-anvil apparatus. All experiments were conducted at $2 \mathrm{GPa}$, based on a previous press-load vs sample pressure calibration (Boujibar et al. 2014), providing an uncertainty of $\sim 0.1 \mathrm{GPa}$ at pressures $<5 \mathrm{GPa}$. We used octahedral pressure media with full length edges composed of $\mathrm{MgO}$ doped with $\mathrm{Cr}_{2} \mathrm{O}_{3}$ (5 wt. \%) in a 25/17 multi-anvil configuration (octahedron edge length / anvil truncation edge length) (Figure 1). Our assembly was designed to accommodate the specific requirements for measurements of thermal conductivity of relatively large samples (4 mm long for 4-3.5 mm diameter). All ceramic parts of the cell assembly, including the pressure media, were fired at $1373 \mathrm{~K}$ prior assembling in order to remove the absorbed moisture. Oxygen fugacity of the sample was not controlled during the experiments but is expected to be quite reducing due to the presence of the graphite furnace. The use of a steeped graphite furnace helped reducing thermal gradients. Thermal loss from the sample zone was further reduced by the use of a thick zirconia $\left(\mathrm{ZrO}_{2}\right)$ sleeve around the furnace. Thermal gradients in our assembly were computed using the software developed by Hernlund et al. 2006. The models show temperature gradients within the sample volume limited to $\sim 7.5 \mathrm{~K} / \mathrm{mm}$ vertically and even less radially/horizontally (Figure S1). On the other hand, uncertainties of our thermocouple reading (i.e. where the conductivity measurement is performed, see below) are less than $5 \mathrm{~K}$ on absolute and $0.1 \mathrm{~K}$ in relative temperatures.

Previous experimental studies described the difficulties to perform a good measurement of thermal diffusivity for a molten sample, due to a potential sample deformation (Hofmeister et al. 2009, 2014; Romine et al. 2012). However, deformation remained minor in our experiments, as evidenced by the good reproducibility of the measurements during the repeated cycles of heating and cooling (Figures 1 and 2) as well as the shape of the recovered samples (Figures S6, S7 and S8).

Two tungsten-rhenium ( $\mathrm{W}_{95} \mathrm{Re}_{5}-\mathrm{W}_{74} \mathrm{Re}_{26}$ ) thermocouples of $75 \mu \mathrm{m}$ of diameter were used to measure temperature oscillations at the center (in 300 and $600 \mu \mathrm{m}$ drilled holes in solids and glasses, respectively) and at the edge of the cylindrical sample. Special care was given to ensure that the junction points of the two thermocouples were located in the same sample plane perpendicular to the cylinder axis. Measurements of the thermal conductivity of melts and glasses have always been particularly challenging due to the risk of thermocouple short circuit, because melts, even dry, are good electrical conductors (Tyburczy and Waff, 1983; Ni et al. 2011). To prevent this effect, thermocouples were inserted in alumina tubes of $0.6 \mathrm{~mm}$ diameter and $170 \mu \mathrm{m}$ wall thickness. While these tubes show good resistance to cold compression and almost no reaction with the samples, even at very high temperature, some leakages for low viscosity basaltic melts have been identified. Their occurrence was taken in account for thermal diffusivity estimations (see Supplementary Text S1 and Figures S2 and S3). 
Angström method for thermal diffusivity measurements

We aim at determining thermal diffusivities of geological samples such as peridotites, mafic and felsic glasses and their melts at high pressure and high temperature using a double contact method: the Angström method. Experimental configurations, assemblies and data treatment are similar to several previous studies (Fujisawa et al. 1968; Kanamori et al. 1969; Katsura 1993; Xu et al. 2004; Manthilake et al. 2011a and 2011b). Briefly, a temperature wave is generated radially in a cylindrical sample by the surrounding heater sleeve of the multi-anvil assembly (Figure 1). Oscillations are generated with controlled frequency and period by modulating the power supply. Periodic temperature signals are recorded by two thermocouples fixed in the center and on the edge of the sample cylinder. At frequencies higher than $1.5 \mathrm{~Hz}$, the signal can get noisier due to a limited time resolution of the recording system.

The recorded signals, for each thermocouple channel, are fitted by a nonlinear least square solver (lsqcurvefit on Matlab@ using Levenberg-Marquardt algorithm):

$$
\Delta T=A_{0}+A_{1} t+A_{2} \sin \left(2 \pi A_{3} t+\frac{A_{4} \pi}{180}\right)
$$

Following this method, we obtained the amplitude of the temperature variation $\left(A_{2}\right)$, frequency $\left(A_{3}\right)$, and phase $\left(A_{4}\right)$ of the recorded wave as a function of time $(\mathrm{t})$, for the two thermocouples. Errors are quantified based on the residue on the non-linear curve fitting (the nlparci function in Matlab@). To infer thermal diffusivity or conductivity from these parameters, the equation of conductive heat transport has to be solved. Here we consider the sample as an infinite uniform cylinder and assume that the heat flow is negligible in the vertical direction, thanks to a relatively long cylindrical heater. The following equation, expressed in cylindrical coordinates by Carlsaw and Jaegger (1959), has to be inverted in order to retrieve the diffusivity of the sample:

$$
\frac{d T}{d t}=D\left(\frac{d^{2} T}{d r^{2}}+\frac{1}{r} \frac{d T}{d r}\right)
$$

where $r$ is the radial distance from the axis, $T$ the temperature, $t$ the time, and $D$ the thermal diffusivity. The boundary condition of our setup is:

$$
\frac{d T}{d r}=0, \text { at } r=0
$$

If we consider harmonic excitation at a distance $r=R$ from the axis in normal or complex form:

$$
T_{R}=B_{0}+B_{1} \cos w t \leftrightarrow T_{R}=b_{0}+b_{1} \operatorname{Re}(\exp i w t)(4)
$$

where $B_{0}, B_{1}, b_{0}$ and $b_{1}$ are constants and $\mathrm{Re}$ is the real part of the exponential. The solution of the radial flow equation with the boundary conditions developed above can be expressed as:

$$
T_{R}=b_{0}+b_{1}\left\lceil J_{0}(\sqrt{-i} * x) * \frac{\exp (i w t)}{J_{0}(\sqrt{-i} * l)}\right\rceil
$$

where:

$$
l=(w / \kappa)^{1 / 2} R \text { and } x=(w / \kappa)^{1 / 2} r(6)
$$

for $0 \leq r \leq R$, where $w$ is the angular frequency and $J_{0}$ is the Bessel function of the first kind (integer order $n=0)$. At $r=0$ and $r=R$ we have:

$$
\begin{gathered}
T_{0}=b_{0}+b_{1} \theta \cos (w t-\varphi)(7) \\
T_{R}=b_{0}+b_{1} \cos w t(8)
\end{gathered}
$$

where:

$$
\begin{gathered}
\theta=\frac{1}{\sqrt{\operatorname{bei}(u)^{2}+\operatorname{ber}(u)^{2}}} \\
\varphi=\tan ^{-1}\left(\frac{\operatorname{bei}(u)}{\operatorname{ber}(u)}\right)
\end{gathered}
$$

where $\theta$ is the amplitude ratio and $\varphi$ the phase shift between the two harmonic temperature measurements and bei and ber are imaginary and real parts of the Bessel function of the first kind, respectively. The solution to the eq. (4) can be written using the dimensionless argument $u$, from 
which thermal diffusivity $(D)$ can be directly estimated knowing angular frequency $(w)$ and sample radius $(d)$.

$$
u=d(w / D)^{1 / 2}(11)
$$

Thanks to the Eqs.9, 10, and 11, the diffusivity was then retrieved via forward Monte Carlo simulation and neighborhood algorithm (Sambridge, 2002). In this step, different values of diffusivities are generated and theoretical phase shifts and amplitude ratios are calculated. These values are compared to the values measured in our experiments. When the differences between the computed solution and the experimental determination tend to 0 (minimization step), the correct diffusivity is then obtained if the sample radius (d) and angular frequency (w) are known. We note that mathematical solutions appear every $360^{\circ}$ for the phase shift. Such erroneous solutions are checked manually and discarded.

For most of our experiments, we observe a significant variation of the refined raw-diffusivity value as a function of the heat-source frequency. This effect was already reported in the literature. Different equations were proposed to refine a real value of diffusivity, corresponding to the infinite frequency asymptote, based on non-linear equations. While Manthilake et al. (2011b) used:

Xu et al. (2004) used:

$$
D=D_{\infty}+A_{0} \exp \left(A_{1} * f\right)(12)
$$

$$
D=D_{\infty}+A_{0} \exp \left(\frac{-f}{f_{0}}\right)
$$

where $D$ is diffusivity, $f$ source frequency, $f_{0}$ asymptote frequency and $A_{0}$ and $\mathrm{A}_{1}$ constants. In these equations, $D_{\infty}, A_{n}$ and $f_{0}$ are inverted parameters. For a better fit of our experimental data and to minimize the uncertainties on the parameters, we adopt Eq. 13. On the other hand, for experiments presenting no systematic dependence of the raw-diffusivity with frequency, we consider as real value the average value between the raw-diffusivity values measured at all frequencies (Xu et al. 2004; Manthilake et al. 2011b).

\section{Experimental uncertainties}

Experimental measurements of thermal diffusivities and their further transformation into thermal conductivities generate uncertainties originating from the estimations of pressure, temperature, sample dimensions and the data fitting itself. Experimental uncertainties on pressure and temperature are presented above $(\sim 0.1 \mathrm{GPa}$ and $\sim 5 \mathrm{~K}$, respectively). Sample lengths prior to the sample loading $\left(d_{0}\right)$ and after the melting experiments were determined with a high precision digital gauge (accuracy of $\sim 1 \mu \mathrm{m}$ ) and using the Scanning Electron Microscope (FEG-SEM), respectively (see Table 1). Then, the sample radius during the experiment at high pressure and temperature was calculated using:

$$
d(P, T)=d_{0} *\left(1-\alpha(T-298)+\frac{P}{K}\right)^{-1 / 3}
$$

where $\alpha$ is the thermal expansion and $K$ the bulk modulus of the sample. For these calculations only samples radii before experiments were considered, as post mortem measurements are affected by decompression cracks (highlighted by the larger values measured after the experiments in Table 1). Moreover, the distance between the two thermocouples could not be measured precisely for a few samples. The values of all experimental parameters are provided in Supplementary Materials (Text S4 and Figure S4). Altogether, final uncertainty on the sample length is between 5 and $10 \mu \mathrm{m}$.

There are other uncertainties associated with the procedure of data fitting for the determination of raw thermal diffusivities. Experimental phase shifts and amplitude ratios (Eqs. 9 and 10) are determined with a precision generally better than $1 \%$ and majored by $3 \%$ in the worst cases. In the course of the Monte Carlo simulation, the differences between experimental and theoretical diffusivities are recorded and used a posteriori to refine uncertainties within $1 \sigma$ errors.

Then, real thermal diffusivities are refined from the raw-diffusivities using either (i) the asymptotic non-linear fit for experiments presenting a dependence in frequency (Eq. 13, which yields 
important uncertainties on the refined parameters) or by averaging (see Methods). The error on average $\left(\sigma_{A V G}\right)$ is:

$$
\sigma_{A V G}=\sqrt{\left(\frac{1}{n}\right)^{2} * \sum_{1: n} \sigma_{D}^{2}}
$$

where $n$ is the number of diffusivity measurements performed at different frequencies and $\sigma_{\mathrm{D}}$ is the error on each diffusivity. Raw diffusivities recovered from Monte Carlo processing have errors of $\sim 1 \%$, similar to those of phase shift and amplitude ratio. If the fitting step is realized with Eq. 13, errors of raw data are used as weights in the inversion. The standard deviations are usually between 1 and $10 \%$ of the real asymptotic diffusivity. If the averaging method is selected, the standard deviation, estimated via Eq. 15, is usually about $1 \%$ of the final value.

A final source of uncertainties come from other technical issues and apparatus reproducibility, which are inherent to such challenging experiments. We considered that final error must be majored by $5 \%$ of the value. The relative uncertainties become even higher after conversion into thermal conductivities due to uncertainties and simplifications on the sample density and heat capacity at high pressure and temperature (see Supplementary Text S4).

\section{Experimental procedure:}

We performed a suite of three heating and cooling cycles to provide an important number of data and maximize the quality of recovered data. A first cycle was run up to $500{ }^{\circ} \mathrm{C}$ for moisture removal by $50^{\circ} \mathrm{C}$ steps (Figure. 2). The second cycle was run up to glass transition temperature $(\mathrm{Tg})$ by $100^{\circ} \mathrm{C}$ steps. Tg varies according to rock composition and its water content (Giordano et al., 2005). For our dry samples, the temperature of $800^{\circ} \mathrm{C}$ happened to be above $\mathrm{Tg}$ for all our compositions. The temperature was then decreased down to $150^{\circ} \mathrm{C}$ by $100^{\circ} \mathrm{C}$ steps. The quality of the measurement is usually better during the cooling cycle once (1) the sample has thermally equilibrated with the assembly, (2) moisture has been removed, and (3) a better contact was achieved between the sample and the thermocouples due to local flow in the solid-state. The redistribution of matter under high temperature cancels most of the potential artifacts associated with the presence of pores/voids between the sample and the thermocouples (Hofmeister et al. 2009). Hence, data recorded during the last cycles were considered for final values.

In the last cycle, we heated the sample up to its melting temperature by $100^{\circ} \mathrm{C}$ steps or $50^{\circ} \mathrm{C}$ near the melting point. The sample was maintained above its melting point for less than 1 hour, to avoid sample leakage and chemical reaction with the surrounding parts. The sample was then quenched to $600-550^{\circ} \mathrm{C}$. This step produces a glassy sample from which measurements at low temperature are performed.

Temperature oscillations of the two thermocouples were measured at each temperature step for both heating and cooling cycles, at 12 different oscillating frequencies between 0.1 and $1.5 \mathrm{~Hz}$. The measurements were performed after at least $2 \mathrm{~min}$ of thermal equilibration to reach a stable regime (the smaller is the frequency, the longer is the required equilibration time). Then, the recording duration was 1 to 2 minutes or at least 10 oscillating periods. The measurement at the 12 frequencies took between 20 to 30 minutes. Thus, the duration of each experiment was more than 12 hours.

\section{Chemical and textural analyses:}

Recovered samples were cut parallel and perpendicular to the cylindrical furnace and each section was polished with great care. We could observe the position of the two thermocouples junctions, measure the sample radius and perform the textural and chemical analyses (see Supplementary Figures S6, S7, and S8).

Micro-textures were observed with a Scanning Electron Microscope (SEM) JEOL Jeol JSM$5910 \mathrm{LV}$ using an accelerating voltage of $15 \mathrm{kV}$ and a working distance of $11.4 \mathrm{~mm}$. The 2D phase proportions of our partially molten peridotite samples were obtained from the analyses of qualitative 
chemical maps obtained by energy-dispersive X-ray spectroscopy (EDX) in the SEM. The images were binarized and phases were individually separated allowing textural analyses with the FOAMS software (Shea et al., 2010). A more detailed description is given in Freitas et al. (2019). On the other hand, quantitative chemical analyses were performed on both our starting materials and experiment products using the electron probe micro analyzer (EPMA). Chemical and textural analyses of starting materials are reported in the Supplementary Text S2, Figures S6 to S13 and Tables S1, S2, S3 and S4. Analyses of recovered runs are detailed in Supplementary Text S3, supplementary Figures S6 to S7 and Tables S1, S2, S3 and S4.

Water contents were estimated using the ICP-AES for the peridotite starting materials and via Raman spectroscopy for the recovered samples. Raman spectra were collected with a Renishaw InVia confocal Raman micro spectrometer, equipped with a $532 \mathrm{~nm}$ diode laser and a Leica DM 2500M optical microscope. Measurements were carried out using a 2400 grooves $/ \mathrm{mm}$ grating, a 100× microscope objective, a slit aperture set to either $20 \mu \mathrm{m}$ or $65 \mu \mathrm{m}$ and a laser power of $8 \mathrm{~mW}$ for glasses and 16 or $75 \mathrm{~mW}$ for olivine. The resulting lateral and axial resolutions were of $\sim 1$ and $3 \mu \mathrm{m}$, respectively, and the spectral resolution was better than $1 \mathrm{~cm}^{-1}$. Daily calibration of the spectrometer was performed based on the $520.5 \mathrm{~cm}^{-1}$ peak of Si. Spectra were recorded from $\sim 100$ to $1300 \mathrm{~cm}^{-1}$ (alumino-silicate network domain) and from $\sim 3000$ to $3800 \mathrm{~cm}^{-1}$ (water domain), with variable acquisition times ranging between 5 and $120 \mathrm{~s}$ for silicate bands and 120 and $240 \mathrm{~s}$ for water domain depending on the water content (Figures S11 to S17). For water quantification in olivine and glass, we followed the procedures reported by Bolfan-Casanova et al. (2014) and Schiavi et al. (2018). We used both (1) the external calibration procedure, which is based on a set of hydrous olivine standards from (Bolfan-Casanova et al. 2014) and different types of silicate glasses ranging from basaltic to rhyolitic compositions (Schiavi et al., 2018; Médard and Grove, 2008), and (2) the internal calibration procedure, based on the correlation between the water concentration in olivine or glass and the relative areas of the water and silicate Raman bands (OH/Si integrated intensity ratio). The discrepancy between the two methods is small. Water contents in the standard materials were previously determined using the FTIR technique.

\section{Results}

We performed a total of 11 thermal diffusivity experiments on various chemical compositions, using the Angström method (details in Table 1). In this section, we first describe phase shifts and amplitude ratios between the two thermocouples and their conversion into thermal diffusivities and conductivities. We detail the post-mortem chemical and textural analyses in the Supplementary Text S3, Tables S1 to S4 and Figures S6 to S13.

\section{Phase shift, amplitude ratio and the refined raw-thermal diffusivities}

Signals recorded during the experiments are sinusoidal oscillations with varying frequencies. The thermocouple located at the sample center (labeled TC1 in Figure 3) presents a phase delay and a smaller amplitude compared to the thermocouple located at the sample edge (labeled TC2 in Figure 3). Typical raw signals and their fits are presented in Figure 3, while the refined (absolute) phase shifts and amplitude ratio are reported in Figure 4. Both the magnitude of phase shift and amplitude ratio change significantly with the type of sample and the experimental conditions, including the source frequency. At a constant frequency, the phase shift increases with increasing temperature. At a constant temperature, the phase shift increases with increasing the excitation frequency. The amplitude ratio is decreasing with increasing frequency and temperature.

Globally, the refined thermal diffusivities present a comparable evolution of temperature at all signal frequencies (see an example in Figure 5). When the frequency dependence is larger than the experimental uncertainty (Figure 6), we use Eq. 13 to refine the true asymptotic value of the thermal conductivity. Alternatively, when the temperature dependence is below the experimental uncertainty 
or when no clear frequency trends is visible, we average the different raw-diffusivity values (see Methods). In the wide majority of the cases, diffusivity values inferred from phase shifts appear to be more robust and with a lesser degree of uncertainty, compared to values inferred from difference of amplitude, in agreement with previous studies (Kanamori et al. 1969 and Xu et al. 2004). Hence, despite similar values obtained with the two methods, values refined from phase shift were preferred.

\section{Results for peridotite}

For peridotite, our two successful experiments present a smooth evolution with temperature, yielding diffusivities values decreasing from $1.7( \pm 0.1) \mathrm{e}^{-6}$ to $7.5( \pm 0.4) \mathrm{e}^{-7} \mathrm{~m}^{2} / \mathrm{s}$ for sample M804 and $1.5( \pm 0.8) \mathrm{e}^{-6}$ to $5.5 \mathrm{e}^{-7} \mathrm{~m}^{2} / \mathrm{s}$ for sample M847 (Figure 6a), with an uncertainty of about 5 to $10 \%$ for each sample. We attribute the relative discrepancy to a difference of sample mineralogy between the two samples, due to the coarse grain size of the core drilled peridotite (see Supplementary Texts S2 and S3 and Figures S8 and S9). Olivine has a higher intrinsic thermal diffusivity than the other phases present in peridotite such as pyroxenes and spinel (Hofmeister and Branlund, 2015). M804 may contain more olivine, inducing higher diffusivities than M847. In this respect, the results for two samples are thus compatible with each other and the differences are representative of the variability of thermal diffusivity that can be expected among the compositional variability of peridotites (from lherzolites to dunites).

Thermal diffusivities of our peridotite samples scale as a function of $\sim 1 / \mathrm{T}$, as expected from the standard equation provided by Hofmeister and Branlund, 2015:

$$
D_{\text {lat }}=a * T^{-b}+c * T(16)
$$

where $T$ is the temperature (K), and $a, b$ and $c$ are adjustable parameters (Table 2). The quality of the fit is excellent up to a temperature of $\sim 1300 \mathrm{~K}$ corresponding to the onset of peridotite melting. We therefore exclude the data points above $1300 \mathrm{~K}$ to model the thermal properties of solid peridotite.

\section{Results for basalts}

For our basaltic samples, the measured diffusivities plot over a broad range of values, from $1.0( \pm 0.1) \mathrm{e}^{-6}$ to $3.0( \pm 0.2) \mathrm{e}^{-7} \mathrm{~m}^{2} / \mathrm{s}$ (Figure $6 \mathrm{~b}$ ), with an uncertainty of $\sim 5 \%$ for each experiment. The discrepancy is particularly important at low temperatures. Also, a same sample yields thermal diffusivity values significantly different along the different cycles of the experimental procedure (between C2, H3 and the final quench, see Figure S5). Samples with the highest diffusivities at low temperatures present a rapid decrease of diffusivity with increasing temperature. On the other hand, samples with the lowest diffusivities show very small temperature dependence. It yields to a convergence of all diffusivity measurements at $\sim 1000 \mathrm{~K}$. Based on a study of rhyolitic glasses, Romine et al. (2012) reported a moderate temperature dependence, similar to our samples presenting a low diffusivity, and an increase of $0.0192 \mathrm{~mm}^{2} / \mathrm{s}$ of the glass diffusivity per percent of crystallinity. For our starting materials with less than 5 vol.\% of crystals (see Supplementary Text S2 and S3, Figure S7), the effect of microlites could account for $\sim 0.1 \mathrm{~mm}^{2} / \mathrm{s}$ of variation in our diffusivity values, which correspond to less than $\sim 10 \%$ of observed differences. However, the presence of 35 vol. $\%$ of crystals in the recovered sample M807 would explain not only its high thermal diffusivity at low temperature, but also its strong temperature dependence that is typical of crystals (see Beck et al., 1978; Romine et al. 2012; Hofmeister and Branlund 2015 and our peridotite trends in Figure 6a). The recrystallization of M807 is not surprising, since the second cycle of annealing was performed above its Tg (Figures 2 and S5). The crystallinity of other samples depends on the applied cycles of annealing at a temperature eventually close to their $\mathrm{Tg}$. Nonetheless, diffusivities of all samples converge at increasing temperatures, because the conductivity of crystals is not much greater than that of the glass at high temperature, especially if microlites are low diffusivity silicates such as pyroxenes, plagioclase or spinels (see Hofmeister and Branlund 2015 for mineral diffusivity compilations). Over the 5 basaltic samples investigated in this study, the diffusivity trends indicate either significant recrystallization of M807 (DR07-MORB) and M662 (EPR-MORB), or negligible 
crystallization of M844 and M846 (DR11-MORB) and M836 (synthetic haplobasalt). The sample crystallization is likely to evolve during the thermal diffusivity measurements in step H3 (up to melting point) of the experiments performed at a temperature significantly above the $\mathrm{Tg}$. For this reason, the crystallinity determined on the recovered samples is only a qualitative measurement of the sample properties at high temperatures.

\section{Results for rhyolites}

Measured diffusivities of rhyolite samples also plot over a broad range of values from $1.4( \pm 0.8) \mathrm{e}^{-}$ ${ }^{6}$ to $4.0( \pm 0.2) \mathrm{e}^{-7} \mathrm{~m}^{2} / \mathrm{s}$, with an uncertainty of about $5 \%$ for each experiment (Figure $6 \mathrm{c}$ ). The discrepancy appears similar than for the basalt samples, as the sample presenting higher diffusivities also show a major temperature dependence at low temperature. The presence of less than 2 vol. $\%$ of crystals in the starting material could account for a diffusivity increase of $0.038 \mathrm{~mm} / \mathrm{s}$ at maximum (Romine et al., 2012). Still, the diffusivity trends suggest a major recrystallization at high-temperature for M808 (Güney Dag) and M843 (ATHO), some crystallization for M843 (ATHO), and negligible crystallization for M850 (Güney Dag).

\section{Properties of melts and partially molten samples}

In addition to the evolutions described above, a strong decrease of the thermal diffusivity is observed for most of our samples at the highest temperatures (Figure 6). The decrease occurs at temperatures around $1300 \mathrm{~K}$ for peridotites, $1200 \mathrm{~K}$ for basalts and $>1050 \mathrm{~K}$ for rhyolites. Such temperatures are in agreement with the melting or glass transition temperatures, depending if the sample is a peridotite or a glass, recrystallized or not. Similar changes were already reported at temperatures above the glass transition (Hofmeister 2009, 2014, Romine et al. 2012).

The amplitude of the decrease is $45-50 \%$ in peridotites, which recovered samples present a degree of partial melting (F) up to $23 \%, 35-70 \%$ for basalts and $<30 \%$ for rhyolites samples. The more pronounced decrease in molten peridotites is probably due to a more contrasted change of the local structure at the melting point, between the minerals and the melt (see discussion). On the other hand, the minor change of diffusivity for rhyolites at $\mathrm{Tg}$ could be related to their high $\mathrm{SiO}_{2}$-content, which preserves a polymerized structure in the melt above the glass transition.

\section{Thermal conductivities}

Thermal conductivities $(\kappa)$ can then be computed from thermal diffusivities following:

$$
\kappa(P, T)=D(P, T) * \rho(P, T) * C_{P}(P, T)(17)
$$

where $\rho(P, T)$ and $C_{P}(P, T)$ are the sample density and heat capacity, respectively. For our calculations, we considered $\rho$ and $C p$ values in standard conditions when the $\mathrm{P}$ and/or $\mathrm{T}$ dependences were not available in the literature (see Supplementary Text S4 and Figure S4).

Conductivities calculated for peridotites evolve from $4.32( \pm 0.48)$ to $1.70( \pm 0.19) \mathrm{W} / \mathrm{m} / \mathrm{K}$ with increasing the temperature up to the melting point. Values for basalts range from $1.7\left( \pm 8.0 \mathrm{e}^{-2}\right)$ to 0.5 $\left( \pm 4.0 \mathrm{e}^{-2}\right) \mathrm{W} / \mathrm{m} / \mathrm{K}$, whereas those for rhyolite lie between $1.1\left( \pm 9.0 \mathrm{e}^{-2}\right)$ and $0.3\left( \pm 3.0 \mathrm{e}^{-2}\right) \mathrm{W} / \mathrm{m} / \mathrm{K}$ for low to high temperatures, respectively. At the melting temperature, our partially molten peridotites display values of $1.19( \pm 0.16)$ to $0.93( \pm 0.10) \mathrm{W} / \mathrm{m} / \mathrm{K}$, whereas melts present relatively lower values of $0.34( \pm 0.2)$ to $0.18( \pm 0.1) \mathrm{W} / \mathrm{m} / \mathrm{K}$ for basaltic and $0.41( \pm 0.3)$ to $0.31( \pm 0.3)$ for rhyolitic compositions (See Figure 7 and Table 3). We note that the important difference in conductivity between basalts and rhyolites (Figure 7) is predominantly due to differences between their heat capacities and densities, while their thermal diffusivities are found similar (Figure 6).

\section{Interpretation of results}

$\underline{\text { General Temperature dependence }}$ 
For all compositions investigated in this study, thermal diffusivities decrease with increasing temperature until reaching a plateau at temperatures between 700 and $1000 \mathrm{~K}$. Based on experiments performed at room pressure, it was observed that the plateau occurs at about the Debye temperature of the mantle minerals (Hofmeister et al. 2009, 2014). For this reason, it was proposed that thermal diffusivities vary largely with temperature until the complete activation of the vibration modes (phonons in minerals). The temperature range observed in our study for the occurrence of a plateau is fully compatible with this interpretation.

For basaltic glasses, a comparable but more moderate decrease of thermal diffusivity was reported up to a saturation temperature corresponding well to the glass Tg (Hofmeister et al. 2009, 2014, Romine et al. 2012). In our experiments, the decrease is of $\sim 30 \%$ to $60 \%$ over the investigated temperature range, depending on the experiment. Such amplitude is compatible with the $\sim 40 \%$ decrease observed during the heating of pyroxene glasses (Hofmeister et al. 2009).

For rhyolite samples, the thermal conductivity increases slightly with increasing the temperature (Figure 7). This is due to the heat capacity that increases more with temperature than the density increases and diffusivity decreases (Eq. 17). The increase is, however, smaller than reported in Romine et al. (2012), due to the use of a different Cp (Neuville et al. 1993) (see Supplementary Text S4) and a stronger temperature dependence of thermal diffusivities observed in our experiments because of different crystallizations states.

\section{Effect of radiative conduction}

Romine et al. (2012) reported an increase in thermal diffusivities of the melts at very high temperatures at ambient pressure. They attributed this feature to an increased role of the radiative component. Such a component can dominate the thermal diffusivity for a sample transparent to the infrared and visible photons at high temperatures. For thin samples, this effect can become problematic if the mean free path of photons is longer than the sample length (ballistic photons, see Hofmeister and Branlund, 2015). No significant increase in thermal diffusivity and conductivity is observed in our high-pressure experiments, except maybe for the rhyolitic samples (Figures 6 and 7). The difference with the previous work is most probably related to the opacity of our basalts and peridotites samples, hence limiting the radiative transfers.

\section{Effect of glass/melt composition}

Overall, our conductivity values are compatible with the values available in the literature (see Figure 8). Differences in absolute values are nonetheless present. Rhyolite melts $(0.31-0.41 \mathrm{~W} / \mathrm{m} / \mathrm{K})$ are found slightly more conductive than basaltic ones $(0.18-0.34 \mathrm{~W} / \mathrm{m} / \mathrm{K})$. Within the same family of glass, thermal conductivity varies by 0.10 to $0.15 \mathrm{~W} / \mathrm{m} / \mathrm{K}$ for rhyolitic and basaltic melts, respectively. This is slightly larger (of at least $10 \%$ ) than the experimental uncertainty, an effect possibly due to larger uncertainties on the dimensions of the molten sample. No clear trend can be retrieved from the comparison between our different basaltic or rhyolitic compositions. Among the major elements, iron could be of major importance, due to its critical impact on glass/melt density. Indeed, the thermal diffusivity of glasses was reported to decrease with increasing density (Hofmeister 2014). The comparison between our rhyolites and basalts is coherent with such a trend. However, our haplobasalt (M836) presents diffusivity values comparable with natural basalts (M662, M807, M844), as well as Fe-bearing (M843 and M848) and Fe-free (M808 and M850) rhyolites (Figure 6), despite a variation of the Fe-content from 0 to $10 \mathrm{wt} . \%$ in these different samples. Other elements could also impact the melt thermal diffusivity, in particular Si and $\mathrm{Al}$, which favor polymerization of the liquid (and alkali elements for the opposite effect) (Ni et al. 2015). Still, within the experimental uncertainty, we observe no clear trend related to these elements, despite a variation of the $\mathrm{SiO}_{2}$ content by more than $20 \%$. Additionally, water, with a total content smaller than $1.10 \mathrm{wt} . \%$, should have a negligible effect on thermal conductivity (Romine et al. 2012, Ni et al. 2015). It could, however, impact the melt density at a low degree of partial melting (Hofmeister 2014). As the water contents estimated in the 
recovered samples are similar to the ones obtained in starting materials (see Supplementary Text S2 and S3), water should not induce any strong diffusivity variation in our data-set. We, therefore, conclude that chemical effects are secondary compared to the structural ones.

Mixing models for thermal conductivities of partially molten peridotite

Our results show that peridotites, and to a lower extent the glasses, present higher thermal diffusivities compared to the melts. This result is not surprising: thermal conductivity is strongly dependent on the local structure and its vibrational properties. The disorder in the atomic structure increases from solid, glasses to molten states (Hofmeister et al. 2014). The composition of the melt appears to be of secondary importance. The final set of thermal diffusivities and conductivities values selected for the applications are given in Tables 3, S5 and Figures 9 and S14.

To propose a predictive law for thermal conductivity of partially molten rocks several mixing equations are now tested. Such equation generally describes the effect of a small amount of conductive phase into an insulating matrix. For thermal conduction, the problem is reversed because the melt is less conductive than the solid. In this section, we explore the different predictive models of thermal conductivity of binary mixtures:

1) Linear mixing model consider parallel thermal resistor:

$$
\kappa_{\text {bulk }}=\kappa_{s} *(1-F)+F \kappa_{m}(18)
$$

Where $s$ corresponds to the solid, $m$ the melt and $F$ the volume fraction of the melt.

2) tube / Ashbie model consider 1/3 of tubes of melt aligned in the heat flow direction (Grant and West, 1965, Schmeling 1986):

$$
\kappa_{\text {bulk }}=\frac{1}{3} * \kappa_{s} *(1-F)+F \kappa_{m}(19)
$$

3) cube model (Waff, 1974) representing cubes of solids into a melt matrix

$$
\kappa_{\text {bulk }}=\left[1-F^{2 / 3}\right] * \kappa_{s}(20)
$$

4) Archie's law, an empirical relation developed for electrical conductivity (Watanabe and Kurita, 1983)

Where $C$ and $n$ are constants.

$$
\kappa_{\text {bulk }}=C *(1-F)^{n} * \kappa_{S}(21)
$$

5) Thermal resistors in series:

$$
\kappa_{\text {bulk }}=\kappa_{s} * \frac{\kappa_{m} / \kappa_{s}}{\kappa_{m} / \kappa_{s}+F\left(1-\kappa_{m} / \kappa_{s}\right)}(22)
$$

6) Hashin Shtrikman lower bound $\left(\mathrm{HS}^{-}\right)$, representing insulating melt spheres into a conductive solid matrix:

7) Maxwell-Eucken relation:

$$
\kappa_{\text {bulk }}=\kappa_{s} * \frac{F}{1 /\left(\kappa_{m} / \kappa_{s}\right)+\frac{1-F}{3 \kappa_{s}}}
$$

$$
\kappa_{\text {bulk }}=\kappa_{s} * \frac{\kappa_{m}+2 \kappa_{s}+2 F\left(\kappa_{m}-\kappa_{s}\right)}{\kappa_{m}+2 \kappa_{s}-F\left(\kappa_{m}-\kappa_{s}\right)}(24)
$$

8) Landauer relation, based on resistors in series:

$$
\kappa_{\text {bulk }}=\frac{1}{4} *\left[\kappa_{m}(3 F-1)+\kappa_{s}(2-3 F)+\left\{\left(\kappa_{m}(3 F-1)+\kappa_{s}(2-3 F)\right)^{2}+8 \kappa_{s} \kappa_{m}\right\}^{\frac{1}{2}}\right]
$$

9) Russel-Rayleigh relation:

$$
\kappa_{\text {bulk }}=\frac{\kappa_{s}\left[\kappa_{s}+F^{2 / 3}\left(\kappa_{m}-\kappa_{s}\right)\right]}{\kappa_{s}+\left(\kappa_{m}-\kappa_{s}\right)\left(\kappa_{m}^{\frac{2}{3}}-F\right)}(26)
$$


These equations provide a different evolution of the thermal conductivity with the fraction of melt (F). In Figure S14, we present the results when either fixing $\kappa_{\text {solid }}$ and $\kappa_{\text {melt }}$ to the average value of our measurements, or adjusting their values to minimize the misfit between the mixing models and our results at varying $\mathrm{F}$ values (Table S5). Among the variety of fits obtained, it appears that the effect of partial melting is underestimated in most of the cases. Only the thermal resistors in series is capable to reproduce adequately the strong curvature observed experimentally at low F values, as well as the end-member values of solid and melt conductivities. For this reason, we use series model (eq. 22) for further discussions.

We note a lack of data points at high melt fractions, preventing to decipher more precisely the mixing trend. At very high temperatures, the experimental measurements become difficult on natural peridotite melting, in particular due to melt escape and chemical reactions with the experimental cell. Complementary data could be acquired working with analog system such as basalt/olivine mixture and could represent a further research direction.

\section{Thermal conductivity of partially molten peridotite: influence of texture}

The 3D solid/melt arrangement is known to influence significantly the geophysical properties of partially molten systems (von Bargen and Waff, 1986; Laporte et al., 1997; Laporte and Provost, 2000, Minarik and Watson, 1995; Yoshino et al., 2005 Maumus et al. 2005; Ten Grotenhuis et al. 2005, Freitas et al. 2019). Their distribution is classically described using dihedral angle value, which translates the ability of a liquid to wet the grain boundaries as a consequence of interfacial energies. The dihedral angle decreases when increasing pressure, temperature, water content and decreasing silica/alumina content of the melt (Yoshino et al. 2007, Mibe et al. 1998, 1999, Laporte et al., 1997, Watson et al 1991). Several studies with similar basaltic or peridotite melts (dry) have shown that basalt-like melts at mantle conditions have dihedral angles significantly lower than the interconnection threshold of $60^{\circ}$, with values between $30-40^{\circ}$ at $2 \mathrm{GPa}$ (Laporte et al., 1997, Yoshino et al. 2005, 2007). Our partially molten samples display a coherent texture and dihedral angles with these observations. Dihedral angles of $23.3^{\circ}$ and $19.0^{\circ}$ were measured from our samples containing $6.4 \%$ and $23.3 \%$ of melt, respectively (Figure S15), in good agreement with previous data given that these mafic melts are moderately hydrous (Table S3). For each melt fraction, a thin layer of melt surround most of the grains, in particular olivines, which in 3D will result into the insulation of the solid gains from their surroundings (Figure S9). This is very well visible on our low melt fraction sample $(\mathrm{F}=6.4 \%)$ where the layers of melt are few microns thick (M804). Even if melt is more abundant near clinopyroxenes and spinel sites in $\mathrm{M} 847(\mathrm{~F}=23.3 \%)$, the melt pockets are interconnected with similar thin melt layers $(<10 \mu \mathrm{m})$ (Figure S9). As a result, thermal conductivity is expected to drop brutally in the first degrees of melting. Still, some grain boundaries should remain un-wetted until the melt fraction rise significantly. For this reason, thermal conductivity should only stabilize at melt fraction corresponding to solid grains completely isolated from each other. This trend is visible in our data and parallel model (Figures 9 and S14) with a strong decrease in the first 10\% of melting highlighted by M804, the change of slope seems to occur around $15 \%$ and values decease more slowly in the $15-50 \%$ range as seen in M847, to stabilize and display near-melt values above $50 \%$. The complete isolation of solids should occur at "packing" threshold, which is a function of the solid shapes and size distribution and is expected to occur between 40 to $60 \%$ of melting. Thus, the first degrees of melting are very crucial in the case of a wetting liquid and affecting importantly the thermal properties.

\section{Thermal conductivity of peridotite: effect of the grain size}

The modelling of thermal conductivity of peridotites and low F molten peridotites should also take in account the effect of grain boundaries thermal resistances as grain size may vary in the different geological contexts (from $100 \mu \mathrm{m}$ to $>1 \mathrm{~cm}$ ), as seen in natural meteoritic examples, (Barrat et al. 1999, Busek, 1977, Keil, 2010, Floran et al. 1978). Indeed, grain boundary scattering could be 
important when the mean free paths of phonons approach the grain size. This effect, which only concerns solids and low fractions of melt, can be quantified with the following equation (Smith et al. 2003, Smith et al. 2013):

$$
\frac{1}{\kappa_{\text {poly }}}=\frac{1}{\kappa_{\text {single }}}+n R_{\text {boundary }}
$$

Where $\kappa_{\text {poly }}$ is the thermal conductivity of the polycrystalline sample, $\kappa_{\text {single }}$ the thermal conductivity of a reference single crystal (average from olivine data of Hofmeister et al. 2016, Table 3 ), $n$ represents the surface of grain boundaries along the heat flow direction per unit length, and $R_{\text {boundary }}$ the thermal resistance of grain boundary plane. The $n$ value should be almost constant with temperature (Smith et al. 2013) and is estimated between $4 \mathrm{e}^{-4}$ and $7 \mathrm{e}^{-3} \mathrm{~m}$ for our two peridotite samples via analyses of SEM images (grain size ranging from 25 to $140 \mu \mathrm{m}$, see Table S4 for textural parameters). We calculate $R_{\text {boundary }}$ values between $1.9 \mathrm{e}^{-6}$ and $5.9 \mathrm{e}^{-6} \mathrm{~W} / \mathrm{m}^{2} / \mathrm{K}$ for M804 and $9.3 \mathrm{e}^{-6}$ and $3.2 \mathrm{e}^{-5} \mathrm{~W} / \mathrm{m}^{2} / \mathrm{K}$ for $\mathrm{M} 847$. These values are compatible or slightly higher than hydrous polycrystalline olivine samples (Zhang et al. 2019).

As a result, the thermal conductivities quantified in our experiments are underestimations of natural ones as the grain size is $<100 \mu \mathrm{m}$, in experiments compared to grain sizes of $100 \mu \mathrm{m}$ up to $>1$ $\mathrm{cm}$ typical of mantle peridotites and reduced meteorites (which could be relic of bodies interiors, from cumulates (Floran et al. 1978), enstatite chondrite/achondrite (Keil, 2010), diogenite (Barrat et al. 1999) to pallasite (Busek, 1977)). Melts and high F partially molten systems are not affected by such effect, thus the observed decrease of thermal conductivity at the melting temperature is probably smaller in our experiments.

\section{Implications for geodynamos on Mercury-like proto-planets}

\section{$\underline{\text { Suitable conditions for a dynamo }}$}

For a thermally driven dynamo to operate in a terrestrial planet, four conditions were found to be necessary (e.g., Monteux et al., 2011): the core heat flow must be at least adiabatic (1), the thermal convection within the core has to supply enough power to compensate the losses due to ohmic dissipation (2), the Reynolds magnetic number must be supercritical (complex turbulent convection) (3) and the mantle heat flow has to overcome the core heat flow needed to induce a dynamo (4). These conditions can be expressed in terms of heat flow balance (See Figure 10 for a schematic representation) and are detailed here:

(1) The metallic core has to convect, meaning that the heat flow out of the core needs to overcome the adiabatic heat flow (Stevenson et al., 1983).

For this, the core thermal conductivity ( $\left.\kappa_{\text {core }}\right)$ is a dominant parameter. A large $\kappa_{\text {core }}$ value increases the heat flux along the core adiabat and reduces the lifetime of a thermally driven dynamo (Breuer et al., 2015). Several laboratory measurements suggested that the thermal conductivity of polycrystalline iron at Mercury's core conditions is $113-125 \mathrm{~W} / \mathrm{m} / \mathrm{K}$ (see Deng et al., 2013 and references therein). However, such values for Mercury are recently challenged with several recent studies proposing a much lower conductivity. In a first one, the conductivity of pure $\mathrm{Fe}$ and $\mathrm{Fe}-\mathrm{Si}$ alloys is reported at $30-40 \mathrm{~W} / \mathrm{m} / \mathrm{K}$ and $35-40 \mathrm{~W} / \mathrm{m} / \mathrm{K}$, respectively (Sibert et al. 2019). Then, it is proposed that the thermal conductivity of Fe-S at the P-T conditions of Mercury's core is as low as $\sim 4 \mathrm{~W} / \mathrm{m} / \mathrm{K}$, thus 1-2 orders of magnitude lower than that of pure iron (Pommier et al. 2019, Manthilake et al. 2019).

This first condition can be expressed as:

$$
Q_{C M B}>Q_{A d}=\frac{\kappa_{c} \alpha_{c} g_{c} T_{C M B}}{C_{p, c}} 4 \pi R_{c}^{2}(28)
$$


To estimate this flux, we assume that $\mathrm{T}_{\mathrm{CMB}}$ is the melting temperature of pure iron at $\mathrm{P}_{\mathrm{CMB}}$. This assumption gives a conservative value of the core heat flow in comparison with considering $\mathrm{T}_{\mathrm{ICB}}$ since the core liquidus is steeper that the core adiabat. We estimate the relation between the melting temperature of pure iron and the pressure using the following expression obtained by fitting the experimental results from Anzellini et al. 2013 with a Simon and Glatzel equation:

$$
T_{m, F e}=1800\left(\frac{P_{C M B}}{27.9}+1\right)^{1 / 2.08}
$$

Such a melting temperature typically lies between the solidus and liquidus of a chondritic mantle for the same pressure conditions (Monteux et al. 2020 and references therein). We also assume that $k_{c}, \alpha_{c}$ and $C_{p, c}$ are constant (see values in Table 4) and $P_{C M B}$ is calculated as follows (Monteux and Arkani-Hamed, 2014):

$$
P_{C M B}=P\left(r=R_{c}\right)=\frac{2}{3} \pi G \rho_{c}^{2}\left(R_{c}^{2}-r^{2}\right)+\frac{2}{3} \pi G \rho_{S i}^{2}\left(R^{2}-R_{c}^{2}\right)+\frac{4}{3} \pi G \rho_{S i} R_{c}^{3}\left(\rho_{c}-\rho_{S i}\right)\left(\frac{1}{R_{c}}-\frac{1}{R}\right)
$$

(2) The energy supplied by thermal convection to the geodynamo has to compensate for the loss due to ohmic decay (Buffett, 2002).

This imposes a condition on the core heat flow at the CMB. In fact, core heat flow will need to overcome a critical value. Assuming that dynamo is generated only by thermal convection in the core, we can write:

$$
Q_{C M B}>Q_{A d}+\frac{4 v_{c} \bar{B}^{2} C_{p, c}}{0.8 \mu_{c} \alpha_{c} G \rho_{c} R_{c}}(31)
$$

This heat flux is estimated by considering that the characteristic magnetic length scale equals the radius of the core. The parameter $\bar{B}$ is the average strength of the magnetic field inside the core and was estimated using a scaling from Christensen and Aubert (2006):

$$
\bar{B}=0.9 \mu_{c}^{\frac{1}{2}} \rho_{c}^{\frac{1}{6}}\left(\frac{g_{c} Q_{B}\left(R_{c}-r_{i}\right)}{4 \pi R_{c} r_{i}}\right)^{\frac{1}{3}}
$$

With $Q_{B}=\alpha_{c} Q_{C M B} / C_{p, c}$ the buoyancy flux and $r_{i}$ the radius of the inner core. In the scaling from Christensen and Aubert (2006), the inner core size cannot be set to 0. On Mercury the size of the inner core is currently not well constrained even if recent constraints via geodetic analysis (Genova et al. 2018) suggest its presence and a possible important size $\left(r_{i} / R_{c}\right.$ between 0.3 and 0.7$)$. As we focus here on the effect of thermal cooling on dynamo generation (i.e. we do not consider the effect of compositional convection related to inner core growth), we consider a small inner core with $r_{i} / R_{c}=$ 0.01. The scaling law used to calculate the average strength of the magnetic field inside the core (Eq. 32 ) is valid for the Earth but overestimates $\bar{B}$ in the case of thin shell dynamos such as the one operating within Mercury (Christensen and Aubert (2006)). Mariner 10 spacecraft measurements showed that Mercury's magnetic field was 100 times weaker than the Earth's one. To account for this discrepancy, we consider that the average strength of the magnetic field is $1 \% \bar{B}$ obtained from Eq. 32 when solving Eq. 31. We also consider that $v_{c}, \mu_{c}$ and $\rho_{c}$ are constants (see values in Tab. 4). We note that most of the power needed to overcome the criterion related to Eq. 31 can be supplied by thermal core convection (i.e. criterion related to Eq. 28) especially for large metallic cores.

(3) The magnetic Reynolds number $\left(R_{m}\right)$ must be supercritical in order to have convective motions, inducing a complex structure needed to carry the magnetic field lines (U. R. Christensen and Aubert, 2006).

Reynolds magnetic number is calculated using Christensen and Aubert, 2006 formulation's and assuming that the characteristic magnetic length scale is the radius of the core:

$$
R e_{m}=\left(\frac{Q_{C M B} G \alpha_{c}}{3 C_{p, c}}\right)^{1 / 3} \frac{R_{c}}{v_{c}}>10-100
$$


The value of the critical magnetic Reynolds number $\left(\mathrm{Re}_{\mathrm{m}, \mathrm{c}}\right)$ is usually constrained for models implying a large inner core. For Mercury-like planets, this value is less documented. Here we make the conservative assumption that this value ranges between 10 and 100 .

\section{(4) The mantle heat flow has to overcome the core heat flow needed to generate a dynamo.}

The mantle's Rayleigh number ( $\mathrm{Ra}$ ) conditions the efficiency of heat evacuation from the mantle:

$$
R a=\frac{\alpha_{S i} \rho_{S i} g \Delta T \delta_{S i}{ }^{3}}{\eta_{S i} \kappa_{S i}}(34)
$$

With $\alpha_{S i}$ the mantle thermal expansion coefficient, $\rho_{S i}$ the mantle density, $\Delta T$ the temperature difference between the core and the surface of the planet, $\delta_{S i}$ the mantle thickness, $\eta_{S i}$ the mantle viscosity, $\kappa_{S i}$ the mantle heat diffusivity $\left(\kappa_{S i}=k_{S i} /\left(\rho_{S i} C_{p, S i}\right)\right)$, and $C_{p, S i}$ the mantle heat capacity. If $R a$ is lower than a critical value $\left(R a_{C} \approx 1000\right)$, the heat is evacuated from the mantle by conduction and the mantle heat flow $Q_{S i}$ is:

$$
Q_{S i}=\frac{k_{S i} \Delta T}{\delta_{S i}} 4 \pi R^{2}
$$

Alternatively, if the $R a>R a_{C}$, the heat is evacuated from the mantle by convection and $Q_{S i}$ scales with $\mathrm{Ra}^{1 / 3}$ (Solomatov, 2007):

$$
Q_{S i}=0.089 \frac{k_{S i} \Delta T}{\delta_{S i}} 4 \pi R^{2} R a^{1 / 3}
$$

In any case, for a thermally-driven dynamo to operate, $Q_{S i}$ has to be larger than the core heat flow $Q_{\text {Core }}$. For these calculations, we consider here that the surface gravity is dominated by the gravity at the CMB $\left(g=g_{c}\right)$. On a planet with a core over planet radius ratio $\left(R_{c} / R\right)$ of $\sim 0.5$, the mantle is thick enough so that $R a>R a_{c}$ and the heat is efficiently evacuated by convection. On such bodies, the dynamo is generated easily and should appear early in the planet history. If the heat evacuation is very efficient, the planet might cool down rapidly, which can potentially lead to a short-lived dynamo. On a Mercury-like body with a large $R_{d} / R$ ratio, the mantle is thin compared to the core and its Rayleigh number, critical criterion for thermal convection, hardly overcomes $R a_{c}$. Hence, conduction should be the main heat evacuation process within the mantle of Mercury-like planets, which can limit the occurrence of an early thermally-driven dynamo.

\section{$\underline{\text { Simulation results }}$}

We now compare the core heat flow needed to generate a dynamo within a Mercury-like body (with e.g. $\mathrm{R}_{\mathrm{c}} / \mathrm{R}_{\text {planets}}$ ) (Figures 11 and 12 ). To do this, we use a maximum possible range of solid conductivities between $\kappa_{\mathrm{Si}}=4.32$ and $1.70 \mathrm{~W} / \mathrm{m} / \mathrm{K}$. We consider a maximum planet radius $\mathrm{R}=2440$ $\mathrm{km}$ with a thin mantle shell to stay in temperature and pressure conditions equivalent to the experimental conditions detailed above $(\mathrm{P} \leq 2 \mathrm{GPa}$ and $\mathrm{T} \leq 1700 \mathrm{~K})$. We also report the critical size of the protoplanet $(\mathrm{R}=215 \mathrm{~km})$ above which $R e_{m}$ is larger than 100 (Eq. 33). The Figure 11 shows that a solid conductive mantle is able to evacuate enough heat to induce a thermally driven dynamo if the planet radius is larger than $\sim 215 \mathrm{~km}$, regardless of the value of thermal conductivity in the outer core, at least up to more than $40 \mathrm{~W} / \mathrm{m} / \mathrm{K}$. In contrast, the change of core conductivities from e.g $40 \mathrm{~W} / \mathrm{m} / \mathrm{K}$ (Sibert et al., 2019) to $4 \mathrm{~W} / \mathrm{m} / \mathrm{K}$ (Manthilake et al. 2019) has a major effect on the maximum size of a planet that can operate a thermally driven dynamo. For a core conductivity $\kappa_{\text {core }}=40 \mathrm{~W} / \mathrm{m} / \mathrm{K}$, the maximum planet radius evolves from 1220 to $1880 \mathrm{~km}$, for $\kappa_{\mathrm{Si}}=1.70$ and $4.32 \mathrm{~W} / \mathrm{m} / \mathrm{K}$, respectively. When $\kappa_{\text {core }}=4 \mathrm{~W} / \mathrm{m} / \mathrm{K}$, the maximum planet radius is more than $2500 \mathrm{~km}$.

We now perform the same type of calculation for a mushy mantle using the silicate-melt conductivity refined in this study (Tables 3 and 4). We consider here neither a complete magma ocean that would evacuate the core heat very efficiently by turbulent convection (Monteux et al., 2016) nor a mushy mantle with a large melt fraction (larger than 40-60\%) which would imply a strong decrease of the bulk viscosity of the mantle (Picard et al., 2013). We consider here a purely conductive mantle where the melt fraction is smaller than $20 \%$. Hence, if this melt fraction is concentrated at the core 
mantle boundary, the molten layer is thin enough to avoid its convection, while if the liquid is equally distributed within the mantle, we can reasonably assume that the bulk viscosity is weakly affected by the liquid phase and close to the viscosity of subsolidus silicate material. Still, the presence of melt may affect mantle properties. An important parameter is the fate of melts, which is primarily controlled by the solid-melt density contrast. The molten material can either be evacuated at the surface during early volcanism or cumulate at the lowermost mantle. For peridotites, negative melt buoyancy is unlikely to happen at pressures lower than 7 GPa (Sakamaki et al. 2006, Matsukage et al. 2005, Freitas et al. 2017). However, the buoyancy of melts generated from the partial melting of a body with composition largely different from peridotite remains uncertain. Molten reservoirs may be trapped at shallow depths at the end of mushy mantle cooling (Monteux et al., 2020) or during the last stages of fractional crystallization within small bodies (e.g. Frossard et al., 2019). On a Moonlike body, a melt layer may be trapped below an anorthositic crust while on a Mercury-like body, anorthite is denser than the melt and then may not float allowing the melt to form a late shallow magma ocean. We consider here that the melt has neutral buoyancy and is equally distributed within the planetary mantle, with the consequence that the mantle viscosity is primarily controlled by the solid fraction of the mantle.

Due to the lower thermal conductivity of the melt compared to the solid mantle, the mushy mantle should limit the heat flow that can be extracted from the core. In our calculation, we consider for simplicity that the entire mantle has the same conductivity as the melt. As a result, the range of planetary radii for which a dynamo is plausible is much narrower than for a fully solid mantle (Figure 12). For a core conductivity of $40 \mathrm{~W} / \mathrm{m} / \mathrm{K}$, a thermally driven dynamo can only operate for planetary sizes ranging between 215 and $350-570 \mathrm{~km}$, depending on the value of $\kappa_{\mathrm{Si}}$ and for $\kappa_{\text {core }}=40 \mathrm{~W} / \mathrm{m} / \mathrm{K}$. The maximum planetary radius becomes $1000-1500 \mathrm{~km}$ for a core conductivity of $4 \mathrm{~W} / \mathrm{m} / \mathrm{K}$. Therefore, the melting of a Mercury-like planetary mantle could limit the establishment of a magnetic field on the planet. This effect could last over different timescales, depending on the size of the planet and of the core, the initial core temperature, the fate of the melt material, etc.

The differences obtained for fully solid (Figure 11) and molten (Figure 12) models show that the presence of melt within a "Mercury-like" planet mantle could result into better thermal insulation of the core, which may prevent the occurrence of a thermally driven dynamo. Of course, planets presenting mantle with supercritical Rayleigh number would not be affected by this effect, because mantle convection could extract enough heat from the core at the CMB. As a consequence, the solid mantle viscosity plays a key role because (1) it controls the planet size above which mantle convection is likely, through the Ra value, and (2) it governs the efficiency of mantle heat evacuation once the critical Rayleigh number is overcome (see Eq. 36). Decreasing the mantle viscosity from $10^{22}$ to $10^{18}$ Pa.s decreases the critical planet size for mantle convection by one order of magnitude (from 1600$1900 \mathrm{~km}$ to $160-200 \mathrm{~km}$ for a solid mantle and from $850-1050 \mathrm{~km}$ to $80-110 \mathrm{~km}$ for a mushy mantle, see Figures 11 and 12). The figures also show that the lower is mantle viscosity, the easier the planet can meet the criteria for a thermally driven dynamo when the mantle of the planet is convecting. We note here that considering the influence of melt on the bulk mantle viscosity should lead to a decrease of the critical Rayleigh number and as a consequence of the critical planetary size where heat in only evacuated by thermal conduction (i.e. green triangles would move to the left). However, this effect should be negligible for the small melt fraction considered here.

The impact of mantle partial melting crucially depends on the melt quantity and its location within the mantle. Whether it is distributed in a mushy mantle or accumulated as a pond at a given mantle depth affects both, locally and globally, the mantle viscosity and the thermal diffusivity. As a consequence, the dynamic regime can evolve from conduction to convection, changing the thermal outputs at the $\mathrm{CMB}$ and making the heat flux enough, or insufficient, to power a thermally-driven dynamo. In this framework, transient phenomena such as mantle overturns (Elkis-Tanton et al. 2003, Ballmer et al. 2017) implying major melt migration will result in a brutal change in the planet magnetic signature. Similarly, the chemical stratification resulting in the production of a crust 
(anorthositic, basaltic etc.) may help insulating the planet interior in its early history suggesting weaker but longer sustained dynamos.

\section{Conclusions}

In this study, we constrain the thermal diffusivities of silicate melts with a wide range of composition at high pressure and temperature conditions using the multi-anvil apparatus and the Angström method. We observed that melting induces a significant decrease in both thermal diffusivities and conductivities. We measure melt thermal diffusivities ranging from $0.18( \pm 0.02)$ $\mathrm{W} / \mathrm{m} / \mathrm{k}$ to $0.41( \pm 0.04) \mathrm{W} / \mathrm{m} / \mathrm{K}$. The composition of the melt does not have a significant impact on diffusivities. We then use our results to address the thermal properties of the molten silicate reservoirs, and the likeliness of a thermally driven dynamo within a Mercury-like planets presenting a large metallic core and a relatively thin silicate mantle (large Rc/Rplanet). The mantle of such bodies is not expected to be convecting easily $\left(\mathrm{Ra}<\mathrm{Ra}_{\mathrm{c}}\right.$ ) leading to an inefficient heat evacuation and difficulty generating a dynamo compared to planets with a thicker mantle (where easily $R a>R a_{c}$ ). Our results illustrate that the presence of a mushy mantle above the CMB in such a Mercury-like planet can significantly reduce the ability of the mantle to evacuate the heat from the core and limit the likeliness of a thermally-driven dynamo. As a consequence, the fate and the lifetime of such a mushy reservoir can have a profound impact on the thermal history of Mercury-like planets. Future observations of Mercury-like planets accreted in orbits close to their star and the eventual detection of their intrinsic 838 magnetic field would in return constrain the state of the mantle surrounding their metallic core. 


\section{Acknowledgments}

We acknowledge D. Laporte, A. Gourgeau, O. Sigmarsson, J-L. Froger and S. Jouhannel for providing the natural samples used in this study, F. Pointud, C. Guillot and J.L. Fruquière for their technical assistance with high pressure apparatus and sample/assembly preparation, J-M Henot and E. Voyer for the SEM analyses, J-L Devidal for the electron microprobe analyses, C. Fonquernie for flash analyses and M. Benbakkar for ICP-AES measurements. This is Laboratory of Excellence ClerVolc contribution number $\mathrm{xx}$.

\section{References}

1. Acuna, M. H., Connerney, J. E. P., Lin, R. P., Mitchell, D., Carlson, C. W., McFadden, J., et al. (1999). Global distribution of crustal magnetization discovered by the Mars Global Surveyor MAG/ER experiment. Science, 284(5415), 790-793.

2. Anderson, B. J., Johnson, C. L., Korth, H., Purucker, M. E., Winslow, R. M., Slavin, J. A., et al. (2011). The global magnetic field of Mercury from MESSENGER orbital observations. Science, 333(6051), 1859-1862. https://doi.org/10.1126/science.1211001

3. Andrault, D., Bolfan-Casanova, N., Nigro, G.L., Bouhifd, M.A., Garbarino, G., Mezouar, M., (2011). Solidus and liquidus profiles of chondritic mantle: implication for melting of the Earth across its history. Earth Planet. Sci. Lett.304, 251-259. http://dx.doi.org/10.1016/j.eps1.2011.02.006.

4. Anzellini, S., Dewaele, A., Mezouar, M., Loubeyre, P., Morard, G., (2013). Melting of iron at Earth's inner core boundary based on fast X-ray diffraction. Science340, 464-466.

5. Asphaug, E., \& Reufer, A. (2014). Mercury and other iron-rich planetary bodies as relics of inefficient accretion. Nature Geoscience, 7(8), 564-568. https://doi.org/10.1038/ngeo2189

6. Bajgain, S., Ghosh, D. B., \& Karki, B. B. (2015). Structure and density of basaltic melts at mantle conditions from first-principles simulations. Nature Communications, 6, 1-7. https://doi.org/10.1038/ncomms9578

7. Ballmer, M. D., D. L. Lourenco, K. Hirose, R. Caracas, and R. Nomura (2017), Reconciling magmaocean crystallization models with the present-day structure of the Earth's mantle, Geochem., Geophys., Geosyst., 18(7), 2785-2806, doi:10.1002/2017gc006917.

8. Bambier, A., Berger, E., Mergoil, J., Valadas, B., Veyret, Y., Weisbord, A., (1985). Carte géologique de la France à 1/50 000 (n 840), Burzet: Des sources de l'Ardèche aux sources de la Loire. Carte et notice explicative.

9. Barrat, J.A, Gillet, PH, Lesourd, M., Blicher-Toft, J., \& G.R Poupeau. (1999). The Tatahouine diogenite: Mineralogical and chemical effects of sixty-three years of terrestrial residence. Meteoritics \& Planetary science, 34, 91-97.

10. Beck, A. E., Darbha, D. M., \& Schloessin, H. H. (1978). Lattice conductivities of single-crystal and polycrystalline materials at mantle pressures and temperatures. Physics of the Earth and Planetary Interiors, 17(1), 35-53. https://doi.org/10.1016/0031-9201(78)90008-0

11. Benz, W., Slattery, W. L., \& Cameron, A. G. W. (1988). Collisional stripping of Mercury's mantle. Icarus, 74(3), 516-528. https://doi.org/10.1016/0019-1035(88)90118-2

12. Berger, E., (1973). Le volcanisme récent de l'Ardèche. Thèse, Orsay, 402 p.

13. Berger, E., Forette, M. C., (1975). Réactions de basaltes alcalins des Causses, du Vivarais et du Velay (France) avec les xénocristaux et les minéraux des enclaves homoéogènes. Bulletin de Minéralogie, 98(6), 366-373.

14. Berger, E., (1981). Enclaves ultramafiques, mégacristaux et leurs basaltes-hôtes en contexte océanique (Pacifique Sud) et continental (Massif Central Français). Thèse d'État, Université de Paris-Sud, Orsay, $470 \mathrm{p}$.

15. Bigazzi, G., Yegingil, Z., Ercan, T., Oddone, M., Özdogan, M., (1993). Fission track dating obsidians in Central and Northern Anatolia. Bulletin of Volcanology, 55(8), 588-595. 
16. Bolfan-Casanova, N., Montagnac, G., Reynard, B., (2014). Measurement of water contents in olivine using Raman spectroscopy. Am. Mineral. 99:149-156. doi: 10.2138/am.2014.4444.

17. Bougault, H., \& Treuil, M. (1980). Mid-atlantic ridge: Zero-age geochemical variations between azores and $22^{\circ}$ N. Nature, 286(5770), 209-212. https://doi.org/10.1038/286209a0

18. Boujibar, A., Andrault, D., Ali, M., Bolfan-casanova, N., Devidal, J., \& Trcera, N. (2014). Metal silicate partitioning of sulphur, new experimental and thermodynamic constraints on planetary accretion. Earth and Planetary Science Letters, 391, 42-54. https://doi.org/10.1016/j.eps1.2014.01.021

19. Boujibar, A., Andrault, D., Bolfan-Casanova, N., Bouhifd, M. A., \& Monteux, J. (2015). Cosmochemical fractionation by collisional erosion during the Earth's accretion. Nature Communications, 6, 1-7. https://doi.org/10.1038/ncomms9295

20. Breuer, D., Hauck, S. A., Buske, M., Pauer, M., Spohn, T., (2007). Interior Evolution of Mercury. Space Sci. Rev. 132, 229-260.

21. Breuer, D., Rueckriemen, T., \& Spohn, T. (2015). Iron snow, crystal floats, and inner-core growth: modes of core solidification and implications for dynamos in terrestrial planets and moons. Progress in Earth and Planetary Science, 2(1), 39. https://doi.org/10.1186/s40645-015-0069-y

22. Buffett, B.A., 2002. Estimates of heat flow in the deep mantle based on the power requirements for the geodynamo. Geophys. Res. Lett. 29 (12), 1-4.

23. Busek, P. R., (1997). Pallasite meteorites-mineralogy, petrology and geochemistry. Geochimica et Cosmochimica Acta, 41, 711-740.

24. Cao, H., Aurnou, J. M., Wicht, J., Dietrich, W., Soderlund, K. M., \& Russell, C. T. (2014). A dynamo explanation for Mercury's anomalous magnetic field. Geophysical Research Letters, 41, 4127-4134. https://doi.org/10.1002/2014GL060196.

25. Charlier, B., and Namur, O., (2019). The Origin and Differentiation of Planet Mercury, Elements, 15 (1): 9-14. https://doi.org/10.2138/gselements.15.1.9.

26. Chen, B., Li, J., \& Hauck, S. A. (2008). Non-ideal liquidus curve in the Fe-S system and Mercury's snowing core. Geophysical Research Letters, 35, L07201. https://doi.org/10.1029/2008GL033311.

27. Christensen, U. R., \& Aubert, J. (2006). Scaling properties of convection-driven dynamos in rotating spherical shells and application to planetary magnetic fields. Geophysical Journal International, 166(1), 97-114. https://doi.org/10.1111/j.1365-246X.2006.03009.x

28. Christensen, U. R., \& Wicht, J. (2008). Models of magnetic field generation in partly stable planetary cores: Applications to Mercury and Saturn. Icarus, 196(1), 16-34. https://doi.org/10.1016/j.icarus.2008.02.013.

29. Christensen, U. R. (2006). A deep dynamo generating Mercury's magnetic field. Nature, 444(7122), 1056-1058. https://doi.org/10.1038/nature05342.

30. Deng, L., Seagle, C., Fei, Y., \& Shahar, A. (2013). High pressure and temperature electrical resistivity of iron and implications for planetary cores. Geophysical Research Letters, 40, 33-37. https://doi.org/10.1029/2012GL054347.

31. Druitt, T. H. (1995). Settling behaviour of concentrated dispersions and some volcanological applications. Journal of Volcanology and Geothermal Research, 65(1-2), 27-39. https://doi.org/10.1016/0377-0273(94)00090-4

32. Dumberry, M., \& Rivoldini, A. (2015). Mercury's inner core size and core-crystallization regime. Icarus, 248, 254-268. https://doi.org/https://doi.org/10.1016/j.icarus.2014.10.038.

33. Ebel, D. S., \& Grossman, L. (2000). Condensation in dust-enriched systems, 64(2), 339-366.

34. Elkins-Tanton, L. T., E. M. Parmentier, and P. C. Hess (2003), Magma ocean fractional crystallization and cumulate overturn in terrestrial planets: Implications for Mars, Meteoritics \& Planetary Science, 38(12), 1753-1771, doi:10.1111/j.1945-5100.2003.tb00013.x. 
35. Fegley, B., \& Cameron, A. G. W. (1987). A vaporization model for iron/silicate fractionation in the Mercury protoplanet. Earth and Planetary Science Letters, 82(3-4), 207-222. https://doi.org/10.1016/0012-821X(87)90196-8

36. Floran, R.J., Prinz M., Hlava, P.F., Keil, K., Nehru, C.E. \& Hinthorne. J. R. (1978). The Chassigny meteorite: a cumulate dunite with hydrous amphibole-bearing melt inclusions. Geochemica et Comsochimica acta, 42 (8), 1213-1219. https://doi.org/10.1016/0016-7037(78)90115-1

37. Freitas, D., Manthilake, G., Schiavi, F., Chantel, J., Bolfan-Casanova, N., Bouhifd, M.A., Andrault, D., (2017).Experimental evidence supporting a global melt layer at the base of the Earth's upper mantle. Nat.Commun. 8:2186. https ://doi.org/10.1038/s4146 7-017-02275 -9.

38. Freitas, D., Manthilake, G., Chantel, J., Bouhfid, M.., Andrault, D., (2019). Simultaneous measurements of electrical conductivity and seismic velocity of partially molten geological materials: Implications for melt fraction in the upper mantle. Phys. Chem. Miner. 0, 0. doi:10.1007/s00269-019-01021-5.

39. Freitas, D., Manthilake, G., (2019b). Electrical conductivity of hydrous silicate melts : Implications for the bottom-up hydration of Earth 's upper mantle EPSL 523, 1-9. doi:10.1016/j.epsl.2019.115712.

40. Frossard P., Boyet M., Bouvier A., Hammouda T., Monteux J. (2019). Evidence for anorthositic crust formed on an inner solar system planetesimal. Geochemical Perspectives Letters vol.11, p.28-32, DOI:10.7185/geochemlet.1921 .

41. Fujisawa, H., Fujii, N., Mizutani, H., Kanmori, H., Akimoto, S., (1968) Thermal Diffusivity of $\mathrm{Mg} 2 \mathrm{SiO} 4, \mathrm{Fe} 2 \mathrm{SiO} 4$, and $\mathrm{NaCl}$ at High Pressures and Temperatures. J. Geophys. Res. 73:4727.

42. Garrick-Bethell, I., Weiss, B. P., Shuster, D. L., \& Buz, J. (2009). Early lunar magnetism. Science, 323(5912), 356-359. https://doi.org/10.1126/science.1166804

43. Genova, A., Goossens, S., Mazarico, E., Lemoine, F. G., Neumann, G. A., Kuang, W., et al. (2018). Geodetic evidence that Mercury has a solid inner core, 1-13. https://doi.org/10.1029/2018GL081135

44. Gillet, P., Richet, P., Guyot, F., Fiquet, G., (1991). High-temperature thermodynamic properties of forsterite. J. Geophys. Res. B96:11805-11816.

45. Giordano, D., Nichols, A. R. L., \& Dingwell, D. B. (2005). Glass transition temperatures of natural hydrous melts: A relationship with shear viscosity and implications for the welding process. Journal of Volcanology and Geothermal Research, 142(1-2 SPEC. ISS.), 105-118. https://doi.org/10.1016/j.jvolgeores.2004.10.015

46. Glassmeier, K. H., Auster, H. U., \& Motschmann, U. (2007). A feedback dynamo generating Mercury's magnetic field. Geophysical Research Letters, 34, L22201. https://doi.org/10.1029/2007GL031662.

47. Grant, F. S., West, G. F., (1965). Interpretation theory in applied geophysics. 583 pp., McGraw-Hill Book Co., New York.

48. ten Grotenhuis, S.M., Drury, M.R., Spiers, C.J., Peach, C.J., 2005. Melt distribution in olivine rocks based on electrical conductivity measurements. J. Geophys. Res. Solid Earth 110, 1-11. https://doi.org/10.1029/2004JB003462

49. Guérin G., (1983). La thermoluminescence des plagioclases, méthode de datation du volcanisme. Application au domaine volcanique français : chaîne des Puys, Mont-Dore et Cézallier, Bas-Vivarais, thèse, université Paris-6, $258 \mathrm{p}$.

50. Harte, B., (1977). Rock nomenclature with particular relation to deformation and recrystallisation textures in olivine-bearing xenoliths. The Journal of Geology, 85(3), 279-288.

51. Hartlieb, P., Toifl, M., Kuchar, F., Meisels, R., \& Antretter, T. (2016). Thermo-physical properties of selected hard rocks and their relation to microwave-assisted comminution. Minerals Engineering, 91, 34-41. https://doi.org/10.1016/j.mineng.2015.11.008

52. Hauck, S. A., Margot, J. L., Solomon, S. C., Phillips, R. J., Johnson, C. L., Lemoine, F. G., et al. (2013). The curious case of Mercury's internal structure. Journal of Geophysical Research E: Planets, 118(6), 1204-1220. https://doi.org/10.1002/jgre.20091 
53. Heimpel, M. H., Aurnou, J. M., Al-Shamali, F. M., \& Gomez Perez, N. (2005). A numerical study of dynamo action as a function of spherical shell geometry. Earth and Planetary Science Letters, 236(1-2), 542-557. https://doi.org/10.1016/j.eps1.2005.04.032.

54. Hernlund, J., Leinenweber, K., Locke, D., \& Tyburczy, J. A. (2006). A numerical model for steady-state temperature distributions in solid-medium high-pressure cell assemblies. American Mineralogist, 91(23), 295-305. https://doi.org/10.2138/am.2006.1938

55. Hofmeister, A. M., \& Branlund, J. M. (2015). Thermal Conductivity of the Earth. Treatise on Geophysics: Second Edition (Vol. 2). Elsevier B.V. https://doi.org/10.1016/B978-0-444-538024.00047-6

56. Hofmeister, Anne M., Whittington, A. G., \& Pertermann, M. (2009). Transport properties of high albite crystals, near-endmember feldspar and pyroxene glasses, and their melts to high temperature. Contributions to Mineralogy and Petrology, 158(3), 381-400. https://doi.org/10.1007/s00410-009$\underline{0388-3}$

57. Hofmeister, Anne M., Sehlke, A., \& Whittington, A. G. (2014). Thermal diffusivity of Fe-rich pyroxene glasses and their melts. Chemical Geology, 384, 1-9. https://doi.org/10.1016/j.chemgeo.2014.06.018

58. Hood, L. L., Harrison, K. P., Langlais, B., Lillis, R. J., Poulet, F., \& Williams, D. A. (2010). Magnetic anomalies near Apollinaris Patera and the Medusae Fossae Formation in Lucus Planum, Mars. Icarus, 208(1), 118-131. https://doi.org/10.1016/j.icarus.2010.01.009

59. Johnson, Catherine L., \& Phillips, R. J. (2005). Evolution of the Tharsis region of Mars: Insights from magnetic field observations. Earth and Planetary Science Letters, 230(3-4), 241-254. https://doi.org/10.1016/j.eps1.2004.10.038

60. Johnson, C. L., \& McFadden, P. (2015). The Time-Averaged Field and Paleosecular Variation. Treatise on Geophysics: Second Edition, 5, 385-417. https://doi.org/10.1016/B978-0-444-53802-4.00105-6

61. Johnson, C. L., Phillips, R. J., Purucker, M. E., Anderson, B. J., Byrne, P. K., Denevi, B. W., et al. (2015). Low-altitude magnetic fieldmeasurements by MESSENGER reveal Mercury's ancient crustal field. Science, 348(6237), 892-895. https://doi.org/10.1126/science.aaa8720.

62. Kabin, K., Heimpel, M. H., Rankin, R., Aurnou, J. M., Gómez-Pérez, N., Paral, J., et al. (2008). Global MHD modeling of Mercury's magnetosphere with applications to the MESSENGER mission and dynamo theory. Icarus, 195(1), 1-15. https://doi.org/10.1016/j.icarus.2007.11.028

63. Kanamori H., Mizutani, H., Fujii, N., (1969). Method of thermal diffusivity measurement. J. Phys. Earth. 17:43-53.

64. Katsura, T. (1993). Thermal diffusivity of silica glass at pressures up to $9 \mathrm{GPa}$. Physics and Chemistry of Minerals, 20(3), 201-208. https://doi.org/10.1007/BF00200122

65. Keil, K. (2010) Enstatite achondrite meteorites (aubrites) and the histories of their asteroidal parent bodies, Chemie der Erde, 70 (4), 295-317. doi:10.1016/j.chemer.2010.02.002

66. Laporte, D., Rapaille, C., Provost, A., (1997). Wetting angles, equilibrium melt geometry, and the permeability threshold of partially molten crustal protoliths BT. In: Bouchez JL, Hutton DHW, Stephens WE (eds) Granite: from segregation of melt to emplacement fabrics. Springer Netherlands, Dordrecht, pp 31-54.

67. Laporte, D., Provost, A., 2000. Equilibrium geometry of a fluid phase in a polycrystalline aggregate with anisotropic surface energies: Dry grain boundaries. J. Geophys. Res. Solid Earth 105, 2593725953. https://doi.org/10.1029/2000jb900256

68. Lawrence, K., Johnson, C., Tauxe, L., \& Gee, J. (2008). Lunar paleointensity measurements: Implications for lunar magnetic evolution. Physics of the Earth and Planetary Interiors, 168(1-2), 71-87.

69. Li, L., Wentzcovitch, R. M., Weidner, D. J., \& Da Silva, C. R. S. (2007). Vibrational and thermodynamic properties of forsterite at mantle conditions. Journal of Geophysical Research: Solid Earth, 112(5). https://doi.org/10.1029/2006JB004546 
70. Lillis, R. J., Frey, H. V., Manga, M., Mitchell, D. L., Lin, R. P., Acuña, M. H., \& Bougher, S. W. (2008). An improved crustal magnetic field map of Mars from electron reflectometry: Highland volcano magmatic history and the end of the martian dynamo. Icarus, 194(2), 575-596. https://doi.org/10.1016/j.icarus.2007.09.032

71. Lillis, R. J., Robbins, S., Manga, M., Halekas, J. S., \& Frey, H. V. (2013). Time history of the Martian dynamo from crater magnetic field analysis. Journal of Geophysical Research E: Planets, 118(7), 14881511. https://doi.org/10.1002/jgre.20105

72. Malavergne, V., Toplis, M. J., Berthet, S., \& Jones, J. (2010). Highly reducing conditions during core formation on Mercury: Implications for internal structure and the origin of a magnetic field. Icarus, 206(1), 199-209. https://doi.org/10.1016/j.icarus.2009.09.001

73. Malfait, W. J., Seifert, R., Petitgirard, S., Mezouar, M., \& Sanchez-Valle, C. (2014). The density of andesitic melts and the compressibility of dissolved water in silicate melts at crustal and upper mantle conditions. Earth and Planetary Science Letters, 393, 31-38. https://doi.org/10.1016/j.epsl.2014.02.042

74. Manthilake, G., Chantel, J., Monteux, J., Andrault, D., Bouhifd, M.A., Casanova, N.B., Boulard, E., Guignot, N., King, A., Itie, J.P., (2019). Thermal conductivity of FeS and its implications for Mercury's long sustaining magnetic field. J. Geophys. Res. E Planets. doi:10.1029/2019JE005979

75. Manthilake, M. A. G. M., De Koker, N., \& Frost, D. J. (2011a). Thermal conductivity of CaGeO3 perovskite at high pressure. Geophysical Research Letters, 38(8), 3-6. https://doi.org/10.1029/2011GL046882

76. Manthilake, G. M., De Koker, N., Frost, D. J., \& McCammon, C. A. (2011b). Lattice thermal conductivity of lower mantle minerals and heat flux from Earth's core. Proceedings of the National Academy of Sciences of the United States of America, 108(44), 17901-17904. https://doi.org/10.1073/pnas.1110594108

77. Matsukage, K.N., Jing, Z., Karato, S., (2005). Density of hydrous silicate melt at the conditions of Earth's deep upper mantle. Nature 438, 488-91. doi:10.1038/nature04241.

78. Maumus, J., Bagdassarov, N., Schmeling, H., 2005. Electrical conductivity and partial melting of mafic rocks under pressure. Geochim. Cosmochim. Acta 69, 4703-4718.

https://doi.org/10.1016/j.gca.2005.05.010

79. Médard, E., McCammon, C. A., Barr, J. A., \& Grove, T. L. (2008). Oxygen fugacity, temperature reproducibility, and $\mathrm{H} 2 \mathrm{O}$ contents of nominally anhydrous piston-cylinder experiments using graphite capsules. American Mineralogist, 93(11-12), 1838-1844. https://doi.org/10.2138/am.2008.2842

80. Mercier, J.-C.C., (1972). Structure des péridotites en enclaves dans quelques basaltes d'Europe et d'Hawaii.vRegards sur la constitution du manteau supérieur. Thèse 3e cycle, Nantes, France, 229 p.

81. Mercier, J. C. C., \& Nicolas, A. (1975). Textures and fabrics of upper-mantle peridotites as illustrated by xenoliths from basalts. Journal of Petrology, 16(1), 454-487. https://doi.org/10.1093/petrology/16.1.454

82. Mibe, K., Fujii, T., Yasuda, A., (1998). Connectivity of aqueous fluid in the Earth's upper mantle. Geo. Res. Lett. 25, 1233-1236

83. Mibe, K., Fujii, T., Yasuda, A., 1999. Control of the location of the volcanic front in island arcs by aqueous fluid connectivity in the mantle wedge. Nature 401, 259-262. https://doi.org/10.1038/45762

84. Mighani, S., Wang, H., Shuster, D. L., Borlina, C. S., Nichols, C. I. O., \& Weiss, B. P. (2020). The end of the lunar dynamo. Science, 1-8.

85. Minarik, W.G., Watson, E.B., (1995). Interconnectivity of carbonate melt at low melt fraction. Earth. Planet. Sci. Lett 133(3-4):423-437. https://doi.org/10.1016/0012-821X(95)00085

86. Monteux, J., Jellinek, A. M., \& Johnson, C. L. (2011). Why might planets and moons have early dynamos? Earth and Planetary Science Letters, 310(3-4), 349-359. https://doi.org/10.1016/j.eps1.2011.08.014 
87. Monteux, J., Arkani-Hamed, J., (2014). Consequences of giant impacts in early Mars: Core merging and Martian dynamo evolution. J. Geophys. Res. 119, 480-505.

88. Monteux, J., Andrault, D., \& Samuel, H. (2016). On the cooling of a deep terrestrial magma ocean. Earth and Planetary Science Letters, 448, 140-149. https://doi.org/10.1016/j.eps1.2016.05.010

89. Monteux J., Andrault D., Guitreau M., Samuel H., Demouchy S. (2020). A mushy Earth's mantle for more than $500 \mathrm{Myr}$ after the magma ocean solidification. Geophysical Journal International DOI:10.1093/gij/ggaa064

90. Namur, O., Collinet, M., Charlier, B., Grove, T. L., Holtz, F., \& McCammon, C. (2016). Melting processes and mantle sources of lavas on Mercury. Earth and Planetary Science Letters, 439, 117-128. https://doi.org/10.1016/j.eps1.2016.01.030

91. Neuville, D. R., Courtial, P., Dingwell, D. B., \& Richet, P. (1993). Thermodynamic and rheological properties of silicate melts. Contributions to Mineralogy and Petrology, 113, 572-581.

92. Ni, H., Keppler, H., \& Behrens, H. (2011). Electrical conductivity of hydrous basaltic melts: Implications for partial melting in the upper mantle. Contributions to Mineralogy and Petrology, 162(3), 637-650. https://doi.org/10.1007/s00410-011-0617-4

93. Ni, H., Hui H., \& G. Steinle-Neumann (2015). Transport properties of silicate melts. Rev. Geophys., 53, 715-744, doi:10.1002/2015RG000485.

94. Nimmo, F. (2002). Why does Venus lack a magnetic field? Geology, 30(11), 987-990. https://doi.org/10.1130/0091-7613(2002)030<0987:WDVLAM>2.0.CO;2

95. Novella, D., Frost, D.J., Hauri, E.H., Bureau, H., Raepsaet, C., Roberge, M., (2014). The distribution of $\mathrm{H} 2 \mathrm{O}$ between silicate melt and nominally anhydrous peridotite and the onset of hydrous melting in the deep upper mantle. Earth Planet Sci Lett 400:1-13. https ://doi. org/10.1016/j.eps1.2014.05.006.

96. O’Rourke, J. G., Buz, J., Fu, R. R., \& Lillis, R. J. (2019). Detectability of Remanent Magnetism in the Crust of Venus. Geophysical Research Letters, 46(11), 5768-5777. https://doi.org/10.1029/2019GL082725

97. Pertermann, M., \& Hofmeister, A. M. (2006). Thermal diffusivity of olivine-group minerals at high temperature. American Mineralogist, 91, 1747-1760.

98. Picard, D., Arbaret, L., Pichavant, M., Champallier, R., \& Launeau, P. (2013). The rheological transition in plagioclase-bearing magmas. Journal of Geophysical Research: Solid Earth, 118(4), 1363-1377.

99. Pommier, A., Leinenweber, K., \& Tran, T. (2019). Mercury' s thermal evolution controlled by an insulating liquid outermost core? Earth and Planetary Science Letters, 517, 125-134. https://doi.org/10.1016/j.epsl.2019.04.022

100. Richet, P., \& Fiquet, G. (1991). High-temperature heat capacity and premelting of minerals in the system $\mathrm{MgO}-\mathrm{CaO}-\mathrm{Al} 2 \mathrm{O} 3-\mathrm{SiO} 2$ Journal of Geophysical Research, 96(B1), 445-456. https://doi.org/10.1029/90JB02172

101. Romine, W. L., Whittington, A. G., Nabelek, P. I., \& Hofmeister, A. M. (2012). Thermal diffusivity of rhyolitic glasses and melts: Effects of temperature, crystals and dissolved water. Bulletin of Volcanology, 74(10), 2273-2287. https://doi.org/10.1007/s00445-012-0661-6

102. Sakamaki, T., Suzuki, A., \& Ohtani, E. (2006). Stability of hydrous melt at the base of the Earth's upper mantle. Nature, 439(7073), 192-194. https://doi.org/10.1038/nature04352

103. Sambridge, M., Mosegaard, K., (2002). Monte Carlo methods in geophysical inverse problems. Reviews of Geophysics, 40(3), 3-1.

104. Schiavi, F., Bolfan-Casanova, N., Withers, A. C., Médard, E., Laumonier, M., Laporte, D., et al. (2018). Water quantification in silicate glasses by Raman spectroscopy: Correcting for the effects of confocality, density and ferric iron. Chemical Geology, 483(February), 312-331. https://doi.org/10.1016/j.chemgeo.2018.02.036 
105. Schmeling, H., (1986). Numerical models on the influence of partial melton elastic, anelastic and electrical properties of rocks. Part II: electrical conductivity. Phys. Earth Planet. Inter. 43(2):123-136. https://doi.org/10.1016/0031-9201(86)90080 -4.

106. Schubert, G., Chan, K. H., Liao, X., \& Zhang, K. (2004). Planetary dynamos: Effects of electrically conducting flows overlying turbulent regions of magnetic field generation. Icarus, 172(2), 305-315. https://doi.org/10.1016/j.icarus.2004.06.007

107. Shea, T., Houghton, B.F., Gurioli, L., Cashman, K.V., Hammer, J.E., Hobden, B.J., (2010). Textural studies of vesicles in volcanic rocks: an integrated methodology. J. Volcanol. Geotherm. Res; 190(34):271-289. https ://doi.org/10.1016/j.jvolg eores .2009.12.003

108. Smith, D. S., Fayette, S., Grandjean, S., Martin, C., Telle, R., \& Tonnessen, T. (2003). Thermal resistance of grain boundaries in alumina ceramics and refractories. Journal of the American Ceramic Society, 86(1), 105-111. https://doi.org/10.1111/j.1151-2916.2003.tb03285.x

109. Smith, D. S., Alzina, A., Bourret, J., Nait-Ali, B., Pennec, F., Tessier-Doyen, N., Otsu, .K, Matsubara, H., Elser, P., \& Gonzenbach, U. T. (2013).Thermal conductivity of porous materials. J. Mater. Res., 28 (17).

110. Solomatov, V., (2007). Magma Oceans and Primordial Mantle Differentiation. Schubert, G. (Ed.), Treatise of Geophysics, vol.9. Elsevier.

111. Spera, F., J., (2000). Physical properties of magma. Encyclopedia on Volcanoes

112. Stanley, S., Bloxham, J., Hutchison, W. E., \& Zuber, M. T. (2005). Thin shell dynamo models consistent with Mercury's weak observed magnetic field. Earth and Planetary Science Letters, 234(1-2), 27-38. https://doi.org/10.1016/j.eps1.2005.02.040

113. Stevenson, D. J., Spohn, T., \& Schubert, G. (1983). Magnetism and thermal evolution of the terrestrial planets. Icarus, 54(3), 466-489. https://doi.org/10.1016/0019-1035(83)90241-5.

114. Stevenson, D. J. (1987). Mercury's magnetic field: A thermoelectric dynamo? Earth and Planetary Science Letters, 82(1-2), 114-120. https://doi.org/10.1016/0012 821X(87)90111-7.

115. Strom, R. G., \& Sprague, A. L. (2003). Exploring Mercury: the iron planet. Springer Science \& Business Media.

116. Tarduno, J.A., Cottrell, R.D., Watkeys, M.K., Hofmann, A., Doubrovine, P.V., Mamajek, E.E., Liu, D., Sibeck, D.G., Neukirch, L.P. and Usui, Y., (2010). Geodynamo, solar wind, and magnetopause 3.4 to 3.45 billion years ago. science, 327(5970), pp.1238-1240.

117. Tian, Z., Zuber, M. T., \& Stanley, S. (2015). Magnetic field modeling for Mercury using dynamo models with a stable layer and laterally variable heat flux. Icarus, 260, 263-268. https://doi.org/10.1016/j.icarus.2015.07.019.

118. Tikoo, S. M., Weiss, B. P., Cassata, W. S., Shuster, D. L., Gattacceca, J. Ô., Lima, E. A., et al. (2014). Decline of the lunar core dynamo. Earth and Planetary Science Letters, 404, 89-97. https://doi.org/10.1016/j.eps1.2014.07.010

119. Tyburczy, J. A., \& Waff, H. S. (1983). electrical conductivity of molten basalt and andesite to 25 kilobars pressures: geophysical significance and implications for charge transport and melt structure. Journal of Geophysical Research, 88(2), 2413-2430.

120. Von Bargen, N., Waff, H.S., (1986). Permeabilities, interfacial areas and curvatures of partially molten systems: results of numerical computations of equilibrium microstructures. J. Geophys. Res. 91:92619276.

121. Waff, H.S., (1974). Theoretical consideration of electrical conductivity in a partially molten mantle and implications for geothermometry. J. Geophys. Res. 79(26):4003-4010.

122. Watanabe, H. (1982). Thermochemical properties of synthetic high-pressure compounds relevant to the Earth's mantle. 
123. Watanabe, T., Kurita, K. (1993). The relationship between electrical conductivity and melt fraction in a partially molten simple system: Archie's law behavior. Physics of the earth and planetary interiors, 78(12), 9-17.

124. Watson, E.B., Brenan, J.M., Baker, D.R., (1991). Continental Mantle. Oxford Univeristy Press.

125. Weidenschilling, S. J. (1978). Iron/silicate fractionation and the origin of Mercury. Icarus, 35(1), 99111. https://doi.org/10.1016/0019-1035(78)90064-7

126. Weiss, B. P., Berdal, James, S., Elkins-Tanton, L., Stanley, S., Lima, E. A., \& Carporzen, L. (2008). Magnetism on the Angrite Differentiation of Planetesimals. Scientific Reports, 322(October), 713-716.

127. Wurm, G., Trieloff, M., \& Rauer, H. (2013). Photophoretic separation of metals and silicates: The formation of mercury-like planets and metal depletion in chondrites. Astrophysical Journal, 769(1). https://doi.org/10.1088/0004-637X/769/1/78

128. Xu, Y., Shankland, T. J., Linhardt, S., Rubie, D. C., Langenhorst, F., \& Klasinski, K. (2004). Thermal diffusivity and conductivity of olivine, wadsleyite and ringwoodite to $20 \mathrm{GPa}$ and $1373 \mathrm{~K}$. Physics of the Earth and Planetary Interiors, 143(1-2), 321-336. https://doi.org/10.1016/j.pepi.2004.03.005

129. Yoshino, T., Takei, Y., Wark, D.A;, Watson, E.B., (2005). Grain boundary wetness of texturally equilibrated rocks, with implications for seismic properties of the upper mantle. J. Geophys. Res. B Solid Earth 110(8):1-16. https ://doi.org/10.1029/2004J B0035 44.

130. Yoshino, T., Nishihara, Y., Karato, S. I, 2007. Complete wetting of olivine grain boundaries by a hydrous melt near the mantle transition zone. Earth Planet. Sci. Lett. 256, 466-472. https://doi.org/10.1016/j.epsl.2007.02.002

131. Zebib, A., Schubert, G., Dein, J.L., \& Paliwal, R.C. (1983) Character and stability of axisymmetric thermal convection in spheres and spherical shells. Geophys. Astrophys. Fluid Dyn. 23, 1-42.

132. Baohua, Z., Ge, J., Xiong, Z. \& Zhai, S., (2019). Effect of water on the thermal properties of olivine with implications for lunar internal temperature. J.Geo.Res. Planets, 124 (12), 3469-3481. doi: 10.1029/2019JE006194 
Figure 1: Schematic cross-section of the high-pressure cell assembly used for Angstrom method with multi-anvil apparatus. For glass and melt experiments, thermocouples were inserted in alumina tubes of $0.6 \mathrm{~mm}$ diameter and $4.5 \mathrm{~mm}$ length in the sample zone.

1195

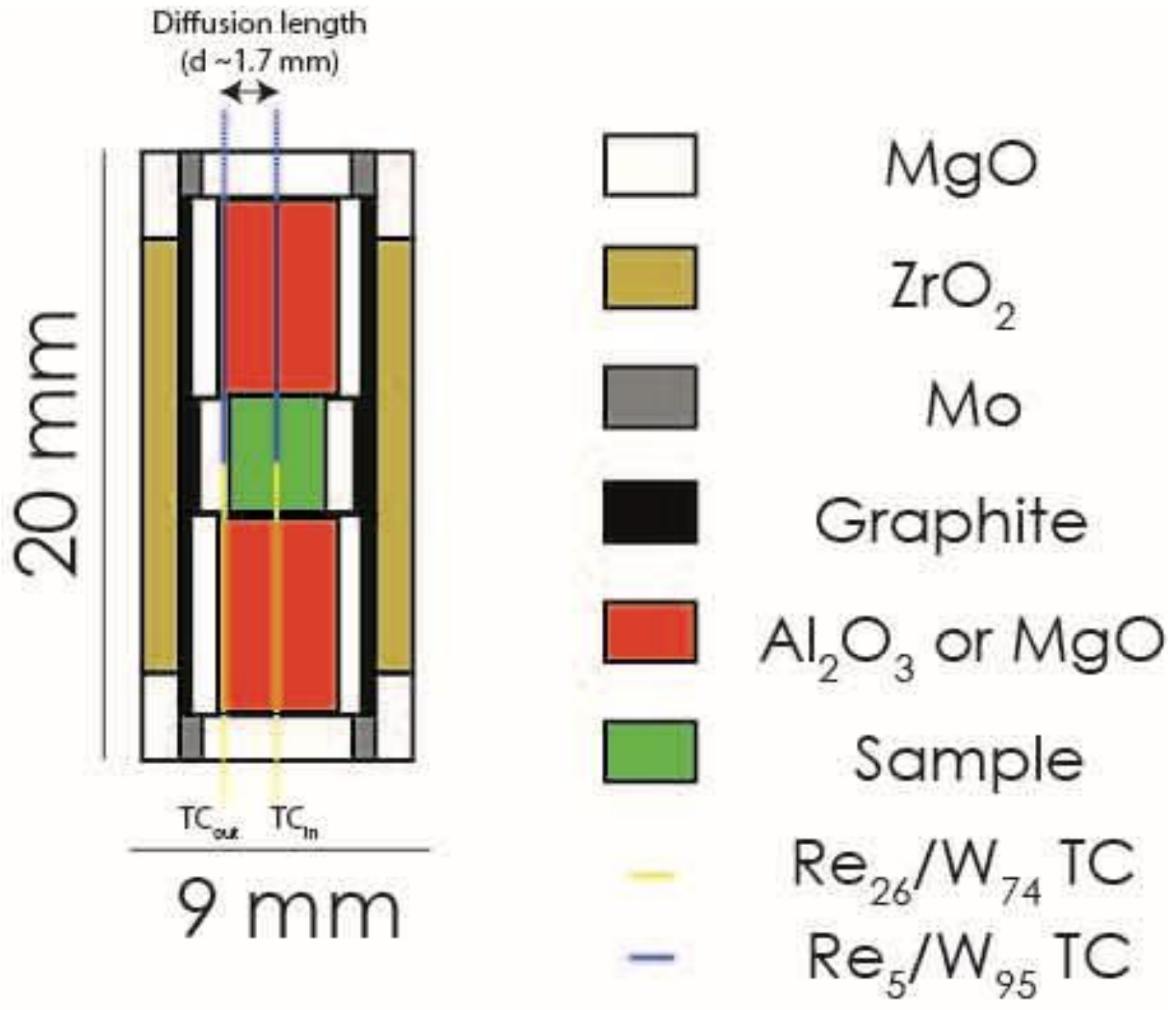


Figure 2: Experimental procedure for the measurement of thermal diffusivity of peridotites, glasses and melts: black, blue and red for cycles 1, 2 and 3 respectively. Heating $(\mathrm{H})$ and cooling $(\mathrm{C})$ parts of the cycles are separated by black dashed lines (for example H1: $1^{\text {st }}$ cycle heating). The expected temperatures for sample dehydration (up to $\sim 500^{\circ} \mathrm{C}$ ), glass transition and melting are illustrated in shaded colors: green, pink and yellow respectively.

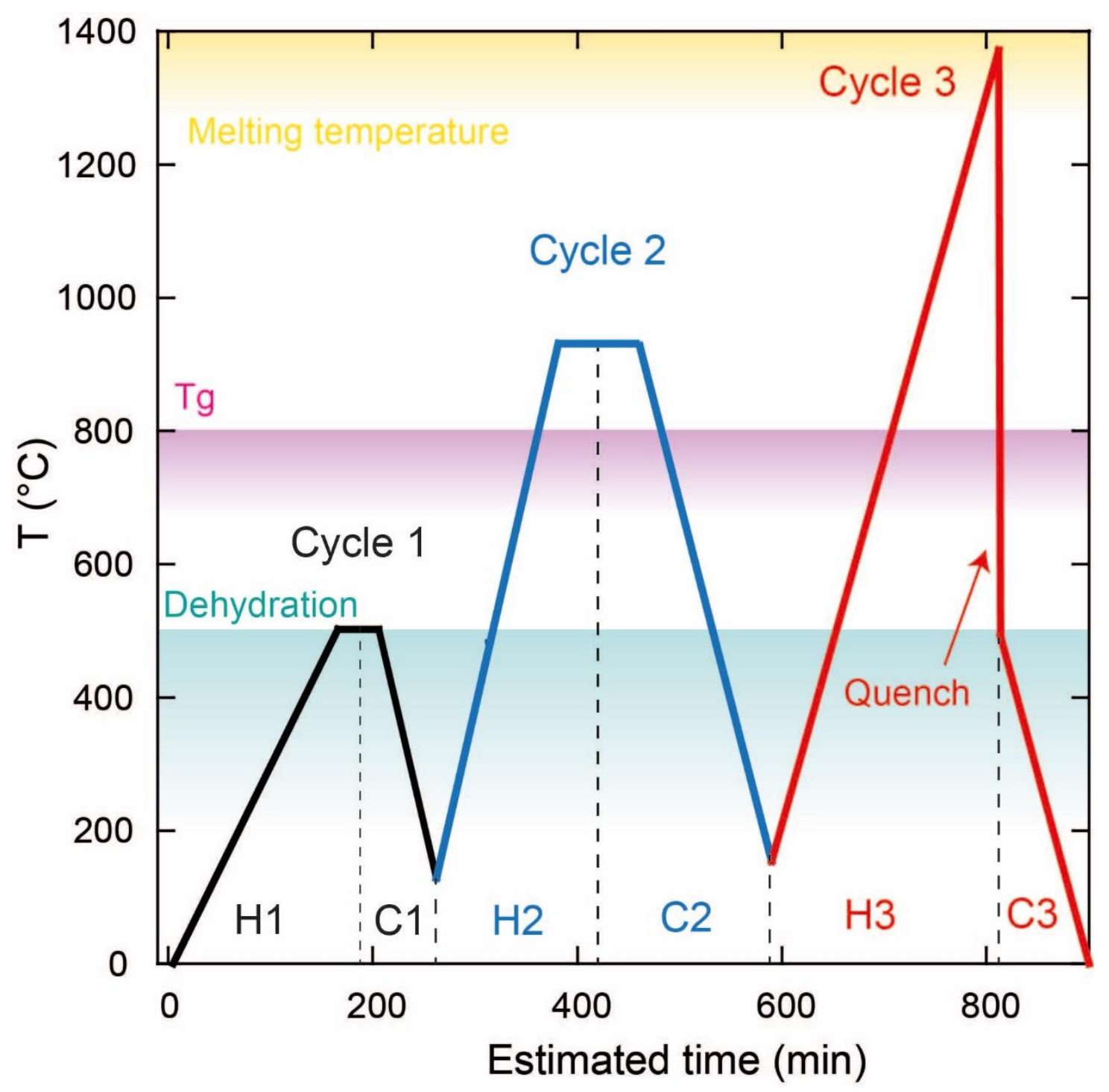


Figure 3: Examples of temperature waves recorded at high temperature during M804 experiments. Such data set is acquired after the sample equilibration at target temperature conditions for a few minutes (here $\mathrm{T}=250^{\circ} \mathrm{C}$ ). Acquisitions are performed at an interval ranging from $40 \mathrm{~ms}$ to $200 \mathrm{~ms}$. At least 10 periods of the temperature oscillation are recorded to ensure a good extraction of phase shifts and amplitude ratio based on the fitting procedure described in Methods. Upper and lower frames correspond to temperature measurements performed at frequencies of 0.3 and $1 \mathrm{~Hz}$, respectively. Red symbols are measured data and the dash thick lines represent the fitted sine waves.
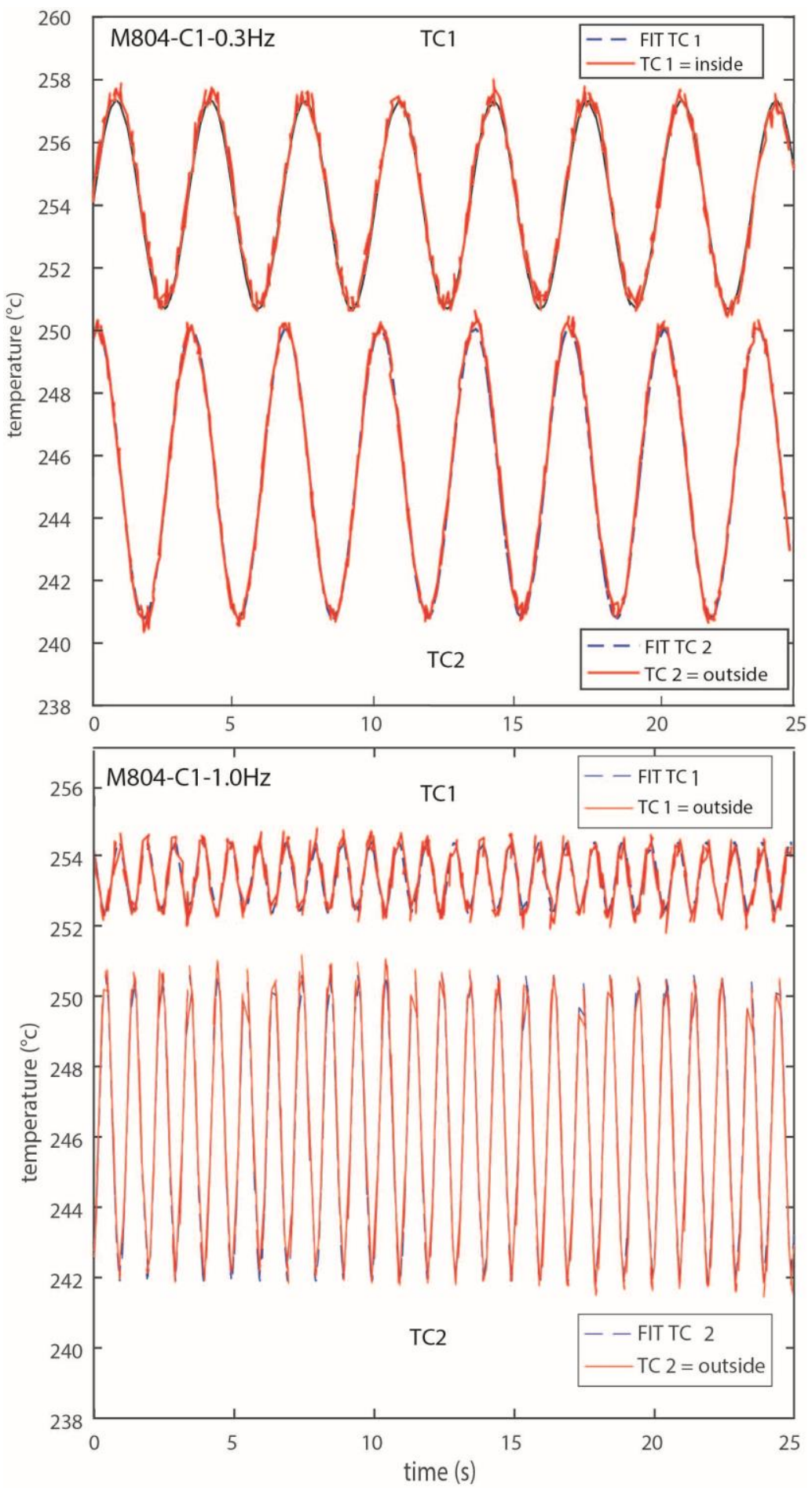
Figure 4: Example of refined phase shifts (top panels) and amplitude ratio (bottom panels) as a function of frequency (from 0.2 to $1.5 \mathrm{~Hz}$, left panels) and temperature (from $428 \mathrm{~K}$ to $1191 \mathrm{~K}$, right panels) for sample M844.

1233

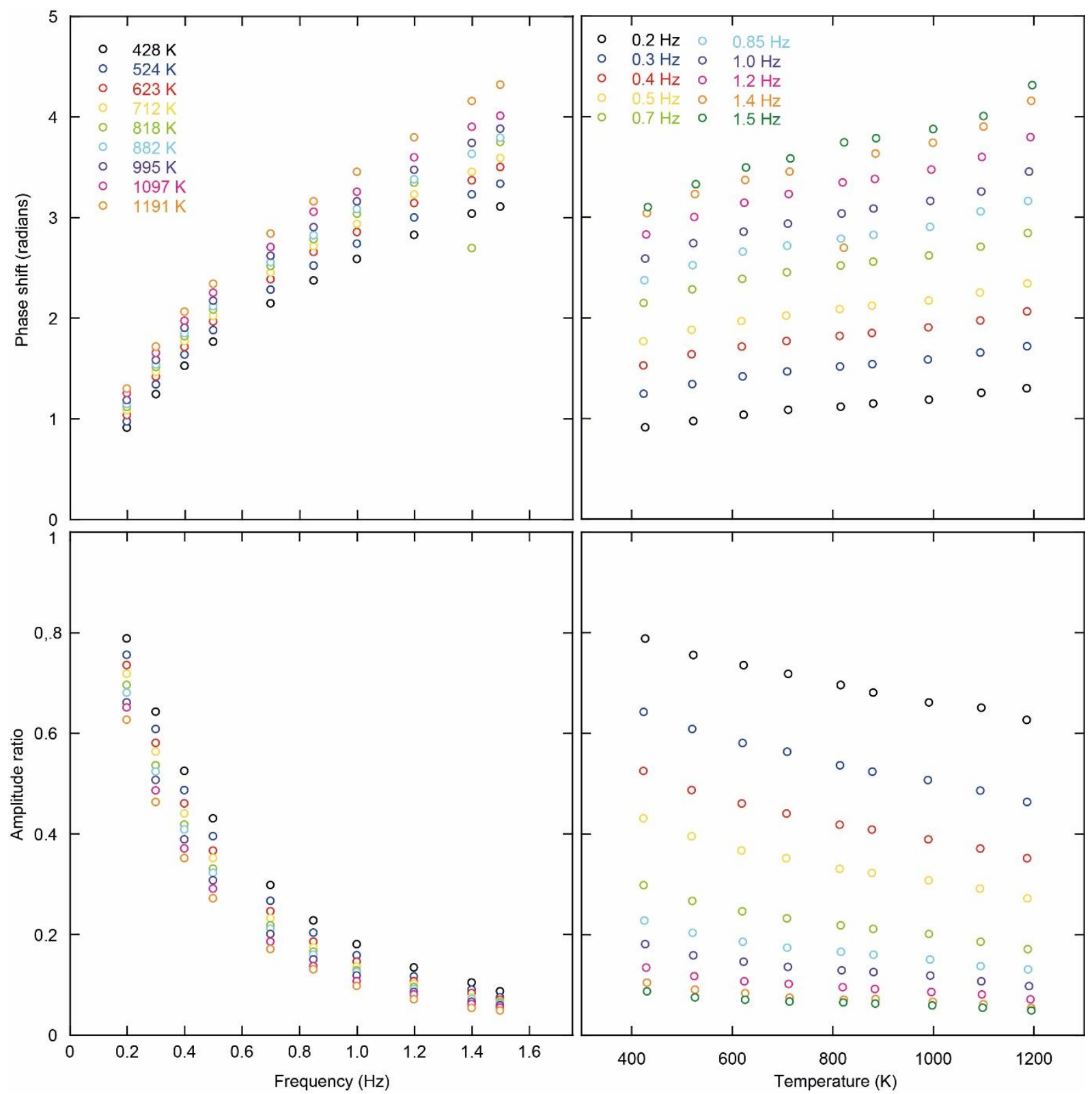


Figure 5: Typical example of a set of raw values of the thermal diffusivity extracted from our measurements for a basaltic glass, presented as a function of the frequency of the heat source. Experimental temperatures range between $\sim 430$ and $\sim 1200 \mathrm{~K}$ at a pressure of $2 \mathrm{GPa}$ (sample M844). Left and right panels correspond to thermal diffusivities calculated from phase shifts and amplitude ratios, respectively. The color code is kept similar in both panels. The fit through the data is made following the equation $D=D_{0}+A \exp \left(-f / f_{0}\right)$ (Xu et al., 2004), were $\mathrm{D}_{0}$ is the high-frequency asymptote of the diffusivity (see text). Error bars are generally within the size of the symbol.
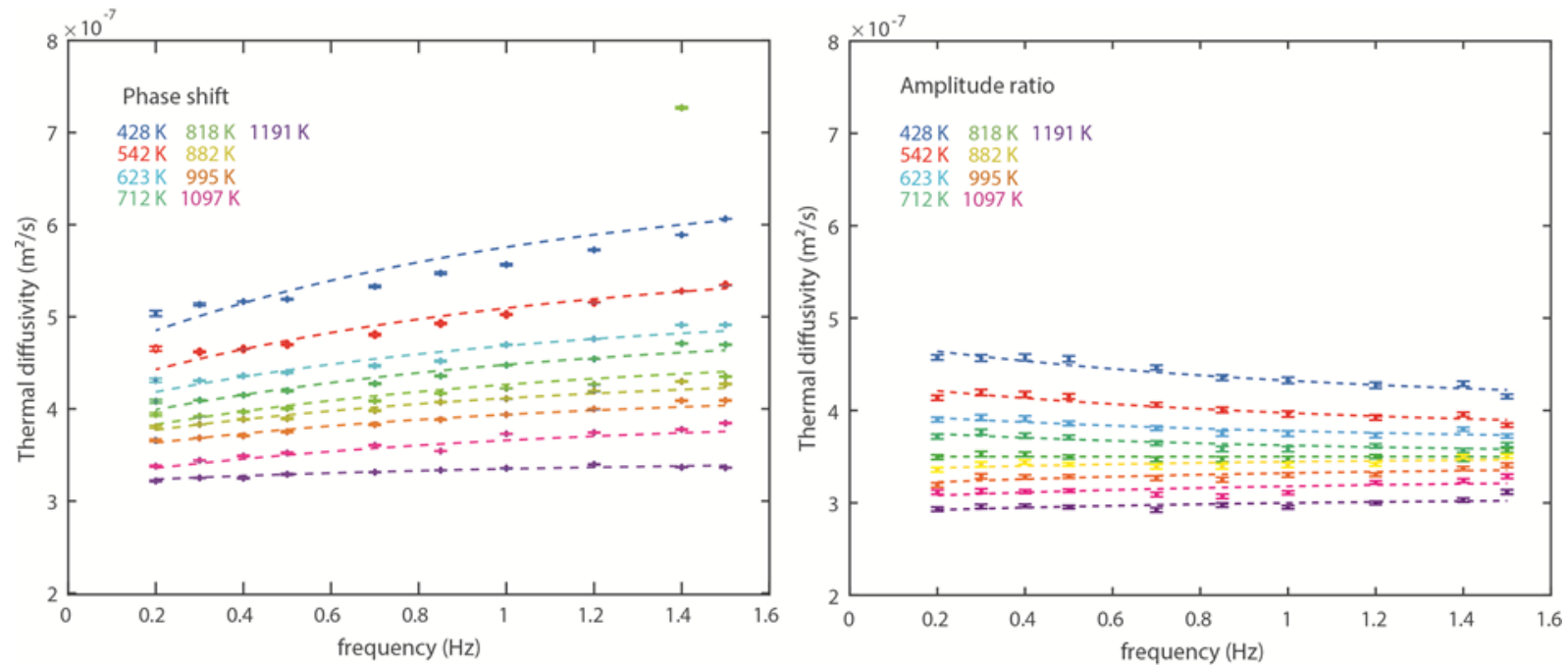
Figure 6: Thermal diffusivities data refined for our peridotites, basalts and rhyolites samples (from top to bottom) as a function of temperature. Associated fits are represented with a solid line of the same color than the symbols. Error bars are shown when larger than the symbol size. Several basaltic (M807, M662) and rhyolite (M848, M808) samples were partially recrystallized during the annealing and dehydration procedures prior to the conductivity measurement, as indicated by their high conductivity values at low temperatures. Thermal diffusivities values converge at high temperatures and melting.
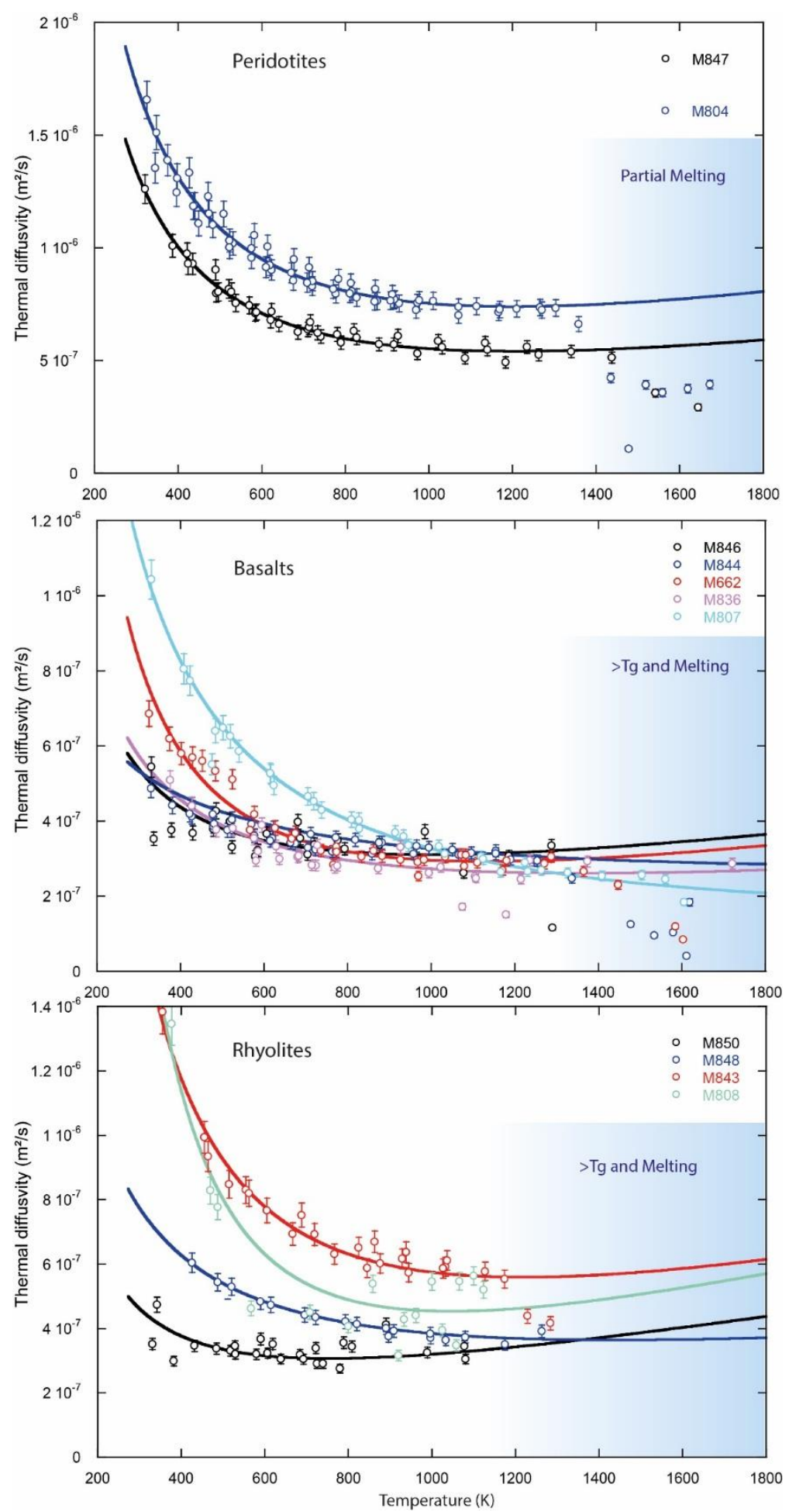
1257 Figure 7: Thermal conductivities inferred from diffusivities (Figure 6), heat capacities and densities 1258 (see Figure S4), based on Eq. 17 of the main text.
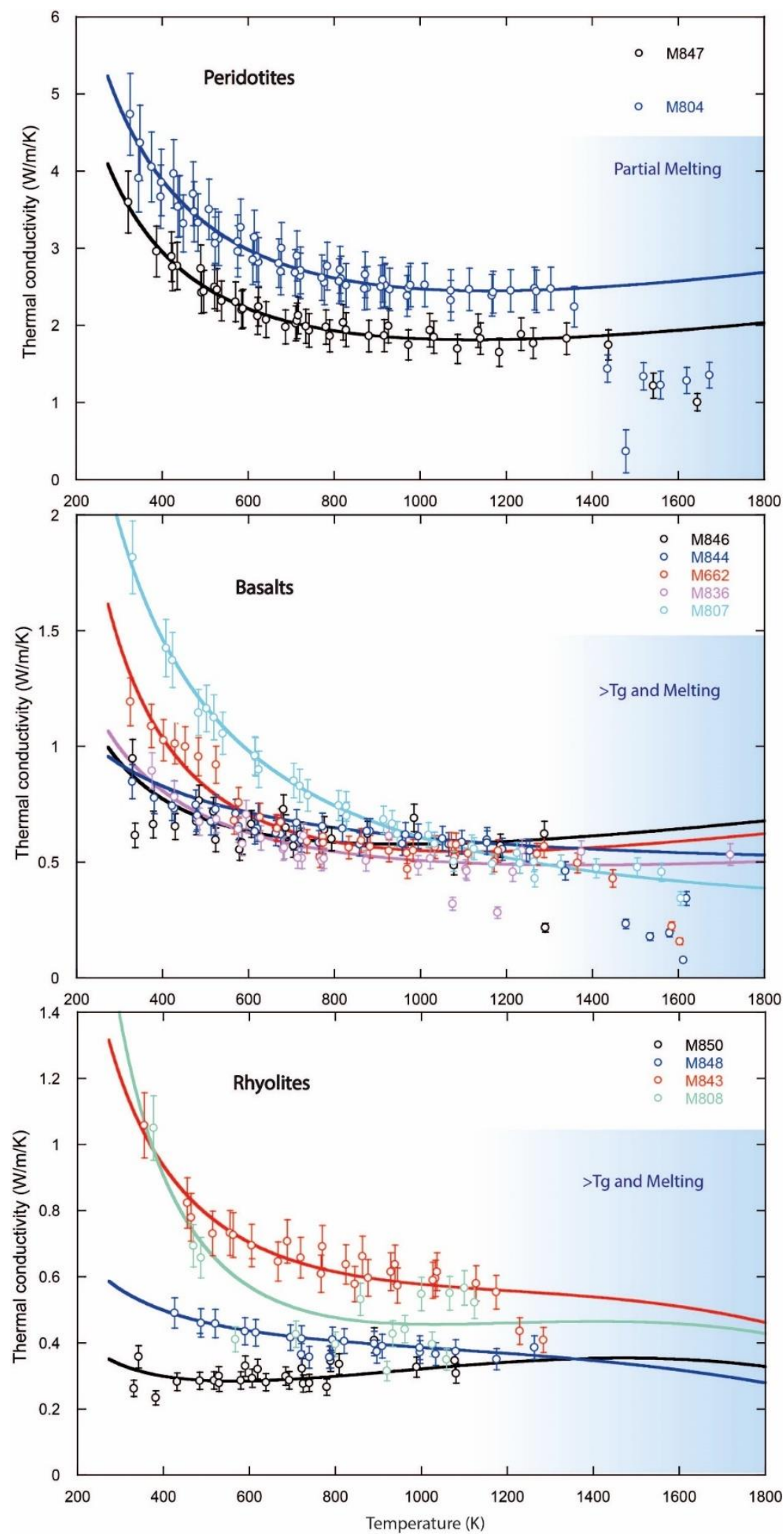
Figure 8: Comparison with the literature of our thermal diffusivities obtained our peridotite (upper panel), basaltic (center panel) and rhyolitic (lower panel) starting materials. Solids (peridotite and glasses) and melts are represented in thick lines and thick dashed line, respectively. Literature data are reported with thinner dashed lines (grey to black). Diopside (Di) glass and melt, $\mathrm{XAlSi}_{3} \mathrm{O}_{8}$ glass, Anorthite melt (An), Albite melt (Ab) and orthose melt (FK) from Hofmeister et al. 2009, NCr Rhyolite from Romine et al. 2012 and Enstatite glass from Hofmeister et al. 2014.
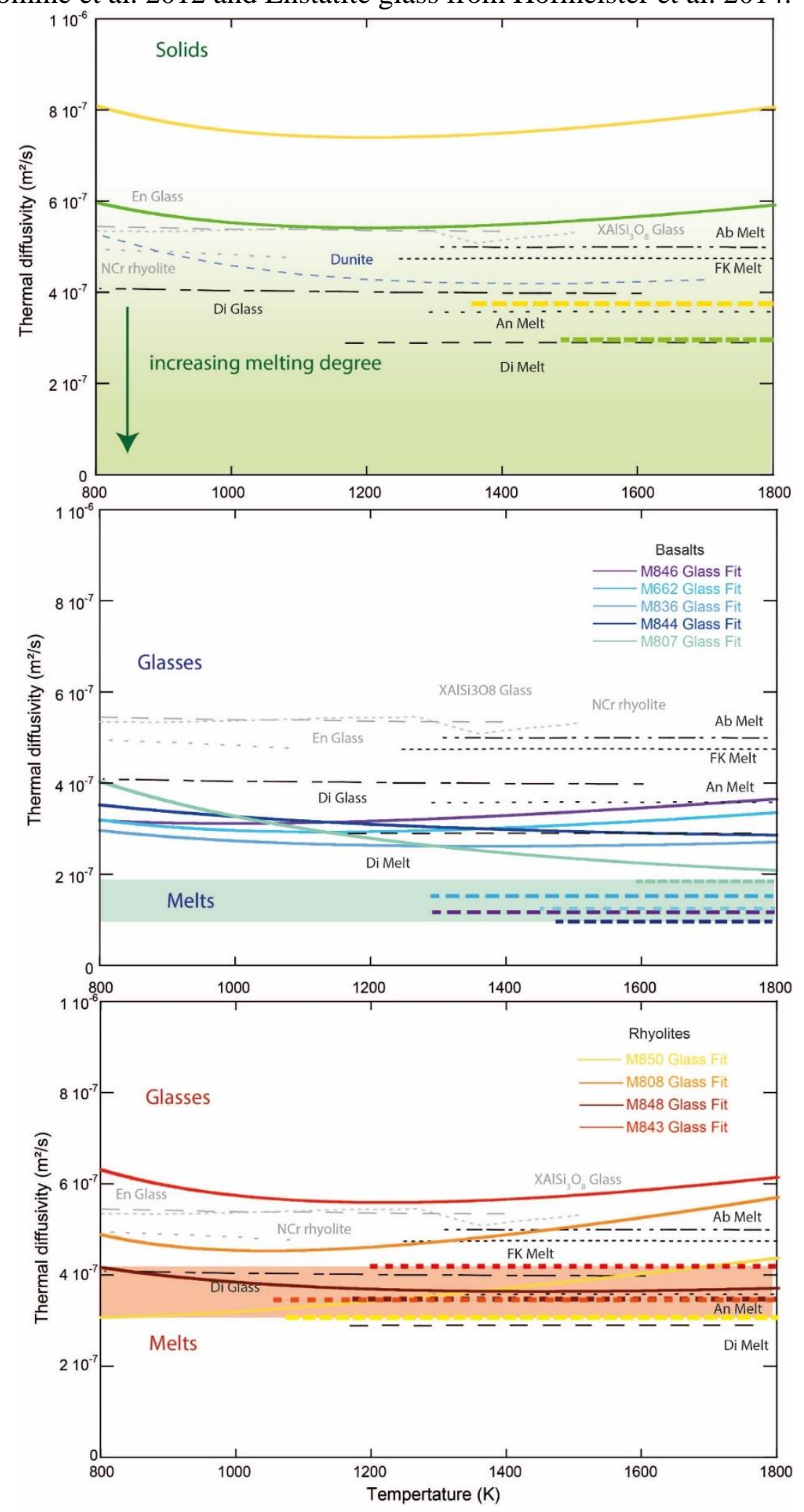
Figure 9: Our best model of the evolution of thermal diffusivity as a function of the melt fraction at high temperature $(>1200 \mathrm{~K})$, based on all available data sets. Solid peridotites at low and high temperature are represented with green and blue diamonds, respectively. Partially molten peridotites with $6.4 \%$ and $23.3 \%$ of melt (see Supplementary Text S3) are represented with red circles and melts (basalts and rhyolites) are represented with blue and pink circles. All the errors represented are 1 standard deviation. The fit represented is using a model of thermal resistors in series (Eq. 22), which fits our data set very well (see Figure S14).

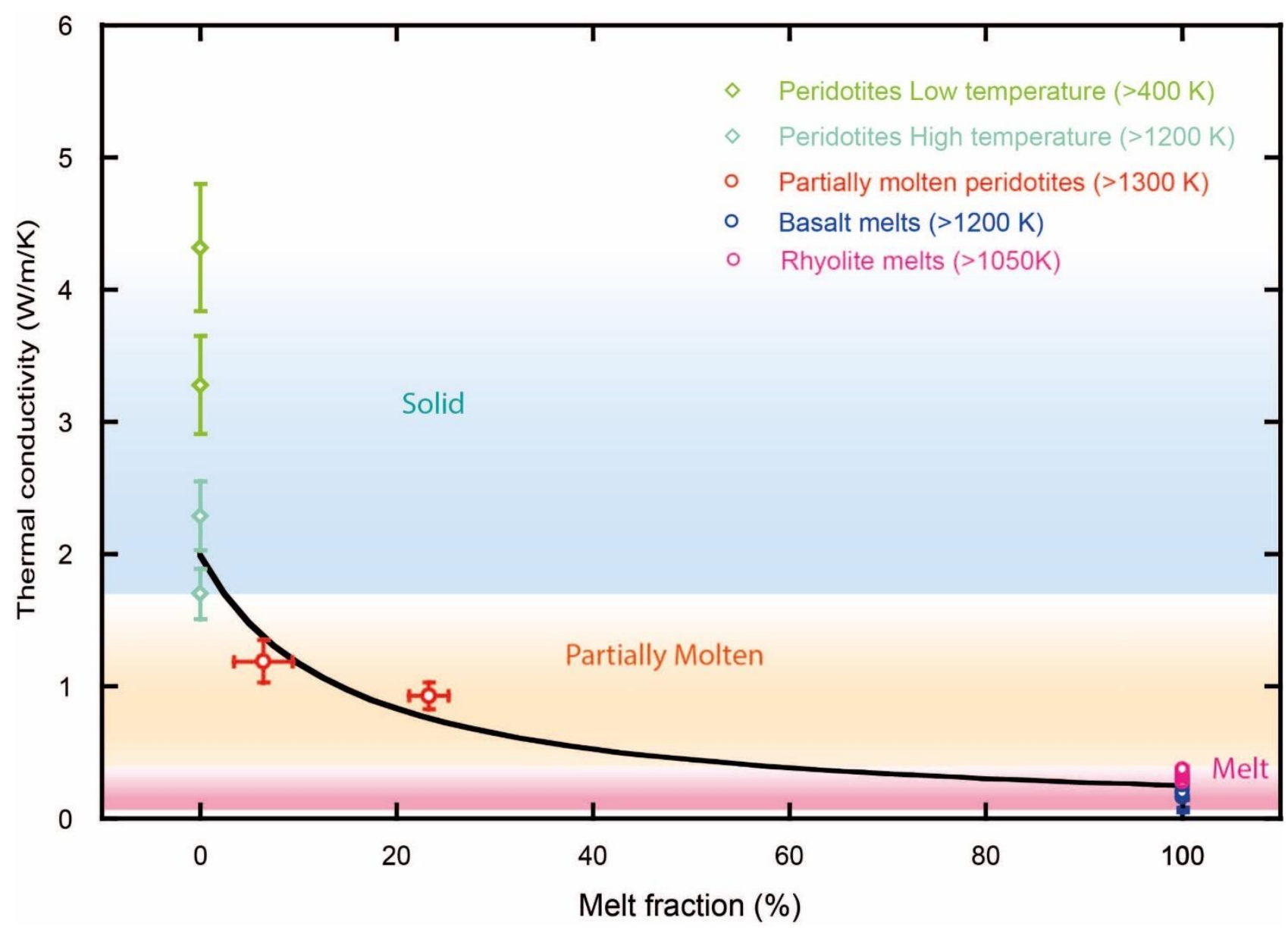


1279 Figure 10: Schematic representation of the geometry and of the heat flows computed in our model. 1280

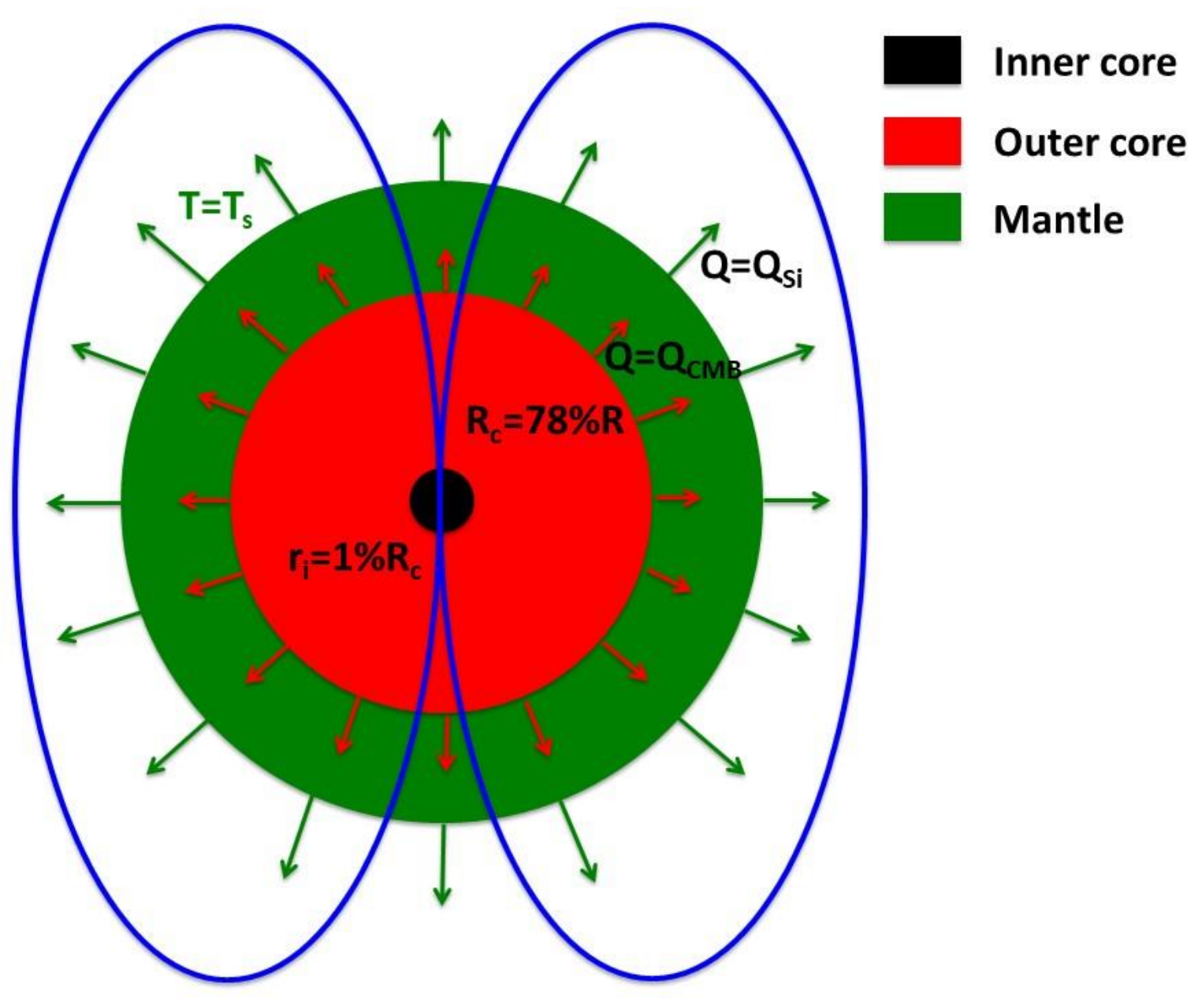


Figure 11: Heat flows as a function of the planetary radius for a fully solid planetary mantle. The black and grey lines represent the critical heat flow needed for a thermally driven dynamo for $\mathrm{k}_{\mathrm{c}}=40$ and $4 \mathrm{~W} / \mathrm{m} / \mathrm{K}$, respectively (Conditions 1 and 2, Eq. 31). The dark and light green lines represent the mantle heat flow in a conductive regime for $\kappa_{\mathrm{Si}}=4.32$ and $1.70 \mathrm{~W} / \mathrm{m} / \mathrm{K}$, respectively (Eq. 35). Green triangles represent the critical planet size at which $\mathrm{Ra}=\mathrm{Ra}_{\mathrm{c}}$, therefore corresponding to the minimum heat flow at the $\mathrm{CMB}$, for mantle viscosity ranging from $10^{18}$ to $10^{22} \mathrm{~Pa}$.s. Extrapolated values at $\mathrm{R}$ $=\mathrm{R}_{\text {Mercury }}=2440 \mathrm{~km}$ are also represented with green circles for conductive heat transfers and red and pink squares for convective cases (eq. 36) with mantle viscosities indicated nearby. The red dashed line represents the critical value for Rem $=100$ (Condition 3). At the left side of this line, a dynamo is unlikely. The likely zone for a planet radius capable of powering a dynamo is represented by the pink shaded area in case $\kappa_{\mathrm{Si}}=4.32 \mathrm{~W} / \mathrm{m} / \mathrm{K}$ and $\kappa_{\text {core }}=40 \mathrm{~W} / \mathrm{m} / \mathrm{K}$.

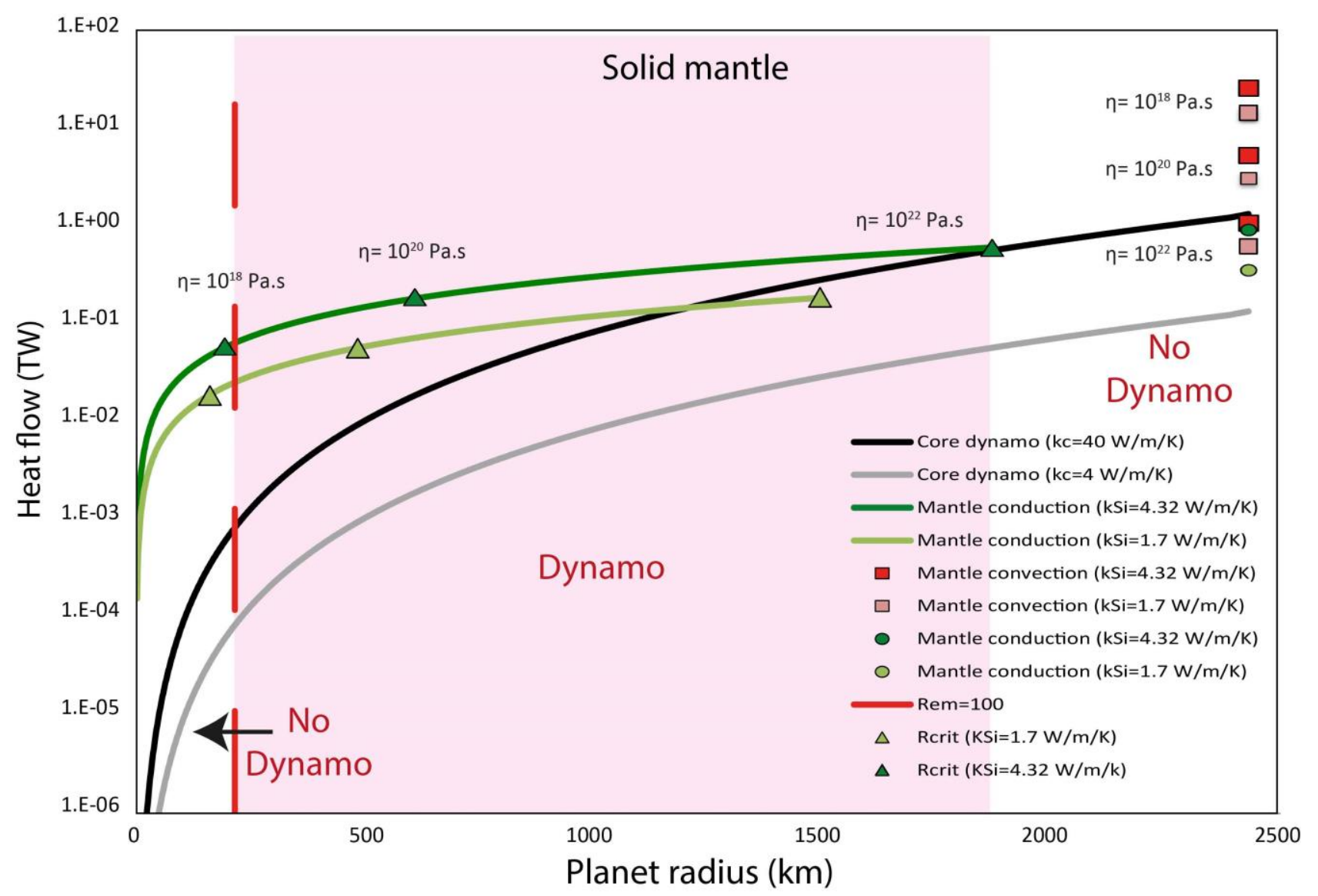


Figure 12.

Heat flows as a function of the planetary radius for a stagnant partially molten planetary mantle. The black and grey lines represent the critical heat flow for a thermally driven dynamo for $\mathrm{k}_{\mathrm{c}}=40$ and 4 $\mathrm{W} / \mathrm{m} / \mathrm{K}$, respectively (Conditions 1 and 2, Eq. 31). The dark and light green lines represent the mantle heat flow for $\kappa_{\mathrm{Si}}=0.41$ and $0.18 \mathrm{~W} / \mathrm{m} / \mathrm{K}$, respectively (Eq. 35). Green triangles represent the critical planet size at which $\mathrm{Ra}=\mathrm{Ra}_{\mathrm{c}}$, for mantle viscosity ranging from $10^{18}$ to $10^{22} \mathrm{~Pa}$.s. Extrapolated values at $\mathrm{R}=\mathrm{R}_{\text {Mercury }}=2440 \mathrm{~km}$ are also represented with green circles for conductive heat transfers and red and pink squares for convective cases (Eq. 36) with viscosities indicated nearby. The red dashed line represents the critical value for Rem $=100$ (Condition 3). At the left side of this line, a dynamo is unlikely. The likely zone for a planet radius capable of powering a dynamo is represented by the pink shaded area in case $\kappa_{\mathrm{Si}}=0.41 \mathrm{~W} / \mathrm{m} / \mathrm{K}$ and $\kappa_{\text {core }}=40 \mathrm{~W} / \mathrm{m} / \mathrm{K}$.

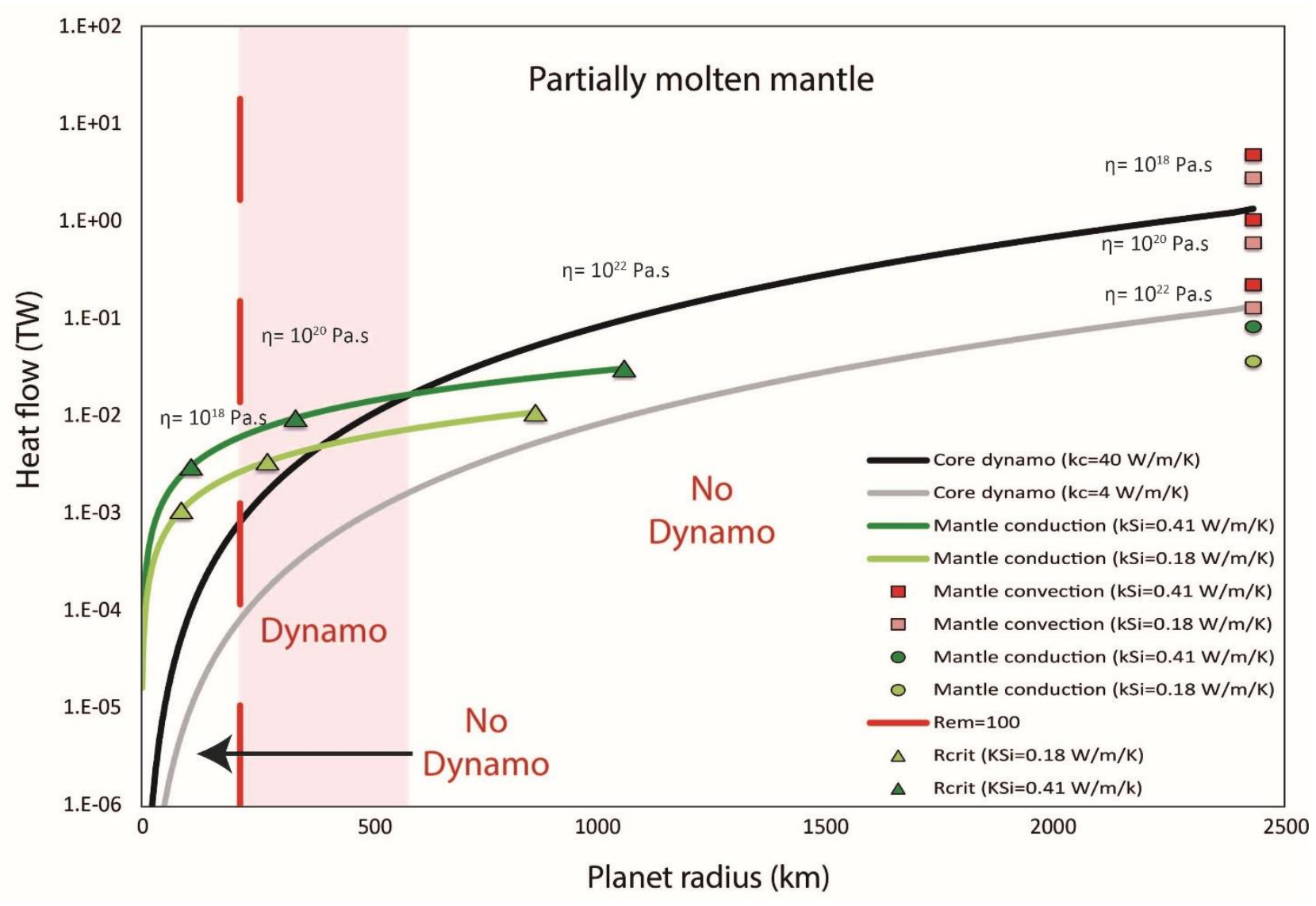


Table 1: Sum up of our Ansgtröm experiments with compositions, P-T ranges and associated parameters.

\begin{tabular}{|c|ccccccccccc|}
\hline Run\# & M662 & M804 & M807 & M808 & M836 & M843 & M844 & M846 & M847 & M848 & M850 \\
\hline Sample name & EPR- & RP4-S2 & DR07- & GD- & Haplo & ATHO- & DR11- & DR11- & RP4-S3 & $\begin{array}{c}\text { ATHO- } \\
\text { S2 }\end{array}$ & $\begin{array}{c}\text { GD- } \\
\text { S2 } \\
\text { Composition }\end{array}$ \\
& MORB & MORB & $\begin{array}{c}\text { Peridoti } \\
\text { te }\end{array}$ & MORB & $\begin{array}{c}\text { Rhyoli } \\
\text { te }\end{array}$ & $\begin{array}{c}\text { S1 } \\
\text { haplobas } \\
\text { alt }\end{array}$ & $\begin{array}{c}\text { Shyolit } \\
\text { e }\end{array}$ & $\begin{array}{c}\text { S1 } \\
\text { MORB }\end{array}$ & $\begin{array}{c}\text { MORB } \\
\text { Peridoti } \\
\text { te }\end{array}$ & $\begin{array}{c}\text { Rhyolit } \\
\text { e }\end{array}$ & $\begin{array}{c}\text { Rhyoli } \\
\text { te }\end{array}$ \\
Pressure (GPa) & 2 & 2 & 2 & 2 & 2 & 2 & 2 & 2 & 2 & 2 & 2 \\
length before $(\mu \mathrm{m})$ & 1400 & 1771.2 & 1061.9 & 1098.8 & 1124.6 & 1541.9 & 1141.3 & 1048.2 & 1652.9 & 1045.1 & 1336.4 \\
$\begin{array}{c}\text { length after }(\mu \mathrm{m}) \\
\text { expected Melting }\end{array}$ & 1334.2 & 1780.0 & - & 1462.7 & 1213.2 & 1666.1 & 1287.6 & 1324.9 & 1643.6 & 1309.1 & 1287.4 \\
$\mathrm{~T}^{\circ}(\mathrm{K})$ & $>1600$ & $>1523$ & $>1600$ & $>1173$ & $>1723$ & $>1173$ & $>1600$ & $>1600$ & $>1523$ & $>1173$ & $>1173$ \\
Max T (K) & 1614 & 1681 & 1612 & 1146 & 1769 & 1219 & 1609 & 1284 & 1573 & 1325 & 1073 \\
Run duration (min) & 544 & 1089 & 953 & 480 & 832 & 800 & 834 & 439 & 767 & 761 & 610 \\
\hline
\end{tabular}

1320

1321

1322 1323 1324

1325

1326

1327

1328

1329

1330

1331

1332

1333

1334

1335

1336

1337

Table 2: Fitting parameters obtained for the last cycle (C2-H3) of each experiment. Associated errors (1 STD) are given in parenthesis

\begin{tabular}{|c|ccccc|}
\hline Run\# & $\mathrm{a}$ & $\mathrm{b}$ & $\mathrm{c}$ & $\mathrm{R}^{2}$ & $\mathrm{R}^{2}$ adj \\
\hline \multicolumn{7}{|c|}{ Peridotites } \\
\hline M804 & $7.0 \mathrm{e}-4(2.2 \mathrm{e}-4)$ & $1.06(0.06)$ & $2.97 \mathrm{e}-10(2.8 \mathrm{e}-11)$ & 0.9659 & 0.9647 \\
M847 & $8.8 \mathrm{e}-4(7 \mathrm{e}-4)$ & $1.15(0.05)$ & $2.37 \mathrm{e}-10(1.8 \mathrm{e}-11)$ & 0.9763 & 0.9750 \\
\hline \multicolumn{7}{|c|}{ Basalts } \\
\hline M846 & $8.6 \mathrm{e}-6(1.5 \mathrm{e}-5)$ & $0.5(0.3)$ & $9.7 \mathrm{e}-11(8.4 \mathrm{e}-11)$ & 0.3933 & 0.3294 \\
M662 & $7.2 \mathrm{e}-4(1.8 \mathrm{e}-4)$ & $1.01 \mathrm{e}-10(4.1 \mathrm{e}-12)$ & 0.9964 & 0.9962 \\
M836 & $5.6 \mathrm{e}-5(7.6 \mathrm{e}-5)$ & $1.03 \mathrm{e}-10(3.5 \mathrm{e}-11)$ & 0.5748 & 0.5421 \\
M844 & $1.9 \mathrm{e}-5(1.1 \mathrm{e}-5)$ & $0.84(0.23)$ & 0.9608 & 0.9556 \\
M807 & $8.1 \mathrm{e}-4(1.9 \mathrm{e}-4)$ & $0.63(0.10)$ & $8.0 \mathrm{e}-11(2,3 \mathrm{e}-11)$ & 0.9933 & 0.9929 \\
\hline \multicolumn{7}{|c|}{} & $2.15(0.04)$ & $4.1 \mathrm{e}-11(9 \mathrm{e}-12)$ & & 0.2101 \\
\hline M850 & $1.9 \mathrm{e}-5(3.5 \mathrm{e}-5)$ & Rhyolites & $1.7 \mathrm{e}-10(7 \mathrm{e}-11)$ & 0.2788 & 0.7696 \\
M808 & $1.8 \mathrm{e}-2(7 \mathrm{e}-2)$ & $0.70(0.32)$ & $2.3 \mathrm{e}-10(1.4 \mathrm{e}-10)$ & 0.8003 \\
M848 & $1.4 \mathrm{e}-4(7 \mathrm{e}-5)$ & $1.7(0.7)$ & $1.3 \mathrm{e}-10(2.0 \mathrm{e}-11)$ & 0.9851 & 0.9826 \\
M843 & $5.1 \mathrm{e}-3(3.3 \mathrm{e}-3)$ & $0.91(0.09)$ & $3.18 \mathrm{e}-10(3.6 \mathrm{e}-11)$ & 0.9715 & 0.9684 \\
\hline
\end{tabular}


Table 3: Thermal diffusivities and conductivities retrieved for our samples at low and high temperatures for solids, above $\mathrm{Tg}$ and/or melting temperature (indicated for each group) for melts and partially molten samples. Literature estimates are also provided on the bottom part: "Xu" refers to polycrystalline olivine (dunite) measurements performed at ambient pressure (Xu et al., 2004). "Per06" refers to average values from 3 oriented $(100,010,001)$ single crystal measurements at room pressure (Pertermann and Hofmeister, 2006) and some dunite values are also available in the same study. "Beck78" refers to Dunite measurements performed at $2 \mathrm{GPa}$ (Beck et al. 1978). Regarding melts, literature data are taken from Hofmeister et al. (2009), Di: diopside, An : anorthite, Fk : orthose, $\mathrm{Ab}$ : albite. Finally, data from a few rhyolites Ncar, NCr and SCE are selected from Romine et al. (2012). When literature data are available in the form of thermal diffusivities, their conductivities are obtained using either the $\mathrm{Cp}$ and $\rho$ provided in the source study or from our own parameters if not available (see Supplementary Materials).

\begin{tabular}{|c|c|c|c|c|c|c|c|}
\hline SAMPLE NAME & Temperature range & Melt fraction & STD & $\kappa$ & STD & D & STD \\
\hline & & $\%$ & $\%$ & $\mathrm{~W} / \mathrm{m} / \mathrm{K}$ & $\mathrm{W} / \mathrm{m} / \mathrm{K}$ & $\mathrm{m}^{2} / \mathrm{s}$ & $\mathrm{m}^{2} / \mathrm{s}$ \\
\hline \multicolumn{8}{|l|}{ SOLIDS } \\
\hline M804 & $\mathrm{LT}<400 \mathrm{~K}$ & 0 & 0 & 4.32 & 0.48 & $1.66 \mathrm{E}-06$ & 2.05E-09 \\
\hline M847 & $\mathrm{LT}<400 \mathrm{~K}$ & 0 & 0 & 3.28 & 0.37 & $1.26 \mathrm{E}-06$ & $3.34 \mathrm{E}-09$ \\
\hline M804 & $\mathrm{HT}>1200 \mathrm{~K}$ & 0 & 0 & 2.29 & 0.26 & 7.33E-07 & $1.80 \mathrm{E}-09$ \\
\hline M847 & $\mathrm{HT}>1200 \mathrm{~K}$ & 0 & 0 & 1.70 & 0.19 & $5.39 \mathrm{E}-07$ & $6.13 \mathrm{E}-10$ \\
\hline \multicolumn{8}{|l|}{ Partially molten samples } \\
\hline M804 & $>1300 \mathrm{~K}$ & 6.44 & 2.98 & 1.19 & 0.16 & $3.74 \mathrm{E}-07$ & $2.55 \mathrm{E}-08$ \\
\hline M847 & $>1300 \mathrm{~K}$ & 23.31 & 2 & 0.93 & 0.10 & $2.92 \mathrm{E}-07$ & $1.22 \mathrm{E}-10$ \\
\hline \multicolumn{8}{|l|}{ MELTS } \\
\hline BASALTS & MELT >1200K & & & & & & \\
\hline M807 & $>1224 \mathrm{~K}$ & 100 & 0 & 0.34 & 0.02 & $1.84 \mathrm{E}-07$ & $1.51 \mathrm{E}-09$ \\
\hline M844 & $>1326 \mathrm{~K}$ & 100 & 0 & 0.18 & 0.01 & $9.52 \mathrm{E}-08$ & $2.96 \mathrm{E}-11$ \\
\hline M662 & $>1450 \mathrm{~K}$ & 100 & 0 & 0.22 & 0.16 & $1.20 \mathrm{E}-07$ & 8.73E-08 \\
\hline M846 & $>1200 \mathrm{~K}$ & 100 & 0 & 0.22 & 0.12 & $1.16 \mathrm{E}-07$ & $6.47 \mathrm{E}-08$ \\
\hline M836 & $1180 \mathrm{~K}$ & 100 & 0 & 0.28 & 0.02 & $1.51 \mathrm{E}-07$ & $6.94 \mathrm{E}-10$ \\
\hline rhyolite & Melt $>1000 \mathrm{~K}$ & & & & & & \\
\hline M850 & $>1080 \mathrm{~K}$ & 100 & 0 & 0.31 & 0.03 & $3.05 \mathrm{E}-07$ & $2.42 \mathrm{E}-08$ \\
\hline M808 & $>1060 \mathrm{~K}$ & 100 & 0 & 0.35 & 0.03 & 3.47E-07 & 5.95E-10 \\
\hline M848 & $>1260 \mathrm{~K}$ & 100 & 0 & 0.39 & 0.03 & $3.91 \mathrm{E}-07$ & $6.21 \mathrm{E}-10$ \\
\hline M843 & $>1280 \mathrm{~K}$ & 100 & 0 & 0.41 & 0.03 & $4.16 \mathrm{E}-07$ & $2.36 \mathrm{E}-10$ \\
\hline \multicolumn{8}{|l|}{ literature } \\
\hline \multicolumn{8}{|l|}{ SOLIDS } \\
\hline Olivine Xu 0 GPa LT & 294 & 0 & 0 & 4.15 & 0.42 & $4.10 \mathrm{E}-06$ & $2.05 \mathrm{E}-07$ \\
\hline Olivine Xu 0 GPa HT & 1377 & 0 & 0 & 1.95 & 0.19 & $5.00 \mathrm{E}-07$ & $2.50 \mathrm{E}-08$ \\
\hline Olivine Hof 16 AVG & $300 \mathrm{~K}$ & 0 & 0 & 6.37 & 0.64 & 2.37E-06 & $4.75 \mathrm{E}-08$ \\
\hline Olivine Hof AVG16 & $>1500 \mathrm{~K}$ & 0 & 0 & 2.76 & 0.28 & 7.01E-07 & 1.40E-08 \\
\hline Dunite Per 06 & $300 \mathrm{~K}$ & 0 & 0 & 4.22 & 0.42 & $1.57 \mathrm{E}-06$ & $3.15 \mathrm{E}-08$ \\
\hline Dunite 2 Per 06 & $300 \mathrm{~K}$ & 0 & 0 & 5.35 & 0.53 & $1.99 \mathrm{E}-06$ & $3.99 \mathrm{E}-08$ \\
\hline Dunite Per 06 & $>1500 \mathrm{~K}$ & 0 & 0 & 1.65 & 0.17 & $4.20 \mathrm{E}-07$ & 8.40E-09 \\
\hline Dunite 2 Per 06 & $>1500 \mathrm{~K}$ & 0 & 0 & 2.23 & 0.22 & $5.65 \mathrm{E}-07$ & $1.13 \mathrm{E}-08$ \\
\hline Dunite Beck 78 2Gpa & $300 \mathrm{~K}$ & 0 & 0 & 4.15 & 0.42 & & \\
\hline Dunite Beck 78 2Gpa & $300 \mathrm{~K}$ & 0 & 0 & 5.49 & 0.55 & & \\
\hline Dunite 2 GPa Dry Z19 & $300 \mathrm{~K}$ & 0 & 0 & 5.21 & 0.26 & $1.71 \mathrm{E}-06$ & 8.55E-08 \\
\hline Dunite $2 \mathrm{GPa} 0.08 \%$ wt $\mathrm{H}_{2} \mathrm{O} Z 19$ & $300 \mathrm{~K}$ & 0 & 0 & 4.86 & 0.24 & $1.59 \mathrm{E}-06$ & 7.95E-08 \\
\hline \multicolumn{8}{|l|}{ Melts } \\
\hline Di Hof 09 & $>1140 \mathrm{~K}$ & 100 & 0 & 1.25 & 0.13 & $2.89 \mathrm{E}-07$ & 5.79E-09 \\
\hline An Hof 09 & $>1290 \mathrm{~K}$ & 100 & 0 & 1.45 & 0.15 & $3.58 \mathrm{E}-07$ & 7.16E-09 \\
\hline Fk Hof 09 & $>1245 \mathrm{~K}$ & 100 & 0 & 1.45 & 0.15 & $4.75 \mathrm{E}-07$ & $9.50 \mathrm{E}-09$ \\
\hline Ab Hof 09 & $>1300 \mathrm{~K}$ & 100 & 0 & 1.60 & 0.16 & 4.99E-07 & 9.99E-09 \\
\hline Rhyolite/obsidian & & & & & & & \\
\hline Ncar Ro 12 & 1384 & 100 & 0 & 1.53 & 0.15 & 5.17E-07 & $1.03 \mathrm{E}-08$ \\
\hline NCr Ro 12 & 1365 & 100 & 0 & 1.50 & 0.15 & $5.08 \mathrm{E}-07$ & $1.02 \mathrm{E}-08$ \\
\hline SCE Ro 12 & 1464 & 100 & 0 & 1.59 & 0.16 & 5.31E-07 & $1.06 \mathrm{E}-08$ \\
\hline
\end{tabular}


$\underline{\text { Table 4: }}$ Typical parameter values for heat fluxes calculations displayed in Figures 11 and 12.

\begin{tabular}{|c|c|c|c|}
\hline$\kappa_{c}$ & Core thermal conductivity & $4-40$ & 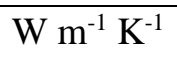 \\
\hline$\alpha_{c}$ & Core thermal expansion & $7.7 \times 10^{-5}$ & $\mathrm{~K}^{-1}$ \\
\hline$C_{p, c}$ & Core heat capacity & 800 & $\mathrm{~J} \mathrm{~kg}^{-1} \mathrm{~K}^{-1}$ \\
\hline$v_{c}$ & Core magnetic diffusivity & 2 & $\mathrm{~m}^{2} \mathrm{~s}^{-1}$ \\
\hline$\mu_{c}$ & $\begin{array}{l}\text { Core magnetic } \\
\text { permeability }\end{array}$ & $4 \pi 10^{-7}$ & $\mathrm{H} \mathrm{m}^{-1}$ \\
\hline$\rho_{c}$ & Core density & 7500 & $\mathrm{~kg} \mathrm{~m}^{-3}$ \\
\hline$B$ & $\begin{array}{l}\text { Average magnetic field } \\
\text { strength }\end{array}$ & Eq. 3 & $\mathrm{~T}$ \\
\hline$R$ & Planet radius & & $\mathrm{m}$ \\
\hline$R_{c}$ & Core radius & $77 \% \mathrm{R}$ & $\mathrm{m}$ \\
\hline$\overline{r_{i}}$ & Inner core radius & $1 \% \mathrm{R}_{\mathrm{c}}$ & $\mathrm{m}$ \\
\hline$G$ & Gravitational constant & $6.67 \times 10^{-11}$ & $\mathrm{~m}^{3} \mathrm{~kg}^{-1} \mathrm{~s}^{-2}$ \\
\hline$\kappa_{S i}$ & $\begin{array}{c}\text { Silicates thermal } \\
\text { conductivity }\end{array}$ & $4.32-1.70$ & 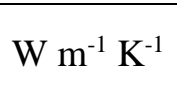 \\
\hline$\kappa_{S i}$ & $\begin{array}{l}\text { Molten silicates thermal } \\
\text { conductivity }\end{array}$ & $0.18-0.41$ & $\mathrm{~W} \mathrm{~m} \mathrm{~m}^{-1} \mathrm{~K}^{-1}$ \\
\hline$\alpha_{S i}$ & $\begin{array}{l}\text { Silicates thermal } \\
\text { expansion }\end{array}$ & $1 \times 10^{-5}$ & $\mathrm{~K}^{-1}$ \\
\hline$C_{p, S i}$ & Silicates heat capacity & 1000 & $\mathrm{~J} \mathrm{~kg}^{-1} \mathrm{~K}^{-1}$ \\
\hline$T_{s}$ & Surface temperature & 500 & $\mathrm{~K}$ \\
\hline$\overline{\delta_{S i}}$ & Mantle thickness & $33 \% \mathrm{R}$ & $\mathrm{m}$ \\
\hline
\end{tabular}


Diffusion length

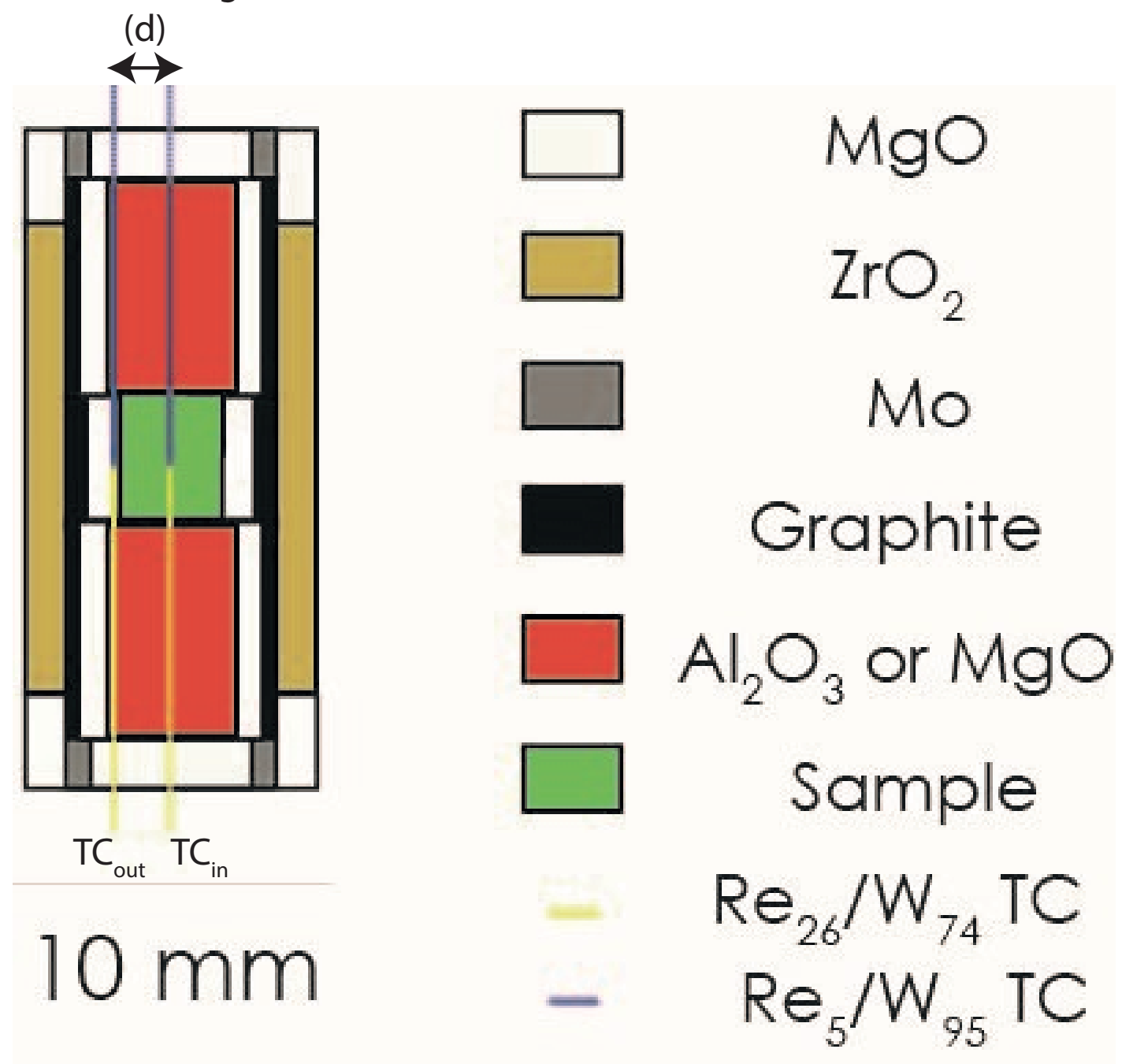




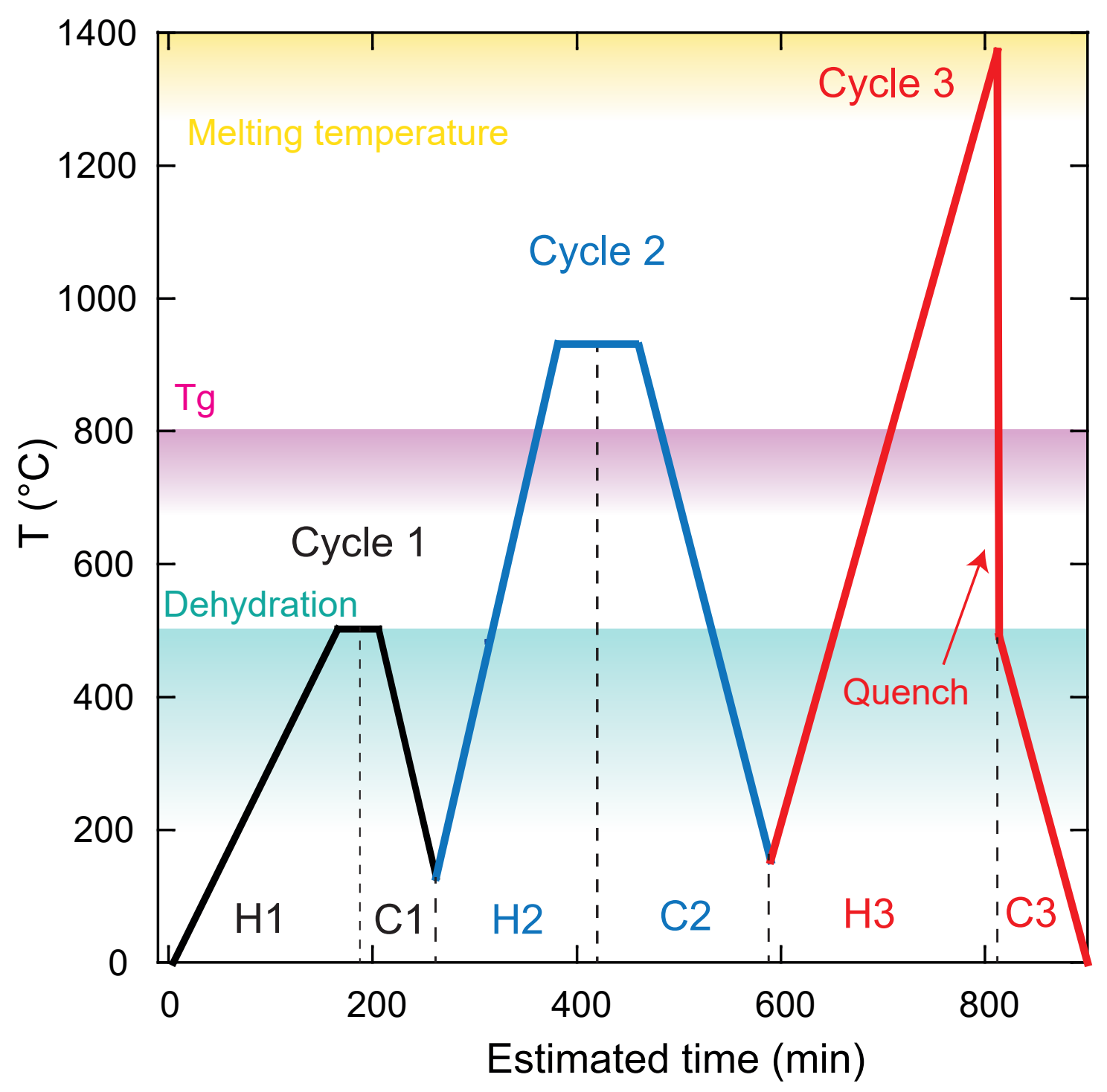



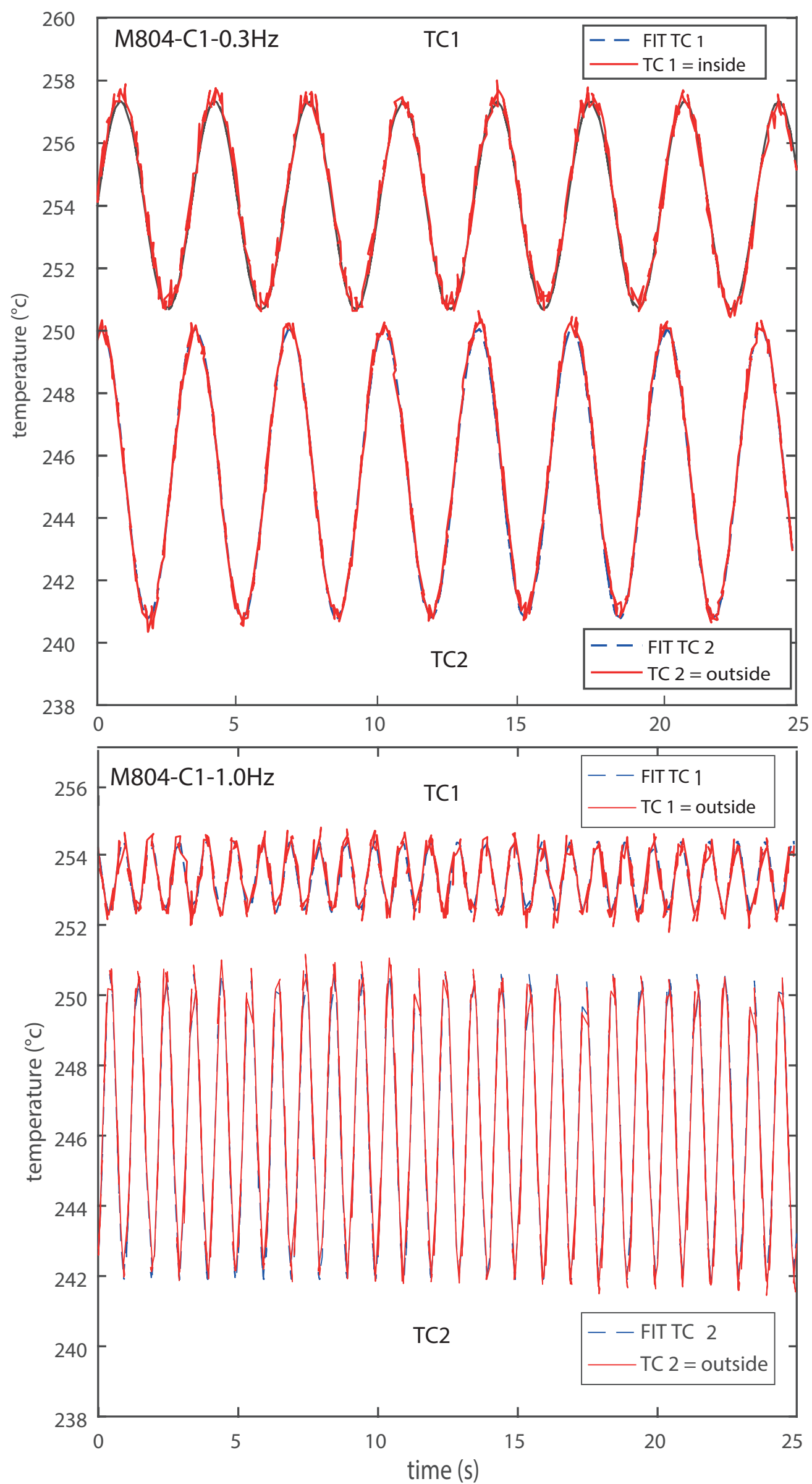


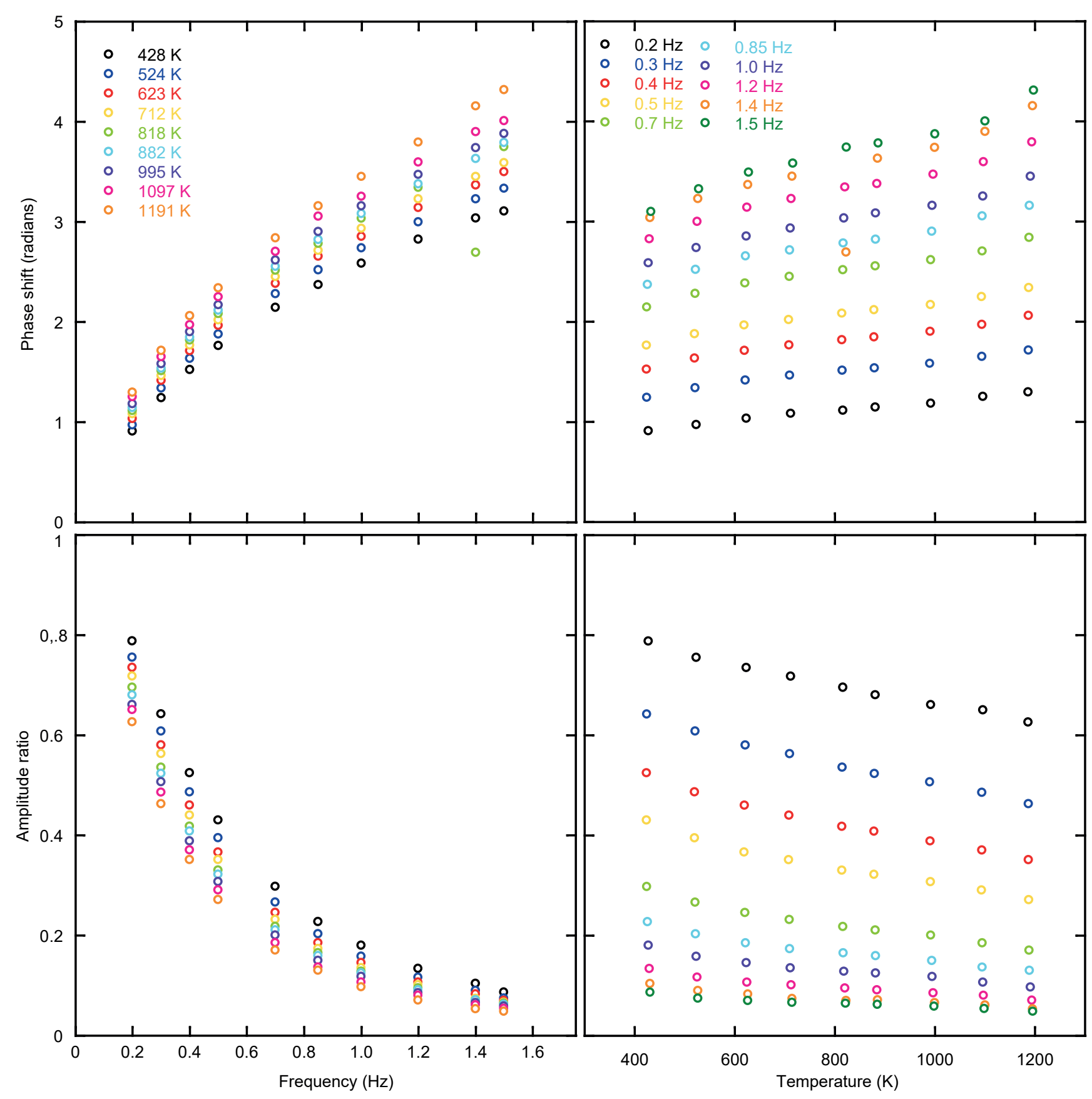



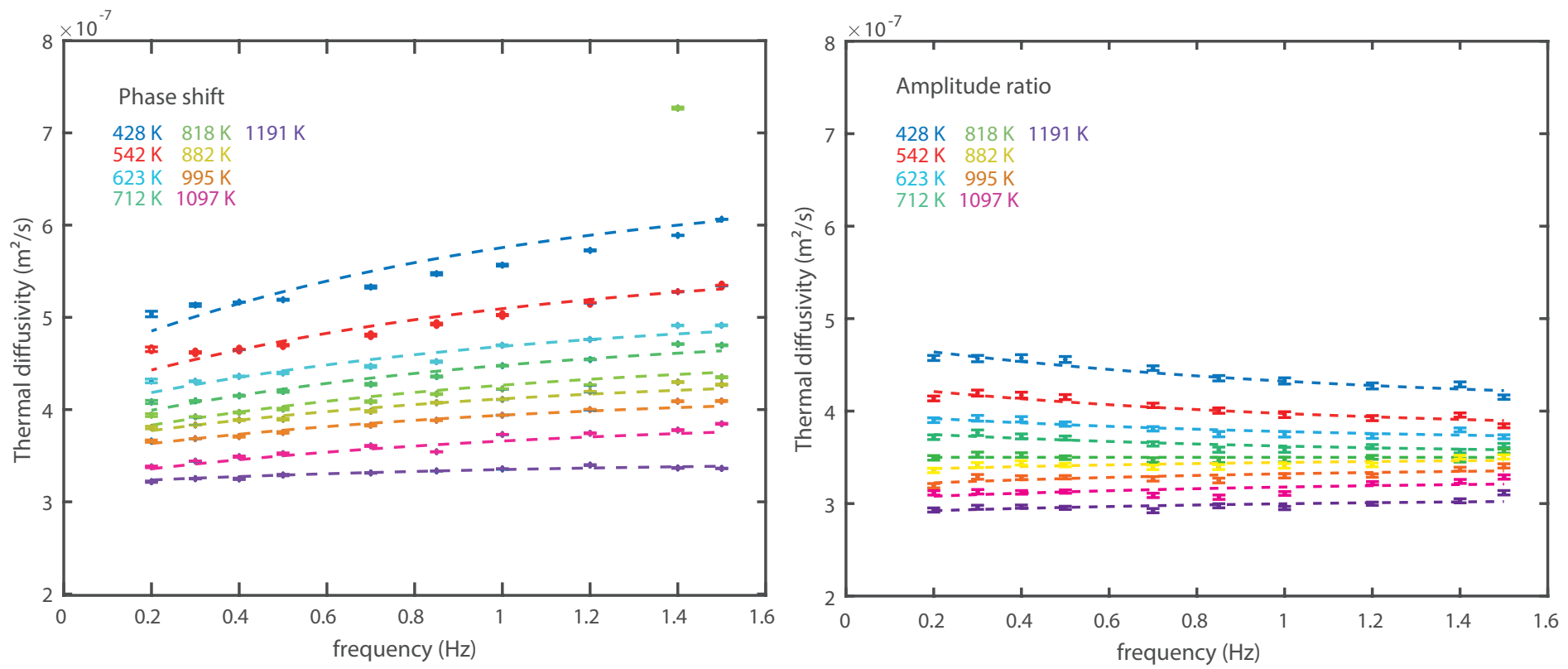

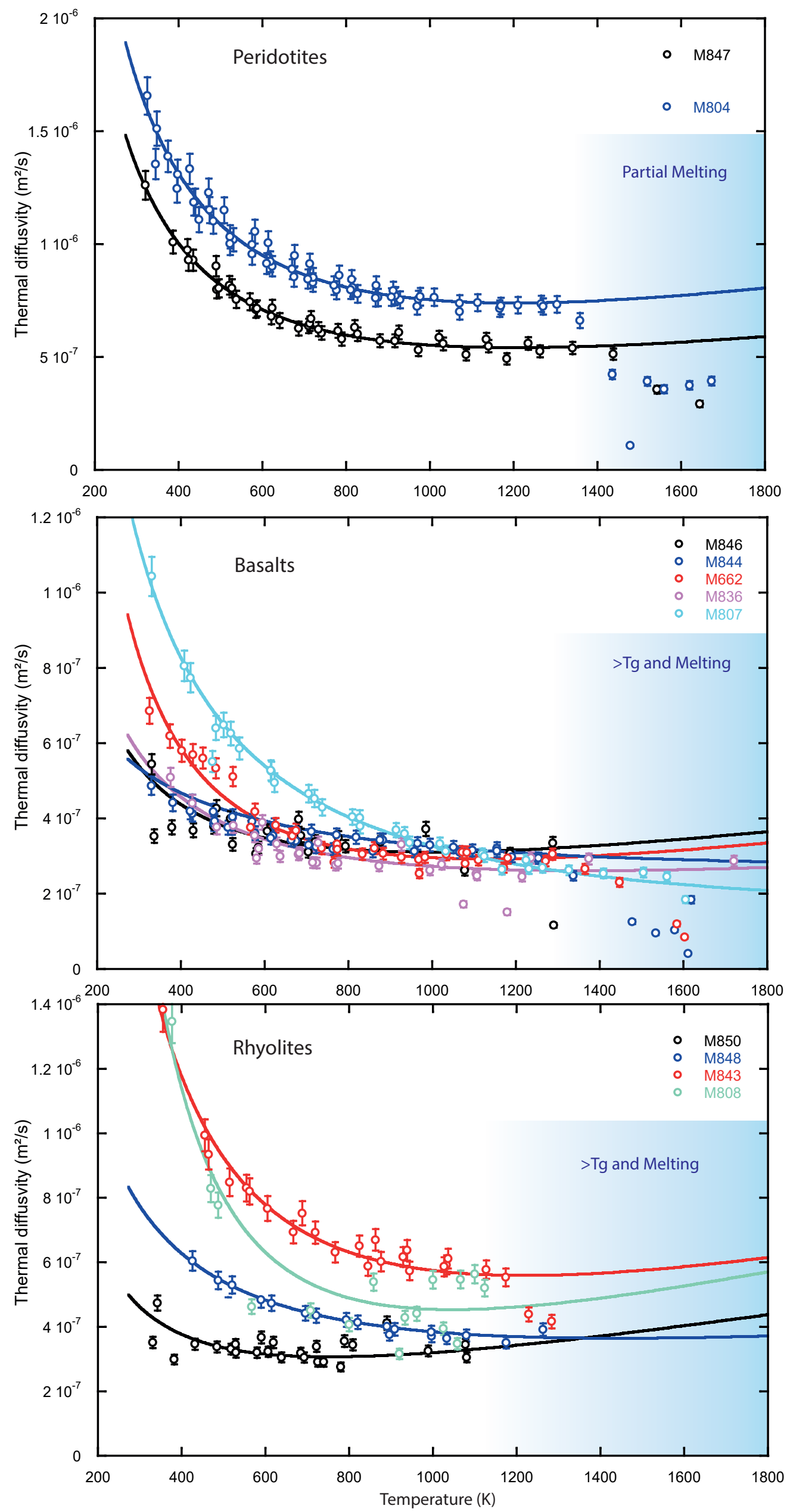

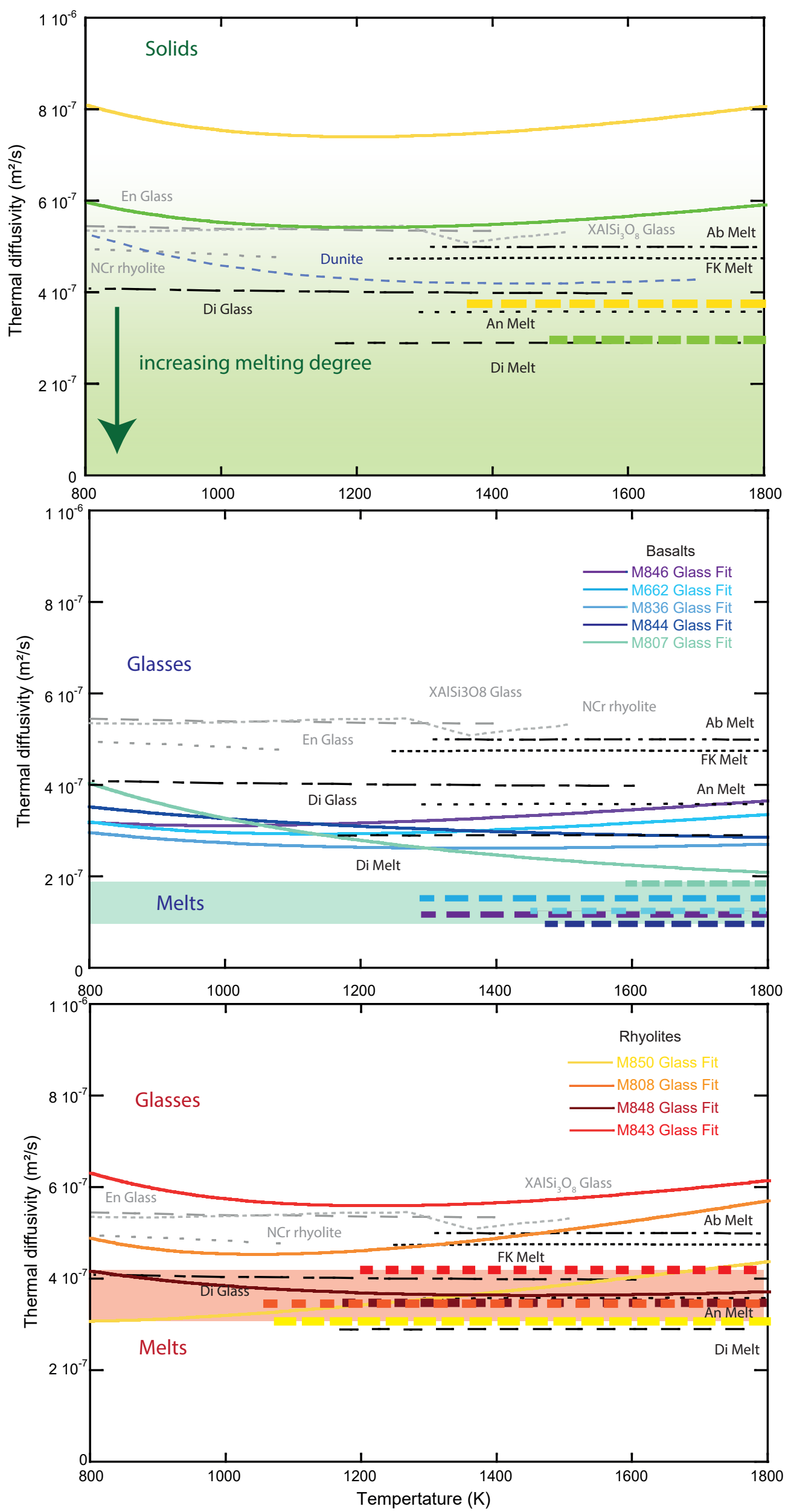


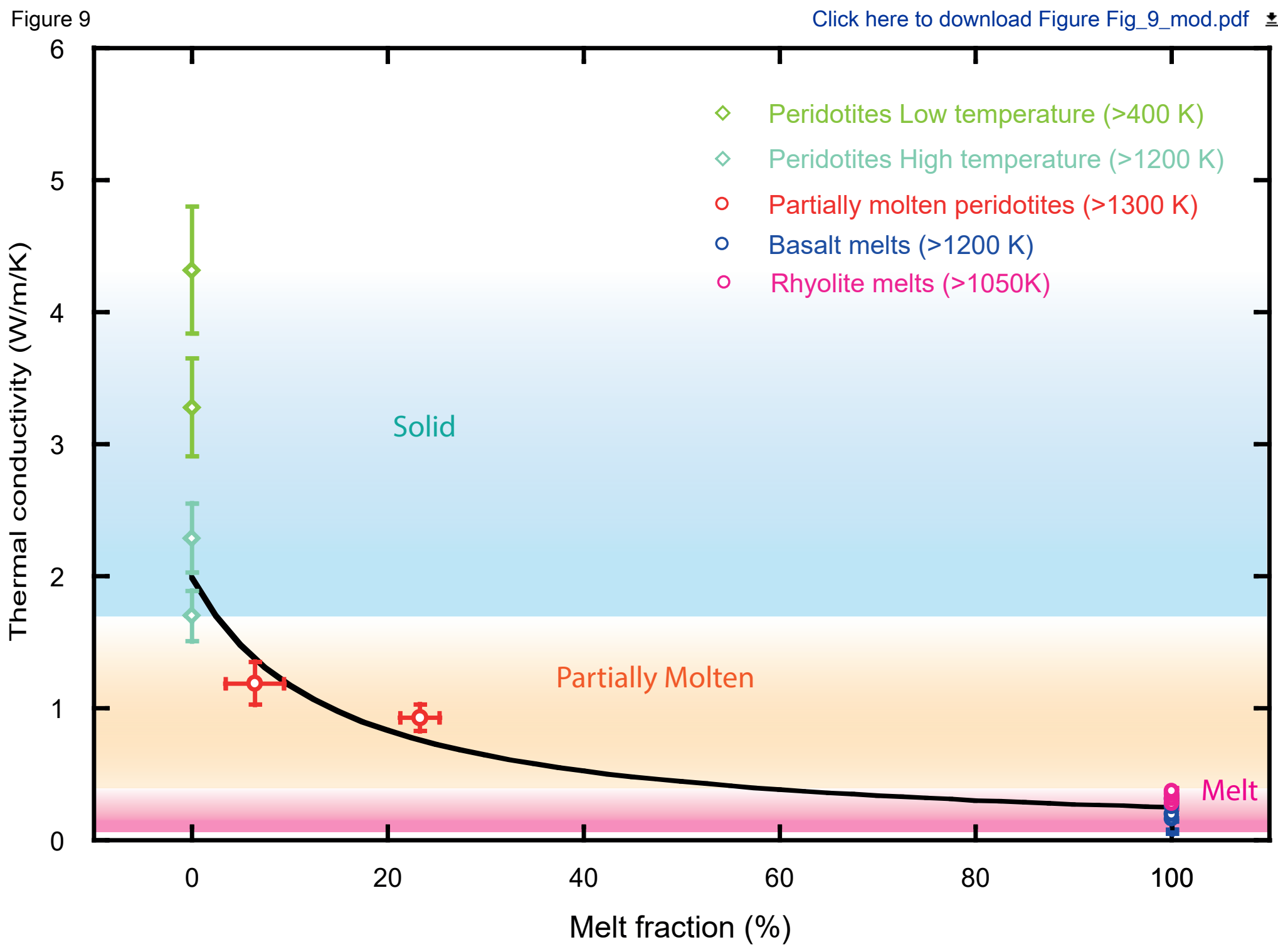




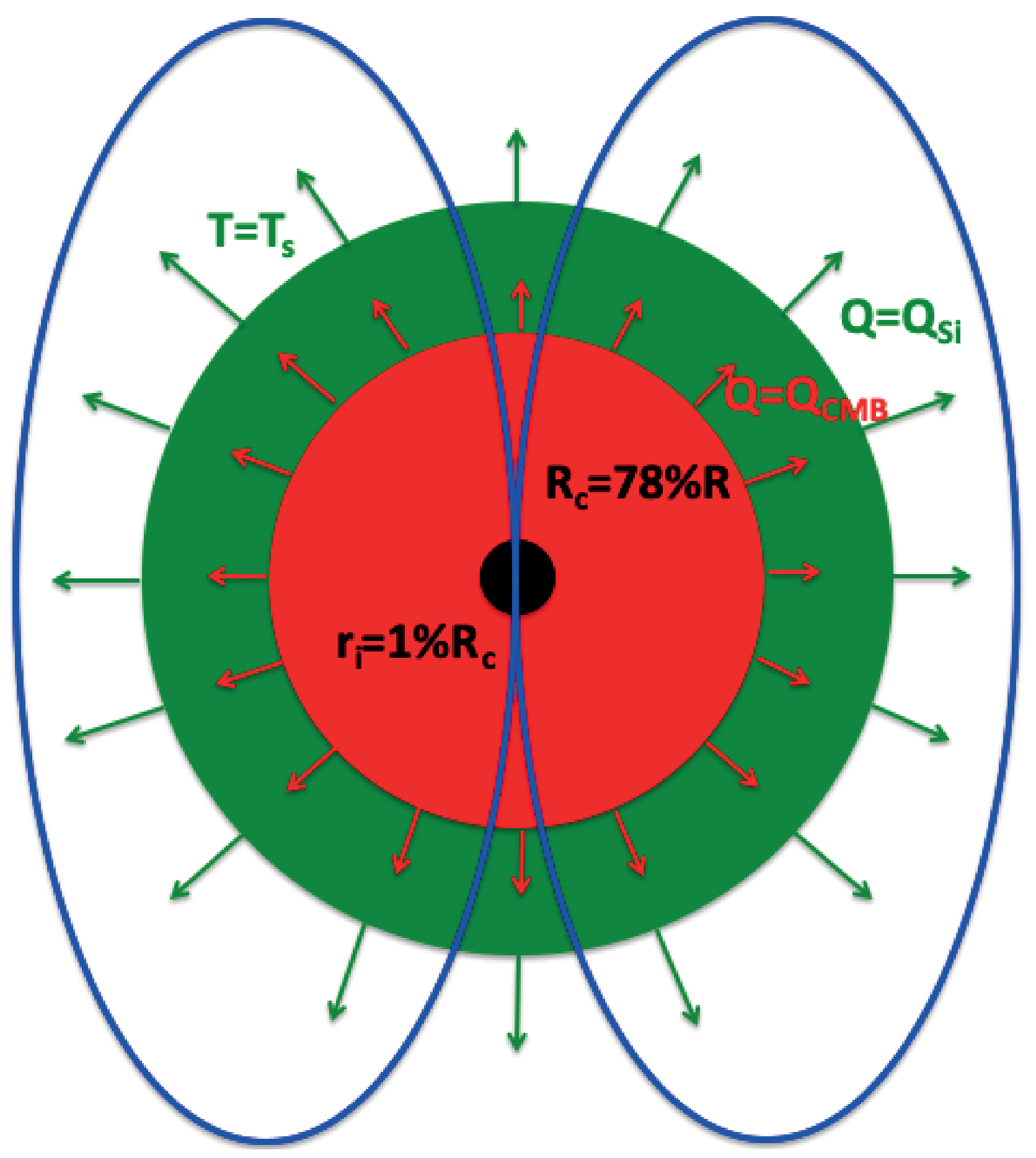




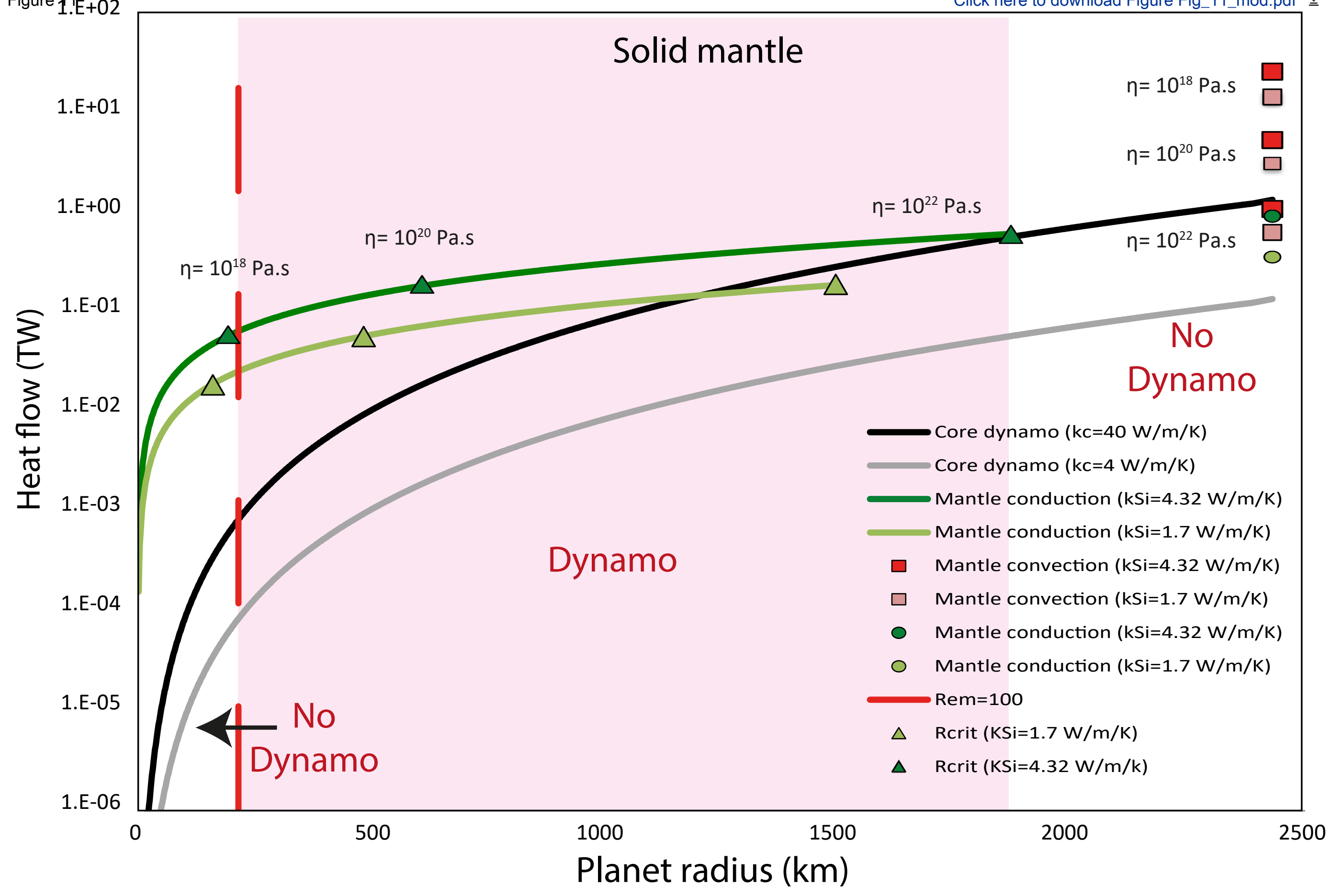




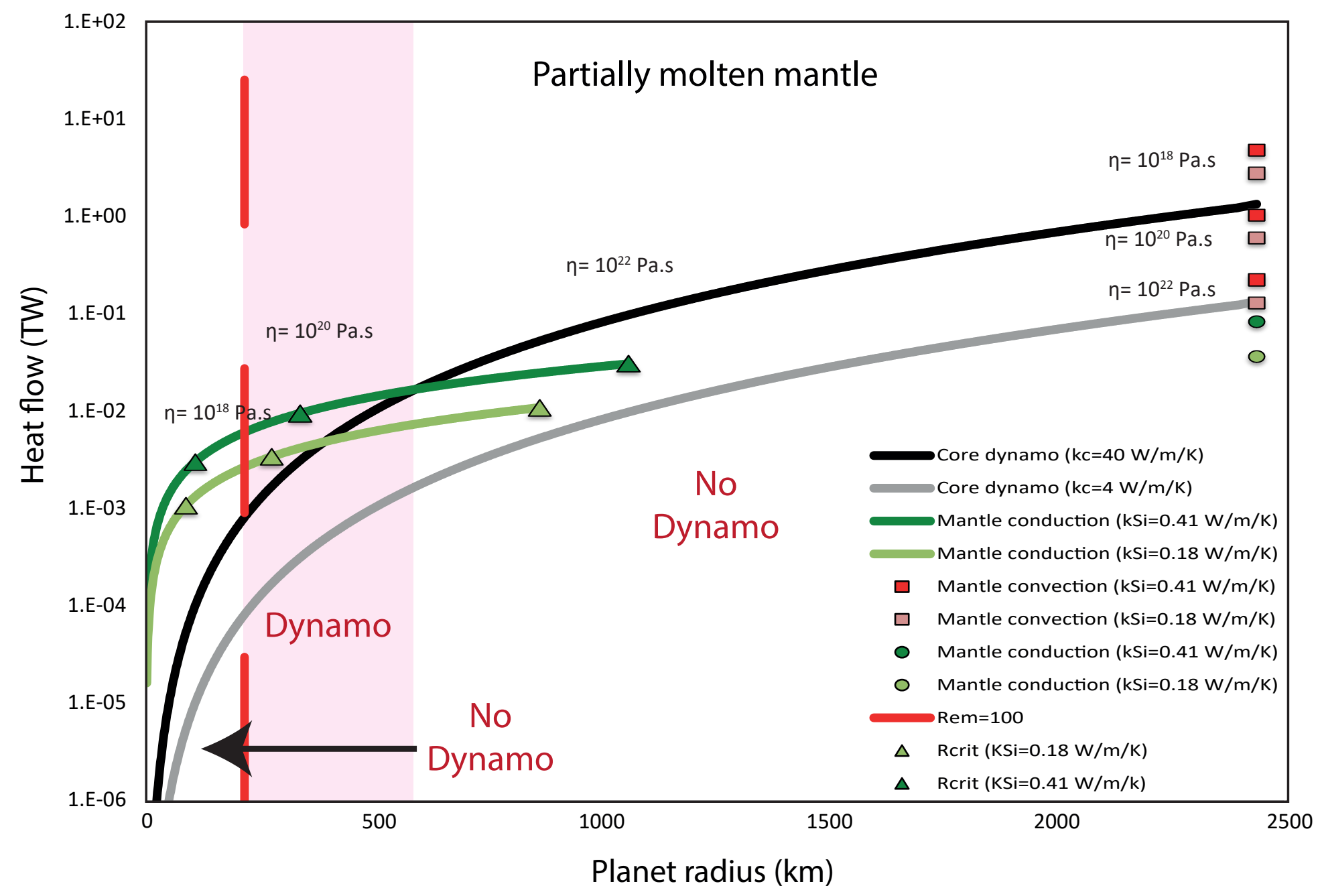

